\title{
Non-probative Photos Promote the Truth of Positive Claims
}

\author{
By Brittany A. Cardwell
}

A thesis submitted to Victoria University of Wellington in fulfillment of the requirements for the degree of Doctor of Philosophy

Victoria University of Wellington 


\begin{abstract}
People's judgments are prone to the influence of feelings, even cognitive feelings such
\end{abstract} as the ease with which related information comes to mind (Alter \& Oppenheimer, 2009; Schwarz \& Clore, 2007). In 14 experiments, we ${ }^{1}$ found evidence that non-probative photosones that relate to what people are evaluating, but that provide no relevant information for their task - produce cognitive feelings that lead people to evaluate claims more positively.

In Part 1, we examined the extent to which photos promote the truth of positive and negative claims. People saw the names of several fictitious wines. Some wine names appeared with a photo that depicted the noun in the name; other wine names appeared without a photo. For each wine people decided whether a positive or a negative claim about it was true. Photos selectively promoted the truth of positive claims, did so most when they could help people comprehend wine names, and swayed people's judgments about the taste of wines.

In Part 2, we showed that those findings translated to when people judged claims about their own (and other people's) experiences. People "interacted" with several unfamiliar animals (on a computer). Later, people saw the animal names again, sometimes with a photo of the animal and sometimes alone, and decided whether it was true that they (or other people) had positive or negative experiences with the animals. Photos selectively led people to think positive claims were true, and exerted their strongest effects when they could most help people bring related thoughts and images to $\operatorname{mind}^{2}$.

\footnotetext{
${ }^{1}$ Although the research in this thesis is my own, I conducted it in a lab and supervised a team comprised of research assistants and honors students. I also received advice and direction from my supervisors. Therefore, I often use the word "we" in this thesis to reflect that fact. As you will also see, I use the word "we" in a different context to refer to what is known (or not known) in the wider scientific community.

${ }^{2}$ Portions of this thesis were adapted from:

Cardwell, Newman, Garry, Mantonakis, \& Beckett (manuscript under review). Photos that increase feelings of learning promote positive evaluations.

Cardwell, Henkel, \& Garry (manuscript in preparation). Non-probative photos lead people to believe positive claims about their recent pasts.
}

But I have expanded on the introduction, results and discussion. 


\section{Acknowledgments}

I am extremely grateful for the funding from Victoria University of Wellington that helped support my $\mathrm{PhD}$ research over the years.

Thanks to the honours and undergraduate students who helped collect data and create materials for these experiments, and for raising interesting ideas during our discussions. I am also thankful for the thousands of subjects who took part in these experiments.

To the Garry labsters: it is hard to imagine a group of people that would have been more fun to spend five years working long hours in a windowless room with. And I'm sure I would have felt the same working along side those of you who graduated long before my time. Thank you all for your interesting insights, conversations, and for mentoring me on all things.

Thanks, Ira Hyman, for introducing me to cognitive psychology, then to the world of academic research, to many of the memory phenomenon I ended up studying at Victoria, and even to my PhD supervisor. As a student, I saw a person that loved what they did, and who even happily danced in front of the class to illustrate how honeybees communicate. I had an epiphany: academia looked fun, I could think and talk about my interests for the rest of my life. After joining your research team I realized there was even more fun to that world. Thanks for leading me down this road, and for all your advice and support over the years.

I could say the same things about Cristina Sampaio. I'm glad I got to spend some time as an undergraduate working in your lab, and am grateful to have you as a mentor. I'd also like to thank Linda Henkel, Antonia Mantonakis, Eryn Newman, and Jeff Foster, who have contributed lots to these projects, and Steve Lindsay's for his interesting insights on these lines of research. I am lucky to have been able to work with so many intelligent people.

I had not considered leaving the US for my PhD, until I saw (my now supervisor) Maryanne Garry give a thrilling talk, and thought "what a fun and interesting person doing such cool research." Those thoughts were only confirmed later on when I met her and then flew to New Zealand. That was a huge turning point in my life. Not just because setting up a new life in a different country changes people. But because Maryanne changes people. To Maryanne: thank you for creating so many opportunities and forcing me to take them, for your constant support and advice, for reducing by more than two-thirds the number of exclamation points I use in emails, and for the fun I've had working with you for the last (nearly) five years.

I also want to thank my family and friends. To the Cardwells: it would have been a much tougher time without all of your love and support. To my friends: thanks for the same old friendship after even the longest talking droughts. Tadhg, thank you for being my best friend and for patiently listening to me describe data you are not all that invested in, sometimes while I jumped up and down like a moron. 


\section{Contents}

\section{Part 1}

Chapter 1

Feelings as information $\quad 9$

Comprehension $\quad 11$

Cognitive fluency 13

$\begin{array}{ll}\text { Positive feelings } & 17\end{array}$

Overview of experiments 19

Chapter 2

$\begin{array}{ll}\text { Experiment 1a } & 20\end{array}$

Method 20

Results \& Discussion $\quad 22$

Experiment 1b 25

Method 25

Results \& Discussion $\quad 25$

Experiment 1c 26

Method 26

Results \& Discussion $\quad 27$

Experiment 2a $\quad 30$

Method 30

Results \& Discussion 31

Experiment 2b 33

Method 33

Results \& Discussion $\quad 34$

Experiment 2c 35

Method 35

Results \& Discussion 36

Experiment 3a 39

$\begin{array}{ll}\text { Method } & 39\end{array}$

Results \& Discussion $\quad 40$

Experiment 3b 41

Method 42

Results \& Discussion $\quad 42$

Chapter 3

Theoretical implications $\quad 46$

Practical implications $\quad 54$ 


\section{Part 2}

Chapter $1 \quad 56$

Non-probative photos affect memories and beliefs $\quad 57$

Repetition, elaboration, and the passage of time 59

Immediate consequences of non-probative photos 61

Personally experienced, recent events 63

Overview of experiments $\quad 65$

$\begin{array}{ll}\text { Chapter } 2 & 67\end{array}$

$\begin{array}{ll}\text { Experiment 1 } & 67\end{array}$

$\begin{array}{ll}\text { Method } & 67\end{array}$

Results \& Discussion $\quad 69$

Experiment 2a $\quad 72$

$\begin{array}{ll}\text { Method } & 72\end{array}$

Results \& Discussion $\quad 73$

Experiment 2b 76

$\begin{array}{ll}\text { Method } & 76\end{array}$

Results \& Discussion $\quad 77$

$\begin{array}{ll}\text { Experiment 2c } & 79\end{array}$

$\begin{array}{ll}\text { Method } & 79\end{array}$

Results \& Discussion $\quad 80$

Experiment 3a $\quad 82$

Method $\quad 82$

Results \& Discussion $\quad 83$

Experiment 3b 85

Method 85

Results \& Discussion 86

Chapter 3

Theoretical Implications $\quad 92$

Practical Implications $\quad 98$

$\begin{array}{ll}\text { References } & 101\end{array}$

$\begin{array}{ll}\text { Appendix A } & 123\end{array}$

$\begin{array}{ll}\text { Appendix B } & 124\end{array}$

$\begin{array}{ll}\text { Appendix C } & 125\end{array}$ 


\section{List of figures and tables: Part 1}

Figure 1. Example of a wine name with and without a photo

Figure 2. Proportion of "true" responses to the "high quality" and "low quality"

claims when wine names appeared with photos or alone (Experiment 1a)

Figure 3. Proportion of "true" responses to the "high quality" and "low quality" claims when wine names appeared with photos or alone (Experiment 1b)

Figure 4. Proportion of "true" responses to the "high quality" and "low quality"

claims when wine names appeared with photos, boxes, or alone (Experiment 1c)

Table 1. Summary of results from each meta analysis

Figure 5. Proportion of "true" responses to the "high quality" and "low quality"

claims when familiar and unfamiliar wine names appeared with photos or alone (Experiment 2a)

Figure 6. Proportion of correct categorizations for unfamiliar and familiar nouns that appeared with photos or alone (Experiment 2b)

Figure 7. Average ratings for how confident people were that they knew what unfamiliar and familiar nouns meant when wine names appeared with photos or alone (Experiment 2c)

Table 2. Means and standard deviations for subjects' responses to the question about 39 how much each factor would affect how wines tasted (Experiments 3a-b)

Figure 8. Proportion of "true" responses to the "tastes high quality" and "tastes low quality" claims when wine names appeared with photos or alone (Experiment 3a)

Figure 9. Proportion of "true" responses to the "tastes high quality" claim when wine names appeared with photos or alone (Experiment 3b) 


\section{List of figures and tables: Part 2}

Figure 1. A photo of a shoebill 56

Figure 2. Example of an animal name with and without a photo 69

Figure 3. Bias scores for animal names that appeared with photos or alone 71 (Experiment 1)

Figure 4. Bias scores for responses to the "fed" and "didn't feed" claims when 74 animals names appeared with photos or alone (Experiment 2a)

Table 1. Summary of results from each meta analysis (Experiments 1-2b) 75

Figure 5. Bias scores for responses to the "gave food" and "took food" claims when 78 animals names appeared with photos or alone (Experiment 2b)

Figure 6. Bias scores for responses to the "healthy food" and "unhealthy food" claims when animals names appeared with photos or alone (Experiment 2c)

Figure 7. Proportion of "true" responses to the "gave food" and "took food" claims when animals names appeared with photos or alone (Experiment 3a)

Figure 8. Proportion of "true" responses to "gave food" and "took food" claims when familiar and unfamiliar animal names appeared with photos or alone (Experiment 3b)

Table 2. Summary of results from each meta analysis (Experiments 3a-b) 


\section{Part 1}

\section{Ghapter 1}

On your big date, a waiter recommends a wine called Yellow Rick. He tells you it has impressed many wine judges, tastes limey and slatey, and will go great with the curries you just ordered. But you know nothing about wine, so you anxiously ask yourself if his many claims are true.

You will probably try to answer these difficult questions by retrieving related thoughts and images from memory (Graesser \& Hemphill, 1991). You imagine how an impressive wine might look and smell, and you "see" judges evaluating its quality. Your search for and interpretation of these thoughts and images will be guided by an assumption that the waiter's claims are true - a possibility consistent with people's bias to look for evidence that supports claims, as opposed to evidence that refutes them (Gilbert 1991; Gilbert, Tafarodi, \& Malone, 1993; for a review, see Nickerson, 1998). But because you know nothing about Yellow Rick, or wine in general, the knowledge you retrieve is unlikely to yield evidence that discerns whether the claims actually are true or false.

Adding to your general uncertainty about the claims is the difficulty you have trying to making sense of the wine name Yellow Rick. Although you can easily picture a yellowish hue, the word "rick" is unfamiliar, so the object you are picturing is unclear: is a rick a type of bicycle, a body of water, or a maybe a tree? Put another way, you cannot easily attach to "rick" concrete images that help you comprehend the wine name (Bransford \& Johnson, 1972; Paivio, 1969). If only you knew what ricks were, or if the name featured a word you did know (such as "apple"), you would at least be able to make sense of the wine name.

Now suppose the waiter shows you a bottle. Printed on the label is Yellow Rick; underneath the name is a photo of a haystack. You conclude, then, that a rick must be a 
haystack. Although that epiphany may be mentally satisfying (see Ripolles et al., 2014; Topolinski \& Reber, 2010), it still does not follow that the waiter's claims are true.

Thus, because you have no diagnostic information for evaluating the waiter's claims, your only option would be to guess. And a large body of literature suggests your guess would be susceptible to the influence of less diagnostic, even irrelevant, information - such as a feeling or gut reaction about Yellow Rick (Jacoby, Kelley, \& Dywan, 1989; Schwarz \& Clore, 1983, 2007; Unkelbach \& Greifeneder, 2013; Winkielman, Schwarz, Fazendeiro, \& Reber, 2003). Several lines of evidence led us to believe your guess would be swayed by a seemingly irrelevant photo that helps you make sense of the wine name.

\section{Feelings as information}

A large body of literature shows that people will use their feelings as evidence for making decisions (Greifenender, Bless, \& Pham, 2011; Higgins, 1998; Schwarz \& Clore, 2007; Unkelbach \& Greifeneder, 2013). People report being more satisfied with their lives when the weather is sunny, and puts them in better mood, as opposed to rainy; people behave as though they are attracted to others they encounter just after doing physiologically arousing activities, such as walking across a high suspension bridge, compared to less arousing activities; and people think cartoons are more humorous if while viewing those cartoons people unwittingly contract facial muscles that trigger positive feelings, compared to muscles that do not (Dutton \& Aron, 1974; Schachter \& Singer, 1962; Schwarz \& Clore, 1983; Strack, Martin, \& Stepper, 1988). What is intriguing about these examples is that people used their feelings as information to evaluate their life satisfaction, attraction to another person, and the humorousness of a cartoon, even though those feelings arose from incidental or irrelevant aspects of the tasks (the weather, heights, and a facial expression).

Why would people draw on irrelevant feelings as evidence for their judgments? One reason is because our experience in the real world tells us that feelings can offer relevant 
information and foster sensible judgments (Damasio, 1994; Halberstadt, 2009; Unkelbach, 2006, 2007). Feeling abnormally hot, for example, usually means you have a fever and should take it easy for a few days. And cognitive feelings are helpful, too. Because feelings of familiarity are typically correlated with repeated exposure to information, those feelings can provide useful evidence for deciding that you have seen a person before, a that a song is popular, or that a city has a large population (Goldstein \& Gigerenzer, 2002; Halberstadt \& Catty, 2008; Jacoby \& Dallas, 1981). Put differently, because there are often relationships between feelings and states of the world, relying on those feelings helps people quickly make difficult decisions or deal with ambiguous information (Damasio, 1994; Halberstadt, 2009; Herzog \& Hertwig, 2013; Gigerenzer, 2008; Schwarz, 2002; Unkelbach, 2006, 2007). In fact, in some cases using feelings leads to more sensible judgments than does putting out the cognitive effort required to analyze reasons for those judgments (Halberstadt \& Catty, 2008; Halberstadt \& Green, 2008; Halberstadt \& Hooton, 2008; Wilson, Lisle, Schooler, Hodges, Klaaren, \& LaFleur, 1993; Wilson \& Schooler, 1991).

What is more, feelings can point us in the right direction even when we are not certain from where those feelings stem. For instance, people can discriminate between word triplets (such as salt, deep, and foam) that share a remote associate that links the three words (sea), and word triplets (such as dream, ball, and book) that do not share a remote associate; and people can make these distinctions without being able to explain how (Bowers, Regehr, Balthazard, \& Parker, 1990). Although this ability may appear to be evidence people hold psychic powers, research suggests it happens for a different reason: words that share a remote associate activate overlapping semantic networks and that process produces positive affect that discriminates triplets that share an associate versus triplets that do not (Topolinski, Likowski, Weyers, \& Strack, 2009; Topolinski \& Strack, 2009a, 2009b, 2009c). In other words, people used feelings that happened to be useful, without knowing how those feelings came about - a 
finding reminiscent of when a feelings of familiarity cause people to "just know" they encountered someone before, without being able to put a finger on exactly how they know (Mandler, 1980; Rajaram, 1993; Tulving, 1985).

These findings tell us that people tune into their feelings because feelings can provide relevant information for making decisions. But because people's default assumption is that feelings that come about during a task must be relevant to the task, people sometimes pay attention to feelings that are actually irrelevant — such as those that are the result of the nice weather, increased physiological arousal, or a smiling facial expression (Dutton \& Aron, 1974; Higgins, 1998; Schwarz, 2004; Schwarz \& Clore, 1983, 2007; Strack et al., 1988).

Considered together, then, this literature suggests that while you evaluate Kellow Rick, you would pay attention to how you "feel" about the wine. And you would be inclined to draw on that feeling as evidence, even if it was irrelevant for evaluating the waiter's claims. But what could cause such a feeling? Several lines of evidence implicate the photo of the rick.

\section{Comprehension}

How could a photo of a rick cause you to feel one way or another about Kellow Rick and affect how you evaluate the waiter's claims? We know photos can be powerful retrieval cues, helping people bring to mind details of prior experiences (Hudson \& Fivush, 1991; Koutstaal, Schacter, Johnson, Angell, \& Gross, 1998). So if you had tried Yellow Rick before, the photo might remind you what the wine was like, and if you recall that you liked the wine that feeling would support the waiter's positive appraisals.

But you have never tried or seen this wine before. So the photo fails to remind you of a specific experience that tells you something useful about the wine and leaves you instead with only the conclusion that a rick is a haystack - a feat that is perhaps unsurprising, given research showing that photos aid comprehension and encourage inferences (Bransford \& Johnson, 1972; Carney \& Levin, 2002; Henkel, 2012; Mayer \& Gallini, 1990). 
In a series of experiments, people read a passage of text written in a way that made the meaning of the text ambiguous. One of the passages described a common procedure in this way:

\footnotetext{
The procedure is actually quite simple. First you arrange things into different groups depending on their makeup. Of course, one pile may be sufficient depending on how much there is to do. If you have to go somewhere else due to lack of facilities that is the next step, otherwise you are pretty well set. It is important not to overdo any particular endeavor. That is, it is better to do too few things at once than too many. In the short run this may not seem important, but complications from doing too many can easily arise. A mistake can be expensive as well. The manipulation of the appropriate mechanisms should be self-explanatory, and we need not dwell on it here. At first the whole procedure will seem complicated. Soon, however, it will become just another facet of life. It is difficult to foresee any end to the necessity for this task in the immediate future, but then one never can tell. (Brandsford \& Johnson, 1972, pg. 722)
}

People who saw a label or image that revealed what ambiguous text passages were about (in this example, doing laundry) comprehended and remembered the texts better, compared to people who did not see a label or image. These findings suggest that when images or titles provide context they help people make sense of otherwise ambiguous, obscure, or difficult information (see Mayer \& Gallini, 1990).

Moreover, there is evidence people's subjective feeling is that it is easier to make sense of information with images, as opposed to just words. In another study, people saw several Swahili-English word pairs (such as kelb-dog) and for each pair judged how well they would remember the Swahili word on a later test. People thought they would remember Swahili words paired with photos (kelb paired with a photo of a dog) better, compared to Swahili words paired with English words (kelb paired with the word $d o g$ ), and reported that it seemed easier to learn from the photos (Carpenter \& Olson, 2012; see also, Serra \& Dunlosky, 2010). It is possible that the photos made related information come to mind more easily, and from 
that ease of processing people inferred that they had better knowledge of word-photo pairs (see Rawson \& Dunlosky, 2002; Schwartz \& Metcalfe, 1992).

Together, these findings suggest the photo of the rick would help you comprehend, or at least feel you comprehend, the word "rick." Still, for all the help the photo provides for comprehending the wine name, it provides no help for evaluating the waiter's claims because it is non-probative. It does not tell you whether the wine really has impressed judges or tastes good. But in this part of the thesis we show that the photo nonetheless affects how you evaluate each of the waiter's claims. How can that be?

\section{Cognitive fluency}

We believe the answer is to be found in several lines of research showing that the fluency with which people make sense of information systematically affects their judgments. A large body of literature shows that when information is processed with relative fluency - such as when it feels easy to comprehend or to perceive - people tend to see it through a positive lens, judging it to be more familiar, likable, and true (Alter \& Oppenheimer, 2009; Hasher, Goldstein, \& Toppino, 1977; Lee \& Labroo, 2004; Reber \& Schwarz, 1999; Reber, Winkielman, \& Schwarz, 1998; Schwarz, 2004; Unkelbach, \& Greifeneder, 2013; Whittlesea, 1993; Winkielman et al., 2003). Indeed, people pay attention to these changes in the ease with which they can execute cognitive tasks, and they use those changes as evidence for their decisions (Dechene, Stahl, Hansen, \& Wanke, 2009; Hansen, Dechene, \& Wanke, 2008; Westerman, 2008; Whittlesea \& Williams, 1998).

\section{Fluency from repetition}

We know that when people repeatedly encounter information, they can (accurately) report that the information feels more familiar. Why? Because encountering information once reduces the effort needed to perceive and comprehend that information later (Collins \& Loftus, 1975; Jacoby \& Dallas, 1981). Seeing a wine name over and over, for example, would 
make it easier for you to identify the letters that make up the words and to access the meaning of those words. Said differently, repetition boosts the fluency of perceptual and conceptual processes (for a review, see Alter \& Oppenheimer, 2009). And with that boost in fluency comes a feeling - typically a positive one - that makes repeated information "stand out" against nonrepeated information (see Harmon-Jones \& Allen, 2001; Winkielman \& Cacioppo, 2001). These changes in fluency, and the feelings they produce, can therefore clue people into what information they have and have not encountered before (Unkelbach, 2006; Westerman, 2008; Whittlesea \& Williams, 1998, 2001a, 2001b). That is why people are inclined to pay attention to feelings associated with the ease of thinking: because, much like other feelings, they can help people make accurate judgments (see Halberstadt, 2009).

But recall that people can misread feelings from one source as being "about" another (Higgins, 1998; Schwarz, 2004); the same is true of feelings that arise from repetition. Indeed, people use fluency from repetition not just as evidence that repeated information is familiar, but as evidence that information is true (see Alter \& Oppenheimer, 2009). In one study, people saw a mix of true and false trivia claims. Later, people saw claims again (some they had seen before and some they had not) and decided whether those claims were true or false. People thought repeated claims were true more often than non-repeated claims (Hasher et al., 1977; see also, Begg, Anas, \& Farinacci, 1992; for a meta analysis, see Dechene, Stahl, Hansen, \& Wanke, 2010).

Repetition wields similar effects over what people prefer, making stimuli seem more attractive or liked (Bornstein, 1989; Kunst-Wilson \& Zajonc, 1980; Zajonc, 1968). In another study, people saw words written in the form of Chinese characters; people saw some of those characters only a few times, and other characters several times. Later, people saw the characters again and rated the extent to which they thought the meaning of the words was 
good or bad. The more often people saw the characters, the more positive they thought their meaning (Zajonc, 1968).

Of course, repetition does not make information more true, nor change its aesthetic features nor the meaning of words. Instead, repetition changes the fluency with which people interact with the information they are evaluating (see Reber \& Schwarz, 1999). And people mistake feelings of fluency from repetition as evidence information is true or positive, in much the same way that people can mistake feelings from their own facial expression as evidence a cartoon is humorous (for reviews, see Greifeneder, Bless, \& Pham, 2011 ; Schwarz \& Clore, 2007; Stepper et al., 1988).

Indeed, although the context of the task can change the interpretation people impose on their feelings, the basic processes are the same (see Schwarz, 2004). People interpret fluent processing from repetition to mean there is something "about" the target of evaluation that makes it different from the others, then infer what that difference signals according to the focus of the task: if judging prior experience ease signals familiarity, if judging fact ease signals truth, and if judging attractiveness ease signals beauty (Jacoby et al., 1989; Reber \& Schwarz, 1999; Unkelbach \& Greifeneder, 2013; Whittlesea, 1993; Winkielman, Halberstadt, Fazendeiro, \& Catty, 2006; for many other ways fluency can be interpreted, see Alter \& Oppenheimer, 2009).

\section{Fluency in the absence of repetition}

But repetition is not the only way to cause feelings of fluency that people use as evidence for their decisions. The same feelings can arise in the absence of repetition and exert similar effects. People think words are more familiar, claims are more true, and shapes are more beautiful if those stimuli are presented in ways that make them easier to perceive (such as in easy-to-read font or high contrast colors; Reber \& Schwarz, 1999; Reber et al., 1998; Whittlesea, Jacoby, \& Girard, 1990). Perhaps more to the point, parallel effects arise when 
priming related concepts, presenting information concretely, or adding semantic context makes information easier to comprehend (Hansen \& Wanke, 2010; Kelley \& Lindsay, 1993; Whittlesea, 1993).

In one study, people saw several lists of words, and after each list, decided whether they had seen a target word on that list. People thought they saw target words (boat) more often when they appeared after highly related sentence fragments (The stormy seas tossed the) compared to loosely related sentence fragments (He saved up his money and bought a; Whittlesea, 1993; see also Lee \& Labroo, 2004). In other words, the semantic context in which words appeared led people to say those words were old. Just as with the photo of the rick, the highly related sentence fragments were non-probative because they did not reveal whether target words were old or new. But against the backdrop of the loosely related sentence fragments, the highly related sentence fragments should have made it surprisingly easy to bring target words to mind, boosting conceptual fluency - a feeling people used to conclude words were familiar and therefore old (Dechene et al., 2009; Hansen et al., 2008; Westerman, 2008; Whittlesea \& Williams, 1998, 2001a, 2001b).

Other research shows similar patterns, including research on images. Sometimes images benefit from semantic context. When paintings appear with related titles or captions that help people make sense of the image, people like them more, compared to when paintings appear with unrelated context or alone (Belke, Leder, Strobach \& Carbon, 2010; Russell, 2003); when pictures (say, of a key) are primed with related words (key or lock) people rate them more positively, compared to when pictures are primed by unrelated words (snow; Winkielman et al., 2003); and when images (a frog) on wine labels are primed (by getting people to imagine a frog), people think those wines are better, compared to when images are not primed (Labroo, Dhar, \& Schwarz, 2007). 
Other times, images provide the context. In one study, people decided whether trivia claims (such as "Macadamia nuts are in the same evolutionary family as peaches") were true or false. Sometimes those claims appeared with non-probative photos that related to the claims but did not reveal the answer (such as a photo of macadamia nuts); sometimes claims appeared without photos. Photos led people to say claims were true more often, a pattern that was especially evident when people evaluated difficult claims - much like the one about macadamia nuts - that they did not know the answer to (Newman, Garry, Bernstein, Kantner, \& Lindsay, 2012; see also, Strange, Garry, Bernstein, \& Lindsay, 2011).

These findings suggest that by helping you comprehend the wine name Yellow Rick, the photo of the rick should boost feelings of conceptual fluency that you would use as evidence for evaluating the waiter's claims. But exactly how you would use that evidence should depend on whether the waiter's claims are positive or negative.

\section{Positive feelings}

Let us return to your date, and to the waiter who said that Yellow Rick impressed judges and tastes good. These claims suggest the wine is high quality. The cognitive fluency literature would predict that if the rick photo increases comprehension, it should bolster the waiter's claims and lead you to think it is true that Yellow Rick is higher quality. But now suppose the waiter tries to steer you away from ordering that wine by saying, with a resigned sigh, that Yellow Rick is bland and low quality. Would the photo also bolster this negative claim? There are reasons to expect the answer is no.

For one thing, people tend to interpret fluency as evidence that targets are positive, preferred, or attractive (for reviews, see Reber, Schwarz, \& Winkielman, 2004; Winkielman et al., 2003). Recall that preceding target words (boat) by highly related sentence fragments (The stormy seas tossed the) leads people to call words "old" more often, compared to preceding target words by loosely related sentence fragments (He saved up his money and bought a). It is also true 
that, compared to the loosely related sentence fragments, the highly related sentence fragments lead people to call target words "pleasant" more often than "neutral" (Whittlesea, 1993; see also, Lee \& Labroo, 2004).

Why are we biased to interpret cognitive ease as evidence that things (people, information, or objects) are positive? One idea is that because ease signals prior encounters, it also signals safety. That is, if we have encountered a stimulus repeatedly and it has not harmed us then we can consider it benign (Zajonc, 1968; see Song \& Schwarz, 2009). Such an interpretation is mostly functional. Because cognitive feelings reflect changes in our environment, those feelings should provide valid cues for categorizing the world into good and bad: people we should trust versus people we should be wary of, information we should accept versus information we should be skeptical of, things we should approach versus things we should avoid (Damasio, 1994; Goldstein \& Gigerenzer, 2002; Haberstadt, 2009; Schwarz, 2002). Therefore, our automatic assumption that fluid processing means "good" and effortful processing means "bad" should help to ensure our survival by producing emotional cues that quickly signal when the environment requires us to spend cognitive resources on carefully scrutinizing the people, information, or objects around us (Schwarz, 2002; Zajonc, 1968; see also, Alter, Oppenheimer, Epley, \& Eyre, 2007; Song \& Schwarz, 2008a).

As it turns out, our cognitive system is tuned to the environment in such a way that easily processed information evokes emotional cues. Boosting cognitive fluency does not just increase positive evaluations, it also increases positive affect (Harmon-Jones \& Allen, 2001; Winkielman \& Cacioppo, 2001; Winkielman et al., 2006). In one study, people liked word triplets that shared a remote associate (salt, deep, and foam share the associate sea) more than triplets that did not (dream, ball, book); moreover, triplets that shared a remote associate activated facial muscles linked with positive affect, a feeling people evidently interpreted to mean that the triplets were positive (Topolinski et al., 2009). 
This literature suggest people should actually "feel" more positively about what they can comprehend. A positive feeling about Yellow Rick should bolster the waiter's claim that it is "high quality," not the claim that it is "low quality" - a prediction consistent with work showing people are reluctant to use fluency as evidence for negative attributes of targets, such as that targets are "ugly" or "disliked" (Reber et al., 1998; Seamon, McKenna, \& Binder, 1998). Thus, if photos boost conceptual fluency and make people "feel" good about the wines they should selectively promote the truth of the waiter's positive claims.

\section{Overview of experiments}

To what extent do non-probative photos promote the truth of positive and negative claims? And what evidence is there that photos exert these effects by increasing comprehension? We addressed those question by showing people the names of several fictitious wines, all of which had ostensibly been part of a wine competition. Some wine names appeared with a photo that depicted the noun in the wine name (a photo of a rick), but was otherwise non-probative; other wine names appeared without a photo. For each wine name, people evaluated whether a claim about the wine was true or false. Some people evaluated the claim that judges said wines were "high quality" and others evaluated the claim that judges said wines were "low quality."

In Experiment la photos promoted the truth of positive claims, but not negative claims. In Experiments 1b-c we addressed alternative explanations by altering and manipulating attributes of the materials. In Experiments 2a-c, we provide support for the idea that photos operate by increasing comprehension. In Experiments 3a-b, we show that the influence of these non-probative photos even extends to when people evaluate how wines taste. 


\section{Chapter 2}

\section{Experiment 1a}

\section{Method}

Subjects

Based on our pilot work, we determined a sample size of 160 . We recruited a total of 167 subjects from Mechanical Turk ${ }^{3}$. These subjects were on average 33.23 years old $(S D=$ $12.46)^{4}$.

Design

We used a 2 (Photo: photo, no photo) x 2 (Claim: high quality, low quality) mixed design with Claim as the between subjects factor.

\section{Procedure}

We developed a set of 30 fictitious wine names by pairing adjectives and nouns selected from the MRC Psycholinguistic database (Wilson, 1988). The adjectives were familiar, and selected from the upper $50 \%$ of the MRC familiarity scale ("yellow"; $M=$ 536.36, $S D=62.23$; scale $=100-700)$. We also selected nouns that fell 0.5 SD below the mean of the familiarity scale ("rick"; $M=195.20, S D=53.47$; scale $M=488$, scale $S D=99$ ), while avoiding nouns with an obvious relation to wine (wine, grapes, vineyards). We chose these unfamiliar nouns because photos should have more room to help people comprehend

\footnotetext{
${ }^{3}$ Mechanical Turk and the survey platform we used (Qualtrics) interact in such a way that it is possible to collect data from more subjects than requested: some subjects go directly to the experiment on Qualtrics, but never formally accept the job with Amazon - apparently because they forget to do so. In Experiments la-b and 2a-b we aimed for 80 observations per between subjects cell. In Experiment 2c we aimed for 100 observations per cell to increase our power to detect correlations. In Experiment 1c, there were fewer photo trials per subject so, to increase precision, we increased the number of observations to 100 per between subjects cell. In Experiment 3a, we aimed to increase precision, and thus boosted sample size. In Experiment 3b, we recruited as many subjects as we could, given constraints on funds, the length of the semester, and our allocation from the departmental subject pool.

${ }^{4}$ We recorded subjects' age in all experiments reported in this thesis. We did not record gender in all experiments, but report that information when available. Our Mechanical Turk samples were restricted to people that were over the age of 18 and living in the United States.
} 
information people do not already understand. Using Google, we found no evidence that any of the fictitious wines existed as products (for the list of wine names, see Appendix A).

We used Qualtrics software (Qualtrics, Provo, UT) to present instructions and materials in subjects' web browsers. Subjects read a cover story that described a California wine competition in which a panel of experts rated wines as either "high quality" or "low quality." Then we told subjects they would see a series of wines names from this competition, and that some of the wine names would appear with a photo and others would appear alone (see Figure 1). When each wine name appeared on the screen, subjects judged whether a claim about the wine was true or false. Some subjects judged the positive claim, "This wine was rated as high quality," and other subjects judged the negative claim, "This wine was rated as low quality." We told subjects to respond by selecting either a "True" or a "False" button within three seconds, or as quickly as possible otherwise. To illustrate what they would see during the experiment proper, we showed subjects the wine name Lazy Ape with and without a photo.
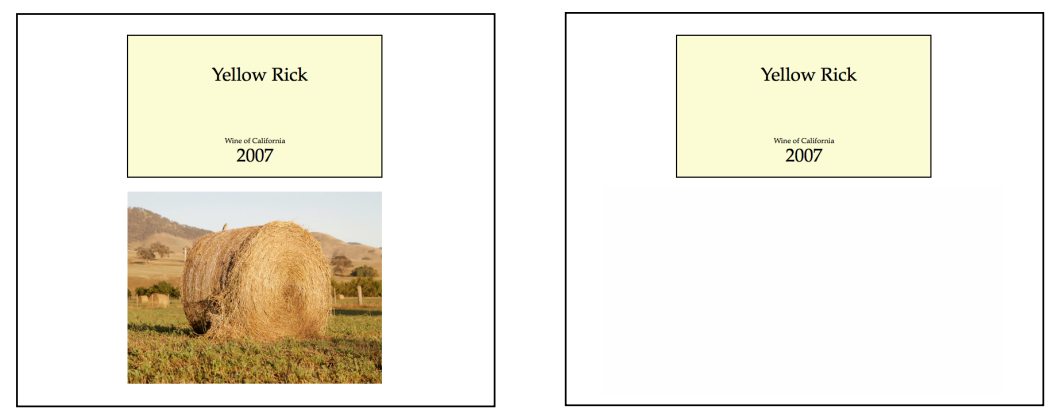

Figure 1. Example of a wine name with and without a photo. Photo credit: Fir0002/Flagstaffotos, Creative Commons license.

When wine names appeared with photos, the photos depicted the noun in the wine name: for instance, the name Yellow Rick appeared with a photo of a haystack. For names comprised of adjectives that were colors or numbers, we selected photos with the same color or number the adjective described (Yellow Rick appeared with a photo of a yellowish rick). 
Figure 1 shows how subjects saw wine names and photos. Wine names appeared in a random order, counterbalanced to appear with and without photos equally often, and wine names were counterbalanced to appear in the top or bottom half of the browser window. A third of the wine names appeared with photos, and two thirds appeared alone. We chose this relatively low proportion of photos because fluency effects tend to be largest when there are few fluent relative to disfluent items (Westerman, 2008).

After the experimental phase ended, we asked subjects questions to identify those who may have failed to pay attention or comply with the experimental instructions. First, we told subjects to read a short (five paragraph) article about how the shape of a wine glass affects the taste of wine, and to decide if the photo in the article (of a glass of wine) was appropriate to help boost understanding. Four paragraphs in, the article explained to subjects that we were actually only interested in whether they are paying attention. Then we told subjects what the "secret word" was, and asked them to enter that word on the following page of the survey. Subjects who produced the secret word passed this attention check (Oppenheimer, Meyvis, \& Davidenko, 2009). Then we asked subjects whether they had maximized their web browser, used their "back" or "refresh" button, completed the experiment in a single session, engaged in other tasks, spoke to others, worked in an environment free of noise and distraction and without help, or had used a search engine to look up the wine names. To encourage truthful responding, we told subjects that we would fully compensate them for participating regardless of their responses to these questions.

\section{Results \& Discussion}


In all experiments, subjects who failed our measures of compliance ${ }^{5}$ did not change

the overall pattern of results, so we included all subjects in the analyses reported. There were no other exclusion criteria.

To what extent did photos promote the truth of positive and negative claims? To answer this question, we calculated the proportion of times subjects responded true to the claims, grouped those proportions according to whether wine names appeared with photos or alone, and grouped them again according to whether subjects evaluated the "high quality" or the "low quality" claim. We display those results in Figure 2. As the figure shows, photos led subjects to respond true more often to the "high quality" claim, but less often to the "low quality" claim. We then calculated raw effect sizes by taking the difference in the proportion of times subjects responded true in the photo versus no photo trials. Photos produced a raw effect size of $0.12,95 \%$ CI $[0.07,0.17]$ for the "high quality" claim, and $-0.08,95 \%$ CI $[-0.12,-0.03]$ for the "low quality" claim. In null hypothesis terms ${ }^{6}$, there was a Photo $\mathrm{x}$ Claim interaction, $F(1,165)=34.72, p<.01$.

\footnotetext{
${ }^{5}$ We recorded these failure rates for only the experiments that used the Mechanical Turk subject pool. In Experiment la, the percentage of subjects who failed the attention check was 32. In Experiments 1b, 1c, 2a, 2b, 2c, and 3a the percentage was 43, 39, 35, 47, 42, and 31 respectively. These failure rates are above or at the high end of those reported research that has investigated Mechanical Turk as a subject pool (10-34\%; Goodman, Cryder, \& Cheema, 2012; Kapelner \& Chandler, 2010). We suspect those high rates are an artifact of the attention check we used. The article people read was five paragraphs long, and came at the end of the experimental task when subjects would be most fatigued and tempted to skim or skip the material presented (see Downs, Holbrook, Sheng, \& Cranor, 2010). Second, although the theme of the article was related to the theme of the experimental task, reading an article about wine is different from judging whether a claim about wine is true. An attention check more similar to the main experimental task may have produced lower failure rates, and provided more useful information for determining whether subjects paid attention.

${ }^{6}$ Our statistical analyses focus on estimates of effect sizes and the precision with which those effects were measured. Presenting data with effect sizes and confidence intervals supports recent efforts to move people away from thinking about effects dichotomously (as significant or not) and towards thinking about how big those effects are, and how certain one can be of their size (Cumming, 2012, 2014). For that reason, we present our primary statistics as effect sizes and confidence intervals, though we include relevant null hypothesis tests in the text and tables.
} 


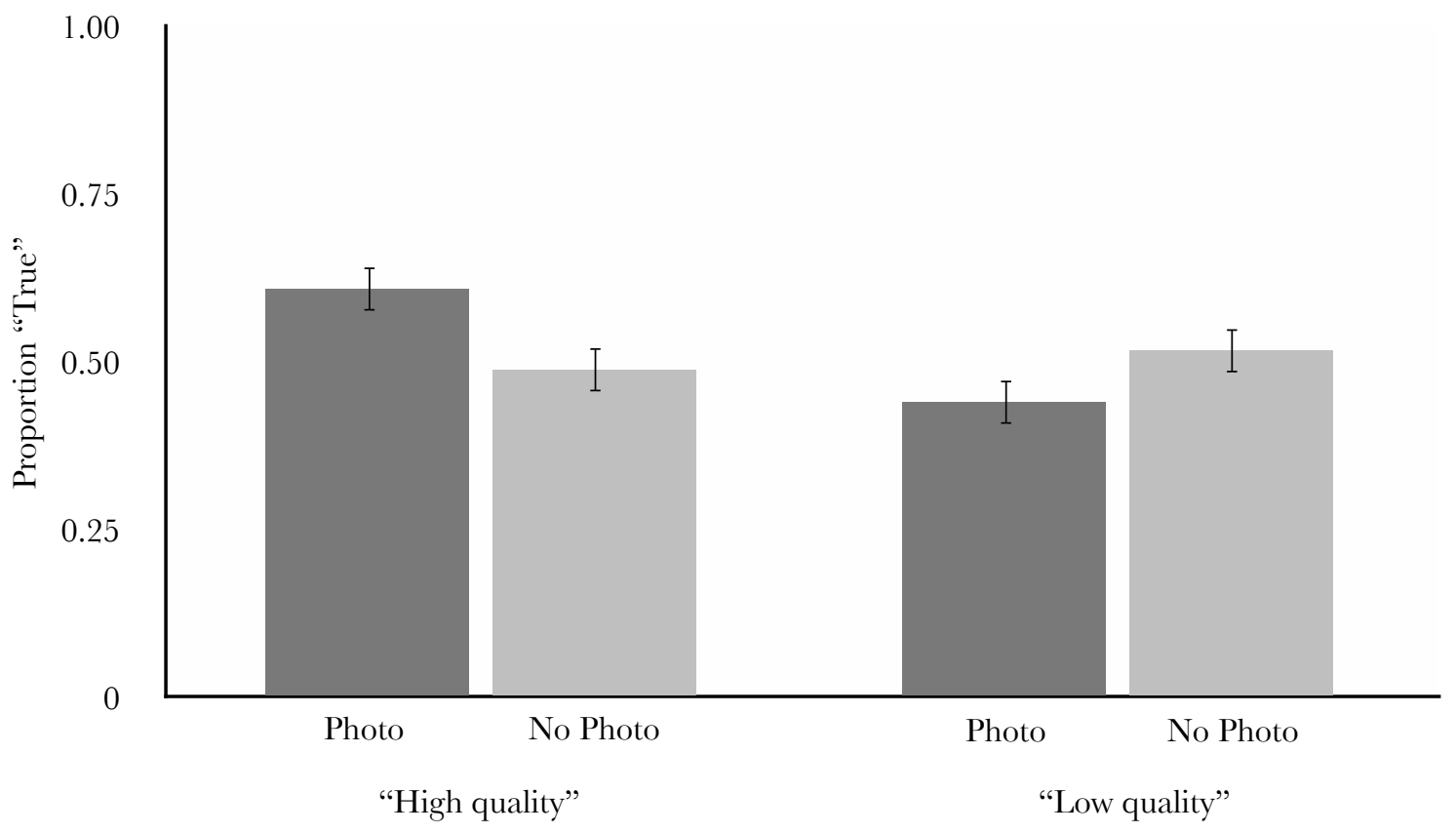

Figure 2. Proportion of "true" responses to the "high quality" and "low quality" claims when wine names appeared with photos or alone. Error bars show 95\% within-subject confidence intervals for the photo/no-photo effect (see Masson \& Loftus, 2003).

These findings fit with the idea that photos increased comprehension of wine names, boosting their conceptual fluency - a feeling people interpreted as a evidence wines were high quality. Indeed, photos even decreased true responses to the "low quality," in line with people's tendency to interpret fluency positively even when a task focuses them on negative attributes of targets. In one experiment, for instance, people saw high contrast (perceptually fluent) shapes and low contrast (perceptually disfluent) shapes; some people judged how "pretty" the shapes were, others judged how "ugly" the shapes were. Regardless of how the judgment was framed, people evaluated fluent shapes more positively — as "more beautiful" and "less ugly" — than disfluent shapes (Reber et al., 1998; see also, Seamon et al., 1998). Our findings are conceptually similar. Regardless of whether subjects got the "high quality" or "low quality" version of the claim, photos led them to evaluate wines more positively.

But another explanation for these patterns is that seeing photos next to wine labels encourages people to mentally graft the photos onto the labels, and to speculate that good companies not only make good wines, they also put more effort into the design of their 
packaging. Could this less intriguing explanation have produced our results? To address this question, in Experiment $1 \mathrm{~b}$ we removed the generic wine labels so that the subjects saw wine names written in black font against a white background.

\section{Experiment $1 b$}

\section{Method}

Subjects

We recruited a total of 164 subjects from Mechanical Turk. These subjects were on average 27.76 years old $(S D=9.19)$.

Design \& Procedure

The design and procedure followed that of Experiment 1a, except that we removed the generic wine labels so that the slides depicted only a wine name (written in black Gill Sans font) and (in a third of trials) a photo against a white background.

\section{Results \& Discussion}

As Figure 3 shows, photos produced the same pattern of results as in Experiment la, leading subjects to respond true more often to the "high quality" claim, but less often to the "low quality" claim. That is, photos produced a raw effect size of $0.11,95 \%$ CI $[0.07,0.16]$ for the "high quality" claim, and -0.08, 95\% CI [-0.13, -0.04] for the "low quality" claim. In null hypothesis terms, there was a Photo x Claim interaction, $F(1,162)=33.12, p<.01$. 


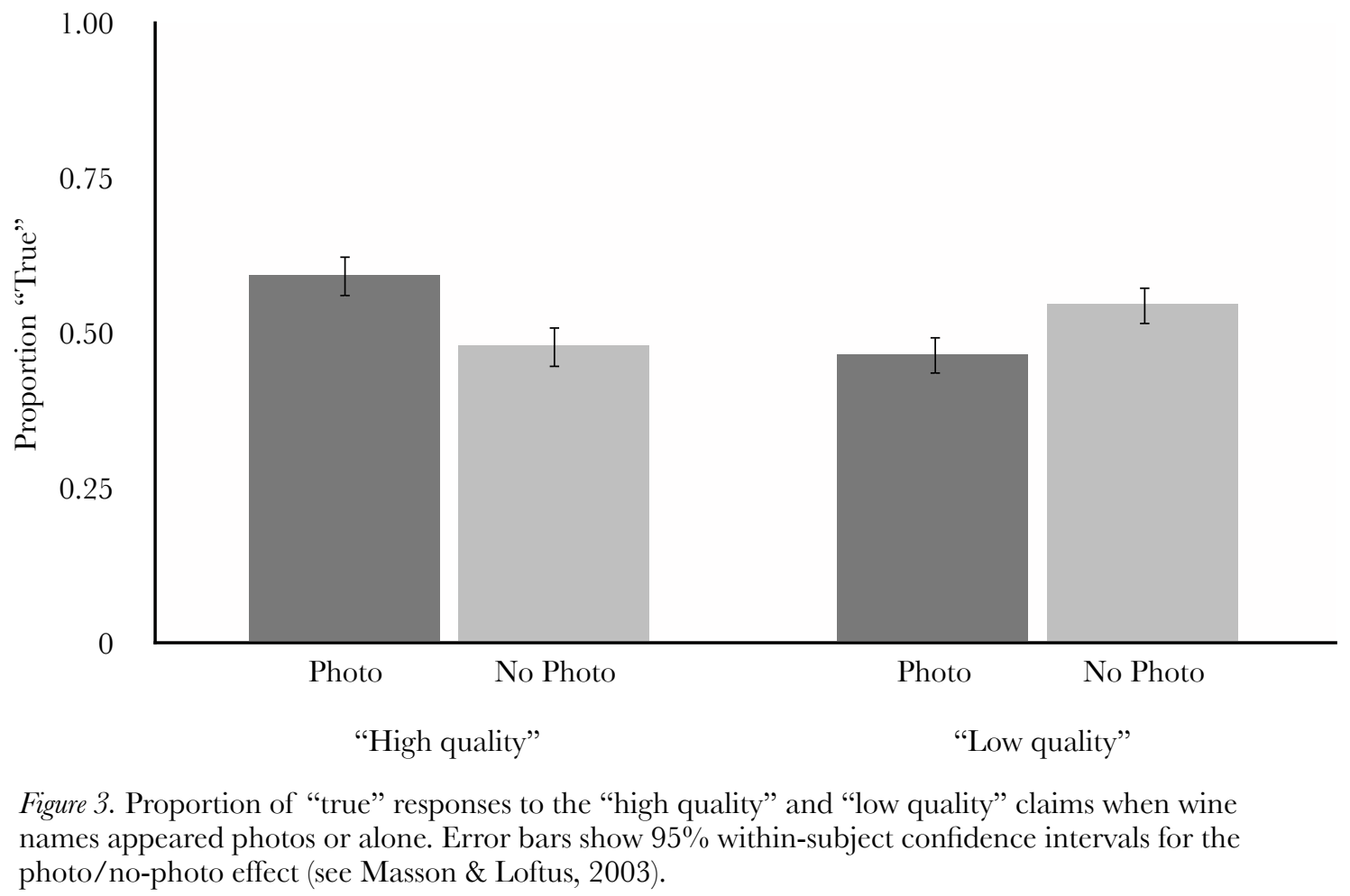

Of course, removing the generic wine labels might make people less inclined to engage in reasoning about the quality of a company, but it would not prevent them from doing so. Thus, to further examine this counter explanation, in Experiment 1c we replaced some photos with a black square, but told subjects a photo was hidden behind each square. If people use a "photo means quality" rule, then even the "hidden" photos should produce results similar to those of Experiments 1a-b. But if people use photos to comprehend the wine names, photos should wield their effects only when their semantic content is visible.

\section{Experiment 1c}

\section{Method}

Subjects

We recruited a total of 235 subjects (124 females, 83 males, and 28 subjects who did not report their gender ${ }^{7}$ ) from Mechanical Turk. These subjects were on average 34.30 years old $(S D=12.06)$.

\footnotetext{
${ }^{7}$ Our demographics measures came at the end of the experiment. Some subjects exit the survey before getting to these measures; those subjects make up the missing values reported here.
} 


\section{Design EP Procedure}

The design and procedure followed that of Experiment 1b, with a few exceptions. First, the type of images subjects saw were photos or "photos behind boxes," making the design a 2 (Type of Image: photo, box, no photo) x 2 (Claim: high quality, low quality) mixed design with Claim as the between subjects factor. This design change also meant that one third of wine names appeared with photos, one third with boxes, and one third alone.

Second, we told subjects they would not see all of the photos, but that instead sometimes photos would be hidden behind a black box. Specifically, after explaining that some wine names would appear with photos, and others alone, instructions read "But there is a twist: you will not actually see all of the photos. Instead, sometimes photos will be hidden behind a black box."

In a replication attempt, we changed the images so that the boxes did not cover the entire photo as a way of encouraging subjects to believe the photos were really there. The boxes covered enough of the photos so that the semantic information was obscured, while leaving a thin edge of the photos visible. Because a few photos had black backgrounds, their edges not appear visible behind the black boxes. So we used gray boxes and changed the experimental instructions accordingly.

\section{Results \& Discussion}

As Figure 4 shows, photos again led subjects to respond true more often to the "high quality" claim, and less often to the "low quality" claim. By contrast, boxes exerted only a trivial influence on how subjects responded. In other words, photos produced a raw effect size of $0.10,95 \%$ CI $[0.05,0.14]$ for the "high quality" claim, and $-0.09,95 \%$ CI $[-0.15,-0.04]$ for the "low quality" claim; boxes produced a raw effect size of $0.02,95 \%$ CI $[-0.02,0.07]$ for the "high quality" claim, and $-0.04,95 \%$ CI $[-0.09,0.01]$ for the "low quality" claim. In null hypothesis terms, there was a Type of Image x Claim interaction, $F(2,232)=14.06, p<.01$. 


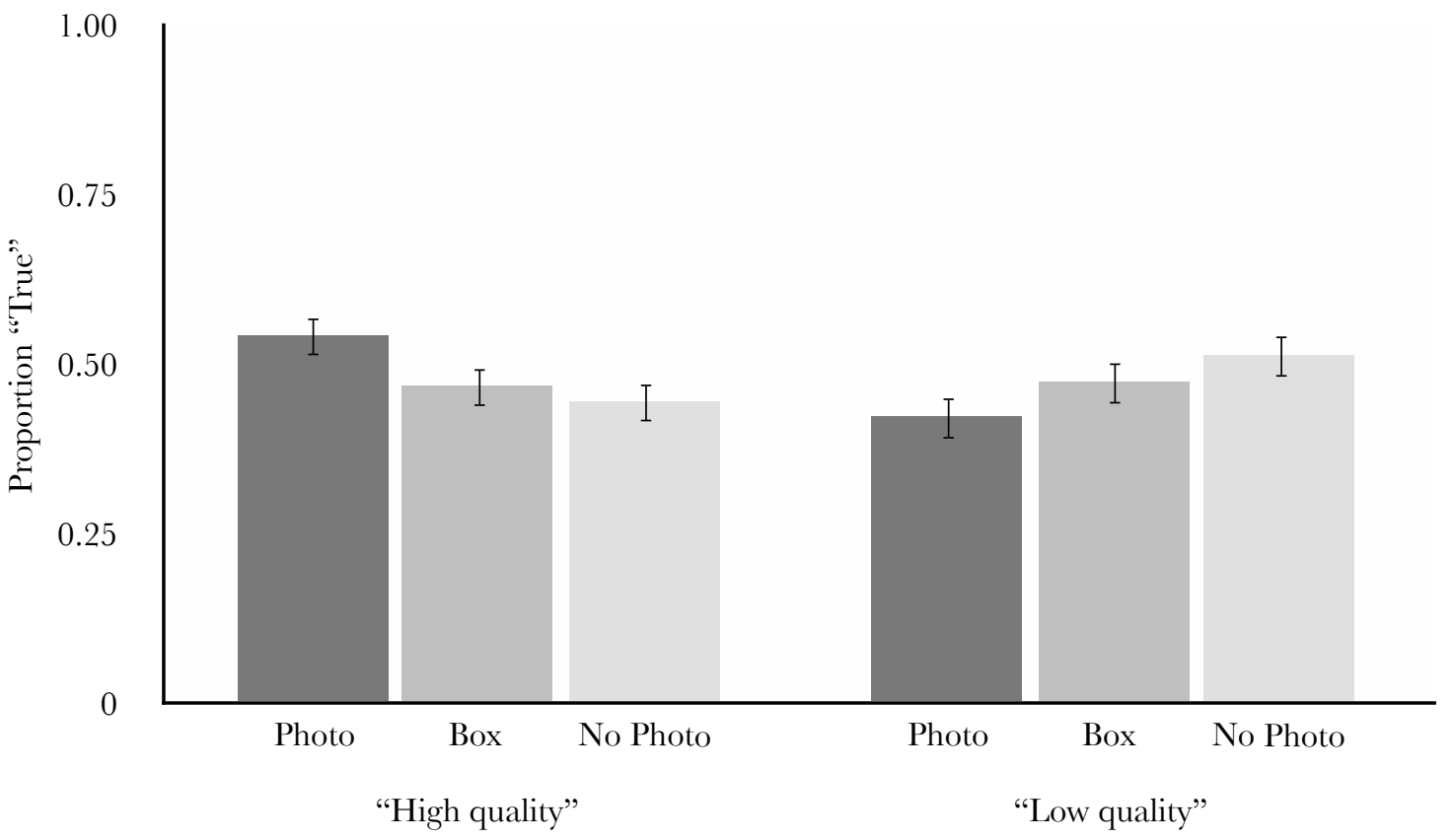

Figure 4. Proportion of "true" responses to the "high quality" and "low quality" claims when wine names appeared with photos, boxes, or alone. Error bars show 95\% within-subject confidence intervals for the photo/box/no-photo effect (see Masson \& Loftus, 2003).

We replicated these patterns with a group of university subjects, and a second group of Mechanical Turk subjects who saw the "gray box" version of the experiment. To arrive at a more precise estimate of the size of these effects, and those reported in Experiments 1a-b, we conducted random effects model mini meta analyses ${ }^{8}$ and report those results, which are consistent with those reported here, in Table 1 (Cumming, 2012).

\footnotetext{
8 These mini meta analyses derive an estimated effect size and its confidence interval based on each replication of the effect, with relatively larger samples exerting more influence over the estimate. We used a random effects model because of problems inherent in fixed effect models. Fixed effect models assume that each study measured the same population effect size and therefore do not take heterogeneity of the experiments into account. For that reason, fixed effect models tend to yield confidence intervals that are too narrow to account for the variance across samples. Random effects models, by contrast, do take heterogeneity in account, and in doing so provide a more realistic confidence interval for heterogenous samples. In fact, random effects analyses will produce the same result as fixed effects analyses when there is no heterogeneity, so there is no concern that using random effects with a homogenous sample would yield inaccurate estimates (Cumming, 2012).
} 


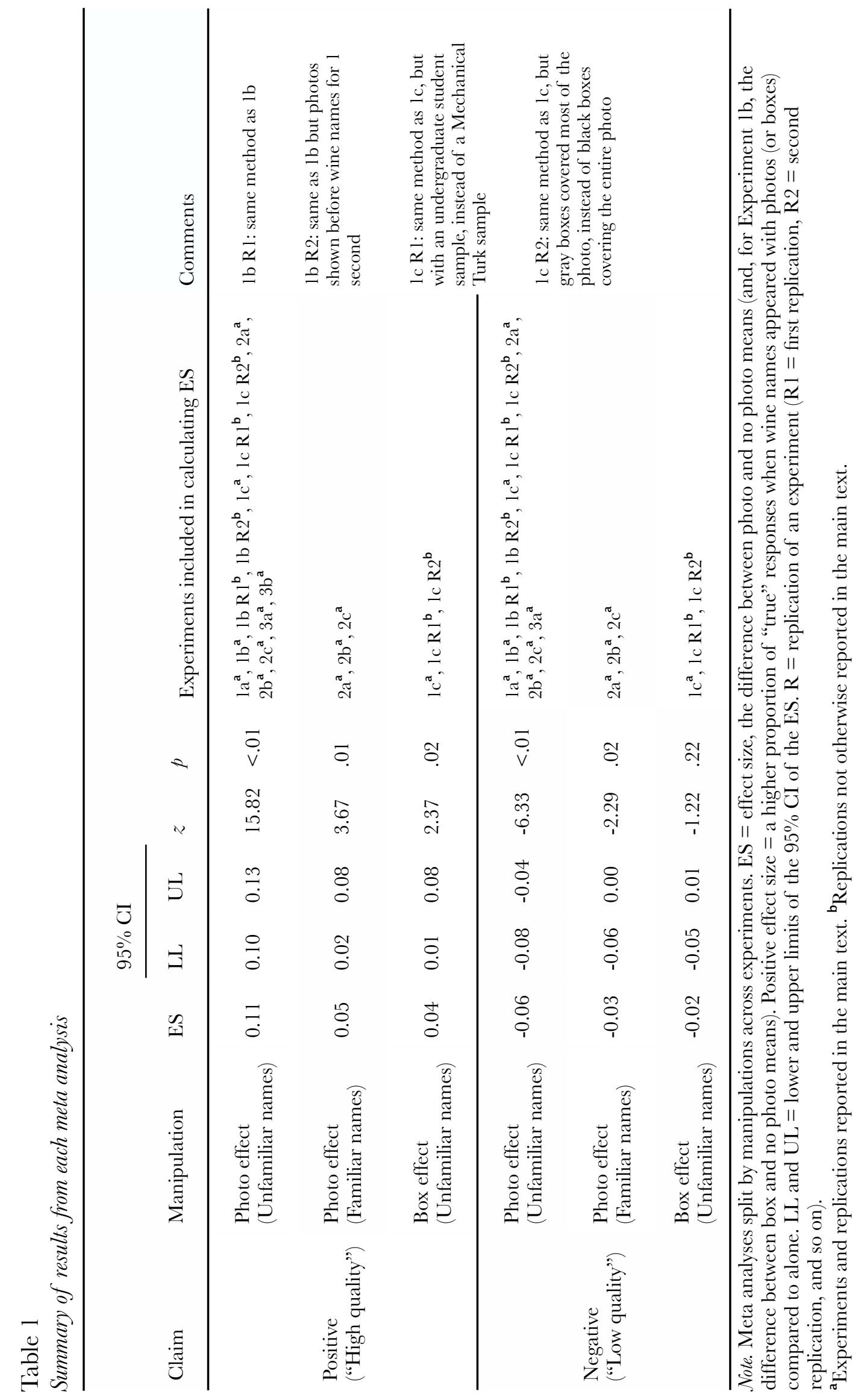


Photos wielded a stronger influence when they were visible, a finding at odds with the idea that people use a "photo means quality" rule. Instead, the findings fit with a conceptual fluency mechanism, which would require people to access the semantic content from photos to bring related information to mind and comprehend the wine names.

But an equally plausible explanation is that seeing the interesting, colorful images in photos makes wines more aesthetically pleasing, and something about that aesthetic appeal makes wines seem higher quality. Perhaps people would use that rule explicitly, reasoning that pretty photos signal quality wines. The same outcome could also occur without relying on an explicit rule: we know that people can mistake positive feelings associated with attractiveness as evidence information is familiar (Garcia-Marques, Mackie, Claypool, \& Garcia-Marques, 2013; Monin, 2003). If aesthetically appealing photos increased feelings of familiarity, that also could lead people to evaluate wines more positively (Zajonc, 1968).

Yet if photos work through such a route, they should exert their effects to a similar extent regardless of whether they increase comprehension. By contrast, if photos operate by increasing comprehension they should exert their strongest effects when they can most increase comprehension - when people evaluate claims about wines with unfamiliar names, such as Yellow Rick compared to wines with familiar names, such as Scarlet Apple. We examined this hypothesis in Experiments 2a-c by showing subjects wine names comprising unfamiliar nouns (as in Experiment 1) versus familiar nouns.

\section{Experiment 2a}

\section{Method}

Subjects

We recruited 158 subjects (62 females, 89 males, and 7 subjects who did not report their gender) from Mechanical Turk. These subjects were on average 31.20 years old $(S D=$ 12.11). 
Design

We used a 2 (Photo: photo, no photo) x 2 (Claim: high quality, low quality) x 2 (Familiarity: familiar names, unfamiliar names) mixed design, with Claim manipulated between subjects.

Procedure

Using the method described in Experiment 1, we developed a set of 30 familiar wine names, all featuring nouns high in familiarity (nouns at least $0.5 \mathrm{SD}$ above the mean, such as "apple"; $M=571.20, S D=25.65$; scale $M=488$, scale $S D=99$; see Appendix A). Subjects saw a set of 60 wine names including the 30 new familiar wine names plus the 30 unfamiliar wine names used in Experiment 1. The presentation of familiar and unfamiliar wine names was random. The procedure was otherwise identical to that of Experiment 1a.

\section{Results \& Discussion}

Figure 5 shows three important findings. First, the pattern from Experiments la-c replicated. For unfamiliar wine names, photos promoted the truth of the "high quality" claim, but not the "low quality" claim. Second, in line with our hypothesis, photos exerted stronger effects when they could most increase comprehension (but as the figure shows, only for the positive claim). Third, a closer look at the patterns on both the "high quality" and "low quality" sides of the figure suggests that even in the absence of photos, subjects turned to what was easier to comprehend - the familiar wine names. The figure also shows raw effect sizes, confidence intervals, and (in null hypothesis terms) a Photo x Claim x Familiarity interaction, $F(1,156)=7.37, p<.01$.

To arrive at more precise estimates of the size of these effects, we conducted random effects model mini meta analyses and report those results, which are consistent with those reported here, in Table 1 (Cumming, 2012). 


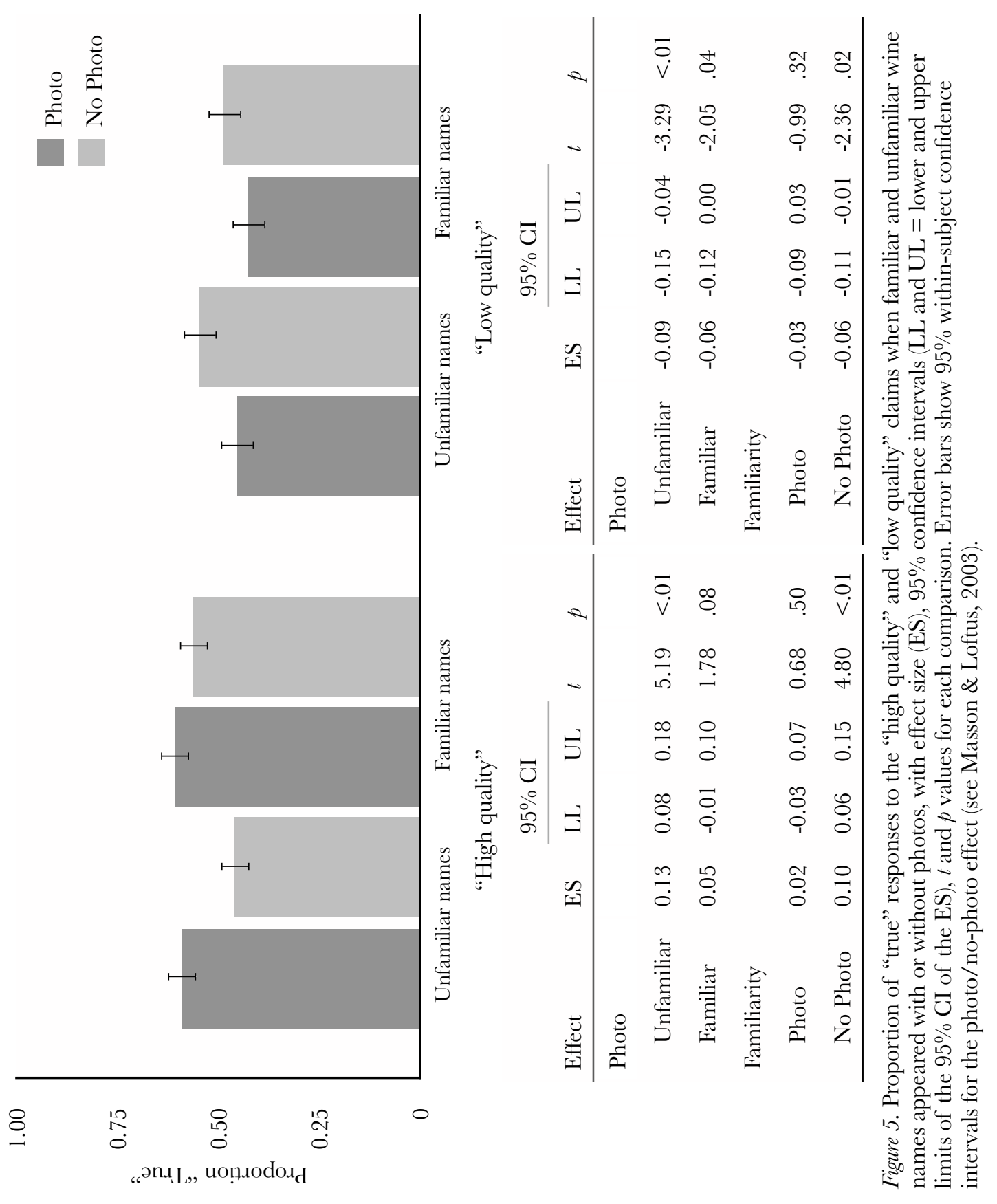


These findings suggest photos exert their strongest effects when they can most increase comprehension and that even in the absence of photos, comprehension per se promotes positive evaluations. We reasoned that if it is true that photos increase comprehension while people evaluate claims, then subjects should be able to demonstrate that increased comprehension at the end of the experiment. That was the purpose of Experiment 2b.

\section{Experiment $2 b$}

\section{Method}

Subjects

We recruited 186 subjects (100 females, 67 males, and 19 subjects who did not report their gender) from Mechanical Turk. These subjects were on average 32.75 years old ( $S D=$ 11.71).

Design E̊ Procedure

The design and procedure were similar to that of Experiment 3a, except that immediately after judging the truth of claims, we showed subjects nouns from wine names they had encountered and asked them to classify each noun into one of five categories. We defined the five categories for subjects as an object, something people make; a food, even if it is a plant; an animal; a plant, but one that people would not typically eat; and a geographical location, something you could walk to or visit. We told subjects to choose the one best category that each word fit into, and that if they were unsure they should go with their best guess. Subjects did this categorization task for the 16 nouns they had most recently encountered. We relied on only these most recent items because they should be easiest for subjects to remember, boosting our chances of detecting increases in comprehension. Nouns appeared one at a time in a random order, and the five categories along with their definitions appeared as options below each noun. Eight of the nouns were familiar, the other eight were 
unfamiliar. For each type of noun, four had earlier appeared with photos and four had earlier appeared alone.

\section{Results \& Discussion}

We replicated the patterns from Experiment 2a. But our primary interest was the extent to which photos help people comprehend familiar and unfamiliar nouns. To that end, we calculated the proportion of nouns subjects classified correctly, and display those results in Figure 6. As the figure shows, photos increased comprehension for unfamiliar nouns but not for familiar nouns. For unfamiliar nouns photos produced a raw effect of $0.08,95 \%$ CI [0.03, 0.13], but for familiar nouns photos produced a raw effect of $-0.02,95 \%$ CI $[-0.06,0.02]$. In null hypothesis terms, there was a Familiarity x Photo interaction, $F(1,185)=9.96, p<.01$.

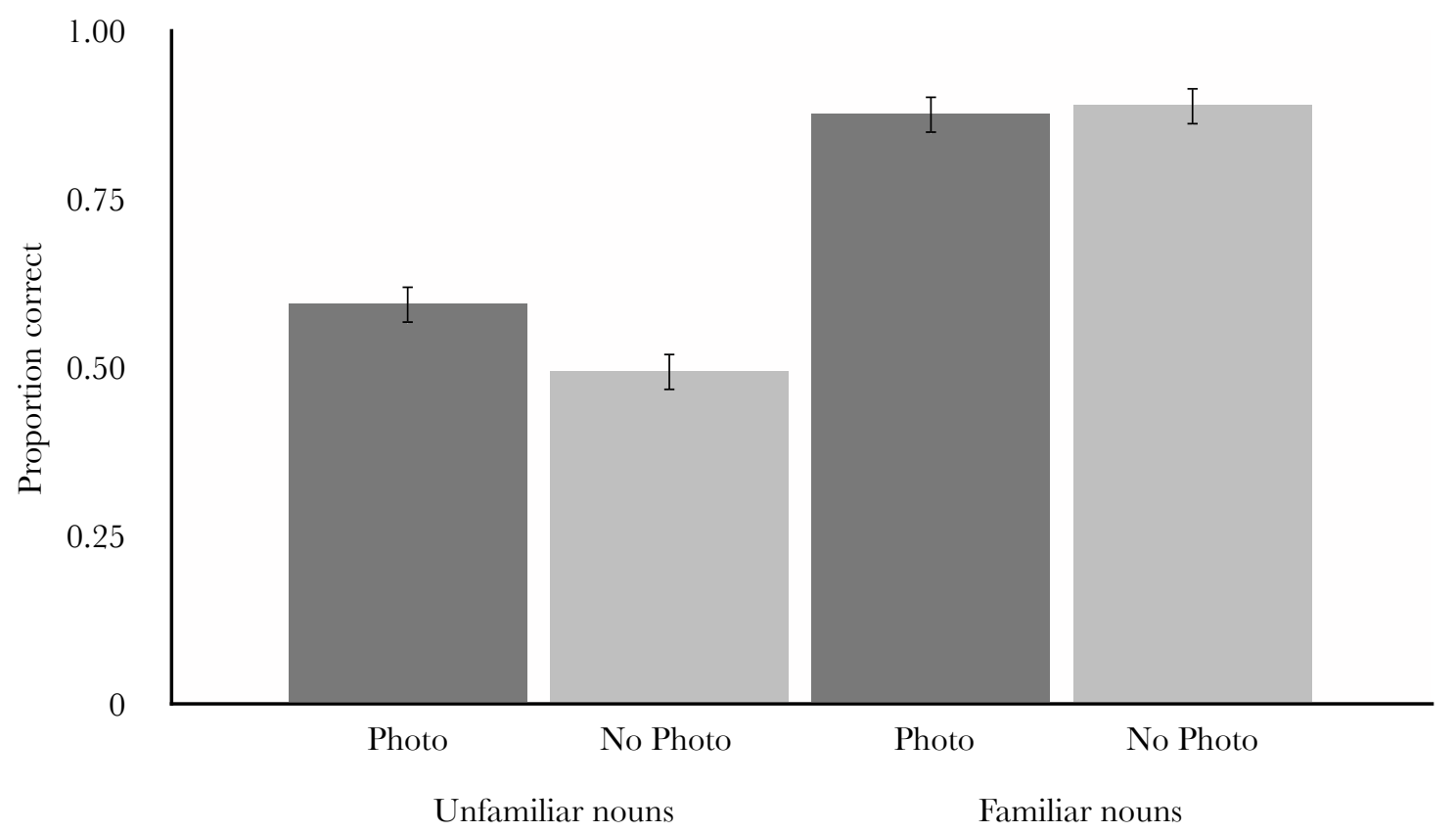

Figure 6. Proportion of correct categorizations for unfamiliar and familiar nouns that appeared with photos or alone. Error bars show 95\% within-subject confidence intervals for the photo/no-photo effect (see Masson \& Loftus, 2003).

These findings provide converging evidence that photos work by making wine names easier to comprehend. Indeed, the findings suggest that while subjects evaluated the claims about wines, photos increased subjects' ability to comprehend the unfamiliar nouns. And it 
was those wine names for which photos boosted comprehension that they most promoted positive evaluations.

It should also be possible to demonstrate with these data that the more photos helped subjects comprehend unfamiliar nouns, the more they led subjects to say the "high quality" claim was true. To investigate this possibility, we calculated the photo effect on truth for the subset of unfamiliar wine names that subjects later saw the nouns of in the comprehension test. We also calculated the photo effect on comprehension for those same nouns. Then we measured the extent to which the photo effect on truth was related to the photo effect on comprehension. We found no evidence of a relationship, a correlation of $-0.03,95 \%$ CI $[-0.23,0.17]^{9}$. In null hypothesis terms, for the "high quality" claim when subjects saw unfamiliar nouns there was no relationship between the effect of photos on truth and comprehension, $p>.05$.

These patterns may seem at odds with a comprehension mechanism. After all, how much photos help people comprehend nouns should predict the extent to which photos lead people say positive claims are true. But on second thought, this mechanism does not require photos to increase people's actual comprehension. Rather, it only requires that photos increased people's feelings of comprehension — how much they feel they know what words mean, accurate or not. To further examine this comprehension mechanism, in Experiment 2c we measured the extent to which photos made subjects confident they knew the meaning of the nouns in wine names.

\section{Experiment 2c}

\section{Method}

\footnotetext{
${ }^{9}$ We ran these same analyses with the "low quality" claim and the familiar nouns and found no significant relationships. We report the statistics for only the "high quality" claims using unfamiliar nouns given that the photo effect consistently appears under those conditions. We used robust analyses (iteratively re-weighted least squares, or IRLS) to account for potential effects of outliers in the dataset. The analysis re-weights data points with unusually large residuals, minimizing their influence and producing a more precise estimate of the relationship between variables. When we ran a Pearson's product-moment correlation we found the same correlation of $-0.03,95 \%$ CI [-0.23, 0.17$], p>.05$.
} 
Subjects

We recruited 226 subjects (133 females, 72 males, and 21 subjects who did not report their gender) from Mechanical Turk. These subjects were on average 33.78 years old ( $S D=$ 11.47).

Design EP Procedure

The design was the same as that of Experiment 2a. The procedure was similar, except that after judging a claim about each wine name, subjects rated how confident they were they knew what the noun in the wine name meant. For example, after judging a claim about Yellow Rick, we asked subjects "How confident are you that you know what "rick" means?" Subjects responded on a scale from $0=$ "Not at all confident" to $100=$ "Totally confident."

\section{Results \& Discussion}

We again replicated the main findings from Experiments 2a-b. But we were primarily interested in how confident subjects were that they knew what nouns in wine names meant when those wine names appeared with photos versus alone. To answer that question, we calculated the mean confidence rating subjects gave to nouns, grouped those means according to whether wine names appeared with photos or alone, and grouped them again according to whether wine names were comprised of familiar or unfamiliar nouns.

As Figure $7^{10}$ shows, photos increased subjects' confidence that they knew what unfamiliar nouns meant; photos trivially increased subjects' confidence they knew what familiar nouns meant. In other words, for the unfamiliar nouns, photos produced a raw effect of $13.25,95 \%$ CI $[11.20,15.31]$; for familiar nouns, photos produced a smaller raw effect of

\footnotetext{
${ }^{10}$ The within subjects confidence interval calculations we used pool the variance of all within subjects factors (Masson \& Loftus, 2003). But because the variance for "familiar nouns" condition was extremely low, including it in the calculations for "unfamiliar nouns" condition would have yielded inappropriately small confidence intervals. We therefore took a more conservative approach, calculating the confidence intervals for the photo/no photo effect separately for unfamiliar and familiar nouns. In the main text we also present confidence intervals on the difference between the photo and no photo conditions.
} 
0.96, 95\% CI $[0.34,1.59]$. In null hypothesis terms, there was a Familiarity x Photo interaction, $F(1,225)=143.51, p<.01$.

Moreover, we found evidence that subjects' tendency to say the "high quality" claim was true was positively related to the extent to which photos made subjects confident they knew what nouns meant, a correlation of $0.27,95 \%$ CI $[0.10,0.43]^{11}$. In null hypothesis terms, for the "high quality" claim there was a positive correlation between the truth effect and the confidence effect, $p<.05$.

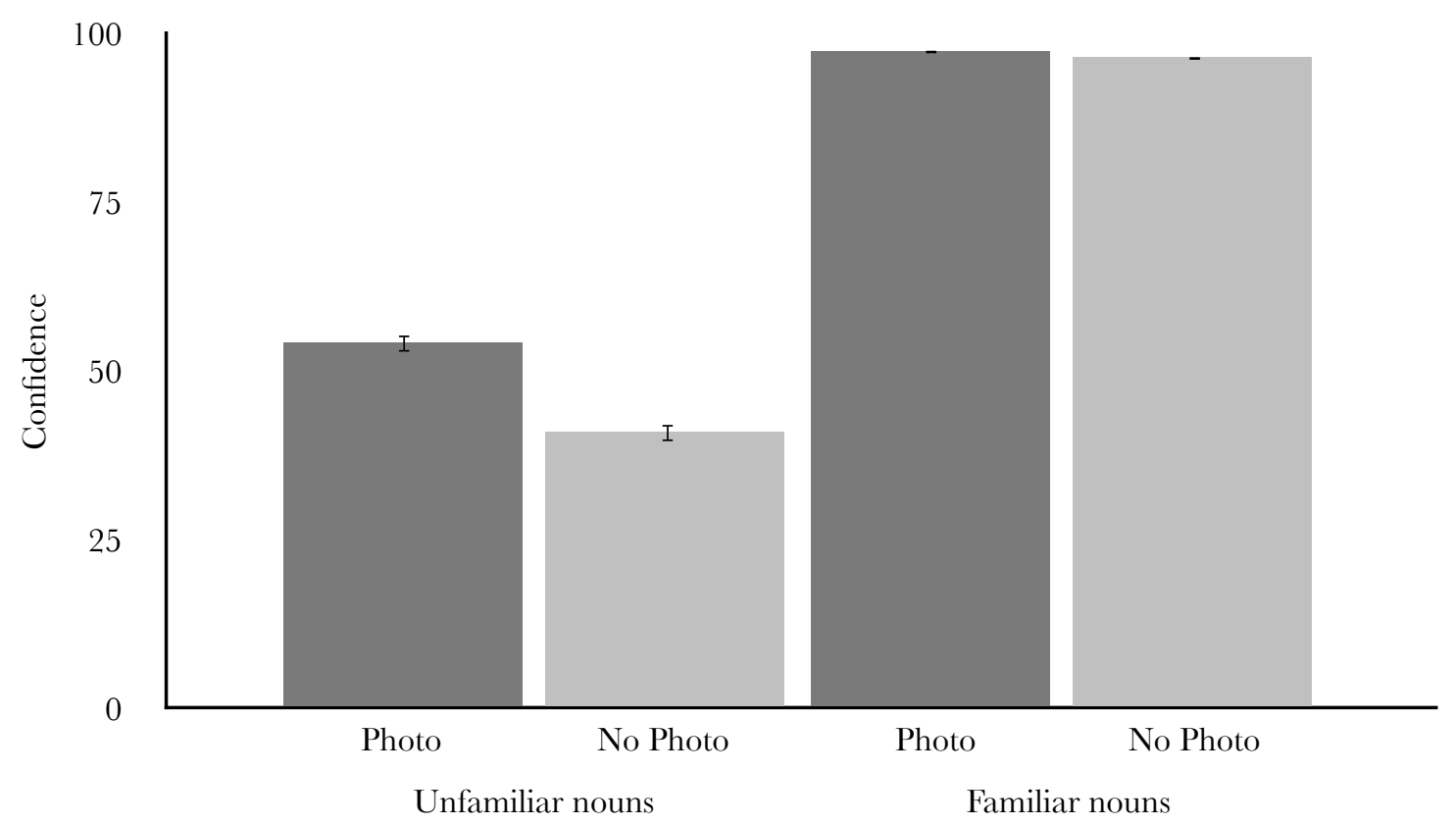

Figure 7. Average ratings for how confident people were that they knew what unfamiliar and familiar nouns meant when wine names appeared with photos or alone. Error bars show $95 \%$ within-subject confidence intervals for the photo/no-photo effect (see Masson \& Loftus, 2003).

Considered together, Experiments 1 and 2 show that non-probative photos promote the truth of positive claims, but not negative claims. Moreover, the findings from Experiment 2 fit with the idea that photos work by increasing comprehension. Not only did photos exert their strongest effects when they could most increase comprehension (Experiments 2a-c), photos increased actual comprehension (Experiment 2b) and subjective feelings of

\footnotetext{
${ }^{11}$ As in Experiment 2b, we report the statistics for only the "high quality" claims using unfamiliar nouns, and used robust analyses to account for potential effects of outliers in the dataset. When we ran a Pearson's productmoment correlation we found a weaker correlation of $0.18,95 \% \mathrm{CI}[0.00,0.35], p<.05$.
} 
comprehension (Experiment 2c). And the extent to which photos increased people's subjective feelings of comprehension was related to how much photos led subjects to think the positive claim was true (Experiment 2c).

Nonetheless, it is one thing to demonstrate that photos influence what people think happened in some fictitious wine competition, but it would be quite another to show that photos influence what people think about a wine once they actually taste it. Yet photos might do exactly that: if photos boost conceptual fluency, they should exert their influence whenever people interpret the resulting feelings as relevant to the task at hand - even if people believe the photos themselves are irrelevant (Higgins, 1998; Schwarz, 2004). The photo of the rick, then, should lead people to think Yellow Rick wine tastes good, even if they believe the photo would do no such thing.

We examined this idea in Experiment 3a-b in three ways. First, we determined whether people actually think photos would affect how they judged the taste of wines. Second, before testing whether photos affect actual judgments of taste, in Experiment 3a we replicated the patterns using the scenario from Experiments 1 and 2 but asked subjects to suppose that they themselves had tasted the wines; that is, subjects imagined the taste of wines that appeared with photos or without photos. Third, in Experiment 3b we examined whether photos affect how people think wines actually tasted by having subjects taste wines that appeared with photos or alone.

We first gathered evidence for our assumption that people believe photos have little effect on how wines taste. 
Table 2

Means and standard deviations for subjects' responses to the question about how much each factor would affect how wines tasted

\begin{tabular}{ll}
\hline Factor & $M(S D)$ \\
\hline Being able to pronounce the wine name & $1.86(1.10)$ \\
The font used to write the name of the wine & $2.16(1.12)$ \\
Seeing a photo on its label & $2.22(1.08)$ \\
Understanding all the words in the name of the wine & $2.26(1.24)$ \\
Knowing what color it was & $3.15(1.19)$ \\
Knowing how much the wine costs & $3.16(1.29)$ \\
Having a friend tell you it was good & $3.31(1.20)$ \\
Whether you had tried it before & $3.49(1.33)$ \\
Smelling the wine & $3.84(1.05)$ \\
\hline
\end{tabular}

We told 55 Mechanical Turk subjects ${ }^{12}$ to suppose they were tasting a wine, and asked them "How much would each of the following affect how the wine tasted to you?" Subjects responded on a scale from 1 (Not at all) to 5 (Very much). As Table 2 shows, subjects thought several factors, such as a photo on the label and being able to understand the words in the wine name, would have relatively little influence over how wines tasted. Unsurprisingly, they thought other factors, such as a friend's opinion, would exert more influence.

Next, in Experiment 3a we asked a separate group of subjects to evaluate claims about how wines tasted.

\section{Experiment $3 a$}

\section{Method}

Subjects

We recruited 209 subjects (100 females, 91 males, and 18 subjects who did not report their gender) from Mechanical Turk. These subjects were on average 34.08 years old ( $S D=$ 12.76).

\section{Design \& Procedure}

12 There were 26 females, 28 males, and 1 subject who did not report their gender. The average age of these subjects was $30.65(S D=11.53)$. 
The design and procedure were similar to that of Experiment 1a, with two exceptions. First, after explaining the wine competition, we told subjects to suppose they had tasted these wines at the competition. Second, the claims subjects evaluated referred to the taste of wines; specifically, some subjects judged the truth of the claim "This wine tastes high quality" and other subjects judged the claim "This wine tastes low quality."

\section{Results \& Discussion}

Despite people's tendency to believe that photos would have relatively little influence over how wines tasted, photos continued to exert their effects. Indeed, Figure 8 shows that photos produced patterns similar to when, in Experiments 1-2, subjects made the more remote decision about how judges evaluated wines. Photos produced a raw effect size of 0.12 , 95\% CI [0.08, 0.15] for the "high quality" claim, and -0.08, 95\% CI [-0.14, -0.03] for the "low quality" claim. In null hypothesis terms, there was a Photo x Claim interaction, $F(1,207)$ $=35.71, p<.01$.

Of course, just because photos influenced hypothetical judgments of taste does not mean they would influence actual judgments of taste. After all, taste provides people with diagnostic, sensory information and diagnostic information tends to trump fluency as evidence (Unkelbach, 2007; for a related finding, see Monin, 2003; for a review, see Greifeneder et al., 2011). Yet we also know that taste is susceptible to cognitive biases. People's tendency to remember and prefer what they encounter first affects taste judgments (Mantonakis, Rodero, Lesschaeve, \& Hastie, 2009). And tangential features of a wine can change how people experience its taste; wines taste better when people think they are more expensive, and when the wine's sponsor seems congruent with the product (Becker, van Rompay, Schifferstein, \& Galetzka, 2011; Clemente, Dolansky, Mantonakis, \& White, 2013; Plassman O’ Doherty, Shiv, \& Rangel, 2008; for a review, see Krishna, 2012). 


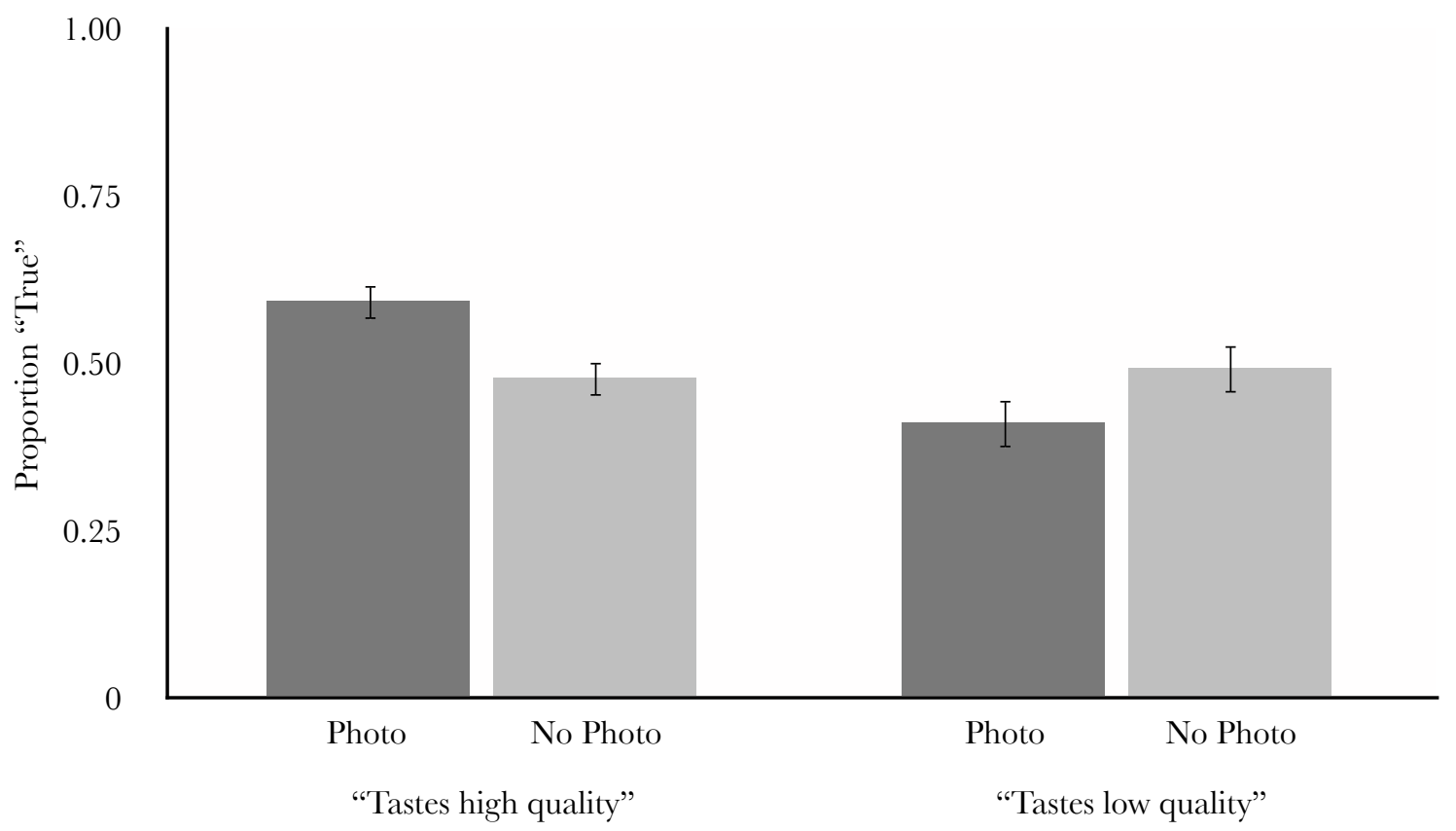

Figure 8. Proportion of "true" responses to the "tastes high quality" and "tastes low quality" claims when wine names appeared with photos or alone. Error bars show 95\% within-subject confidence intervals for the photo/no-photo effect (see Masson \& Loftus, 2003).

What is more, recent evidence suggests that comprehending words while tasting would change how people experience taste. When people saw familiar words while tasting a drink in which sweetness was difficult to detect, they more often reported experiencing sweetness in the drink, compared to when people saw less familiar words. One explanation for this pattern is that familiar words were more conceptually fluent, and the positive feelings they produced led people to experience taste in line with that feeling (Liang, Roy, Chen, \& Zhang, 2013). This possibility fits more broadly with people's tendency to judge ambiguous information in line with their current expectations, beliefs, or feelings (Carmichael, Hogan, \& Walter, 1932; Brewer \& Treyens, 1981; Nickerson, 1998).

Combining these findings suggests that by helping people comprehend wine names, photos should alter people's subjective experience of how those wines taste. To examine that possibility, in Experiment 3b we asked subjects to taste wines that appeared with photos or alone.

\section{Experiment $3 b$}




\section{Method}

Subjects

We recruited 121 students (54 females, 67 males) from Brock University (Canada). These subjects were on average 23.74 years old $(S D=5.27)$.

Design E Procedure

The design and procedure departed from that of Experiment 3a in four ways. First, because the IRB (Institutional Review Board, or ethics committee) decision limited subjects to consuming no more than $90 \mathrm{~mL}$ of wine (just under one standard drink), we reduced our set of wine names to six, and for each wine name subjects tasted $15 \mathrm{~mL}$ of wine. The IRB decision also led us to maximize power by pairing half the wine names with photos, rather than a third. Second, subjects completed the experiment seated at a tasting station. In front of them was a computer and the wines arranged from left to right, numbered 1 through 6.

Subjects learned they would taste each wine in order and were instructed to sip water between tastings. What subjects did not know was that we adopted a method used in wine tasting research, and served the identical wine (a Pinot Noir from the same producer and vintage; see Mantonakis et al., 2009), a fact we concealed by pouring wines in black glasses. Third, just before each wine name appeared on the screen, instructions prompted subjects to pick up, swirl, smell, and taste the wine. While tasting, subjects saw the wine name and decided whether the claim "This wine tastes high quality" was true or false. We included only the positive version of the claim to further maximize power. Finally, after the experiment, we asked questions to determine whether subjects knew all of the wines were actually the same (What did you think of the wines?, Did you like them?, and Great, which one was your favorite?).

\section{Results \& Discussion}

Did photos change how subjects judged the taste of wines? As Figure 9 shows, the answer is yes. 


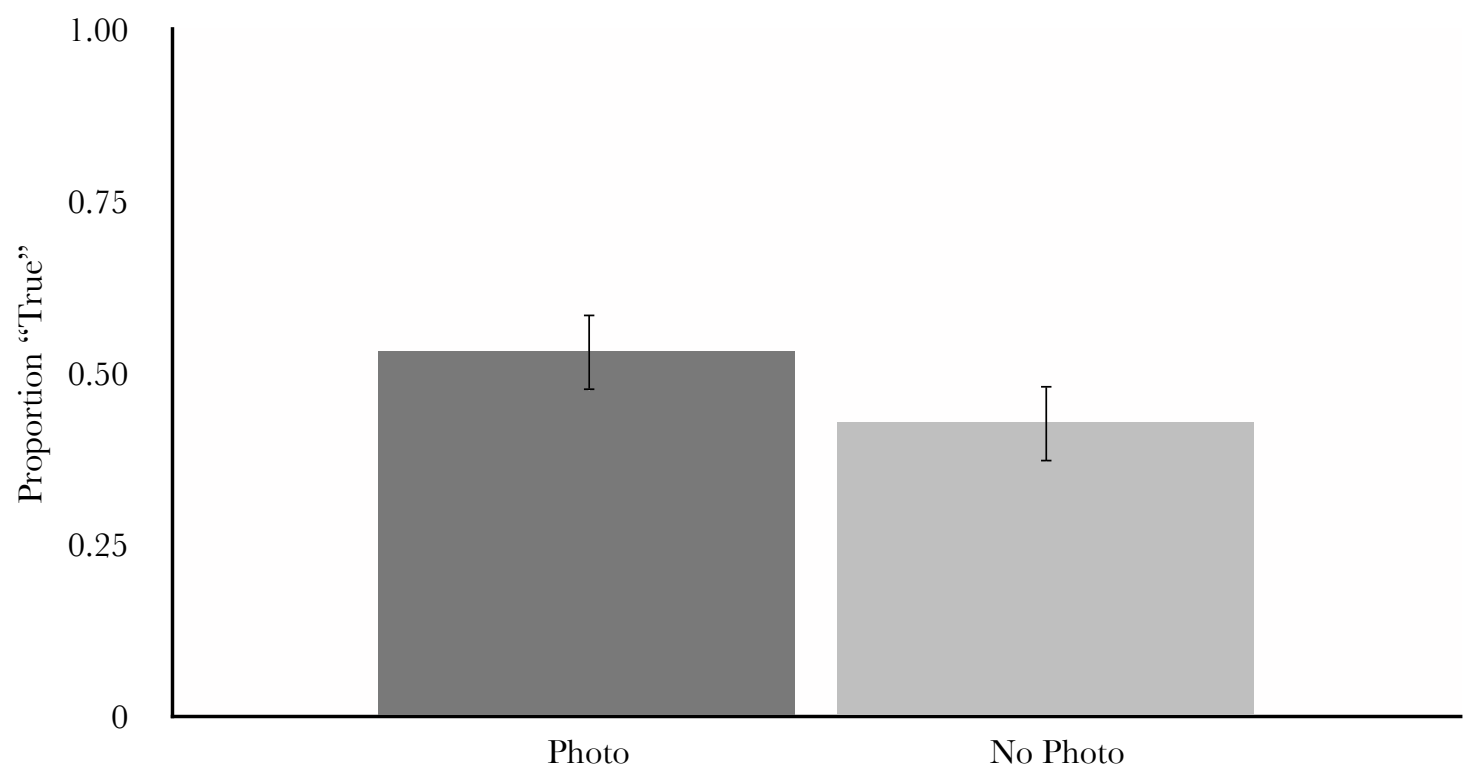

Figure 9. Proportion of "true" responses to the "tastes high quality" claim wine names appeared with photos or alone. Error bars show 95\% within-subject confidence intervals for the photo/no-photo effect (see Masson \& Loftus, 2003).

Subjects said the claim "This wine tastes high quality" was true more often when wine names appeared with photos compared to alone. Photos produced a raw effect size of 0.08 , 95\% CI [0.01, 0.16]. In null hypothesis terms, there was an effect of photos, $t(120)=2.19, p$ $=.03$. Although $12 \%$ of those subjects thought the wines were the same, excluding them from the analysis produced the same pattern of results, a raw effect size of $0.10,95 \%$ CI [0.02, $0.19], t(105)=2.53, p=.01$. Note that although the confidence intervals are reasonably wide, more plausible values are concentrated around the mean (Cumming, 2012).

In Experiment 3b, identical wines tasted better when they appeared with photos, suggesting photos trumped diagnostic sensory information about taste. Considered together, Experiments 3a-b also fit with the idea that even though people believe photos are irrelevant to the task at hand, photos exert their influence by producing feelings that seem relevant. 


\section{Chapter 3}

In eight experiments we examined the extent to which non-probative photos promote the truth of positive and negative claims. Across all experiments, photos that depicted nouns in wine names - but that otherwise had nothing to do with wine - selectively promoted the truth of related positive claims. We found evidence consistent with the idea that photos exerted these effects by helping people comprehend wine names, and that photos even swayed people's judgments about the taste of wines.

In Experiment la, photos led people to think the claim that wines were "high quality" was true, but did not lead people to think the opposite "low quality" claim was true. This finding fits with other effects in which adding context or priming related ideas makes information feel more conceptually fluent, and people mistake that feeling as evidence for positive (but not negative) evaluations (Belke et al., 2010; Reber et al., 1998; Seamon et al., 1998; Topolinski et al., 2009; Whittlesea, 1993; for reviews, see Alter \& Oppenheimer, 2009; Reber et al., 2004; Winkielman et al., 2003).

But an alternative explanation was that people simply responded on the basis of a rule associating photos with quality. People might have reasoned that good companies put more effort into designing their packaging and would therefore have used photos more often than bad companies. Several of our findings work against that explanation. First, photos promoted positive evaluations in Experiment $1 \mathrm{~b}$ even when we removed the generic wine labels that could have encouraged people to consider what a wine's packaging signaled about its quality. Second, in Experiment 1c, telling people there was a (hidden) photo did not make wines seem higher quality, suggesting it was not enough for people to know there was a photo associated with the wine, people actually had to see those photos.

Although that pattern fits with the idea that photos operated by helping people comprehend wine names, there was another reason people might have needed to see photos 
for those effects to emerge. Perhaps photos were aesthetically pleasing, and that aesthetic pleasure produced positive feelings people mistook as evidence wines were familiar (GarciaMarques et al., 2013; Monin, 2003). That route also could have promoted positive evaluations and would not have required photos to boost comprehension to do so.

Nonetheless, several of the findings from Experiments 2a-c were at odds with that possibility. In each of those experiments, photos exerted stronger effects when wine names were made up of unfamiliar nouns, suggesting a mechanism related to comprehension. And when we actually measured comprehension in Experiment 2b, we found that photos increased comprehension for unfamiliar nouns more than for familiar nouns. Perhaps that result is not all too surprising, given that photos can aid understanding (Carney \& Levin, 2002; Bransford \& Johnson, 1972; Henkel, 2012; Mayer \& Gallini, 1990). But it suggests that at the time people evaluated the claims, photos boosted comprehension most for the same wine names they also most increased positive evaluations.

Similar patterns arose in Experiment 2c when, after people evaluated each wine, we measured how confident they were that they knew what each noun in the wine name meant. Moreover, there was a relationship between people's subjective comprehension and positive evaluations; the more photos made people feel that they knew what words meant, the more they promoted the truth of the positive claim.

Finally, Experiments 2a-c also showed that even in the absence of photos, people turned to what they could comprehend, responding more positively when wine names were familiar. That pattern fits with work showing that people prefer stimuli they have repeatedly encountered, and suggests people's judgments were prone to sources of comprehension other than photos - familiarity (Bornstein, 1989; Jacoby et al., 1988; Kunst-Wilson \& Zajonc, 1980; Zajonc, 1968). 
Together, Experiments 1 and 2 revealed two important findings. Photos promoted positive evaluations and exerted their strongest effects when they could most increase comprehension - results consistent with the idea that photos cause feelings of conceptual fluency that people use as evidence for positive evaluations (Reber et al., 2004; Topolinski et al., 2009; Winkielman \& Cacioppo, 2001; Winkielman et al., 2006).

Such a mechanism suggests it is not the photos that are important, but the boost in conceptual fluency they afford (see Newman et al., 2012). In line with that idea, in Experiments 3a-b we demonstrated that even though people tend to believe photos are irrelevant for judging the taste of wines, photos nonetheless influenced those judgments. In Experiment 3a, photos promoted positive evaluations about the hypothetical taste of wines. But the results of Experiment $3 \mathrm{~b}$ are perhaps more intriguing: photos also produced that pattern when people actually tried the wines and therefore could have drawn on more diagnostic information (its taste) to evaluate the claims. This finding meshes well with recent work showing that comprehending words while tasting can change how people experience taste (Liang et al., 2013). And the findings fit more broadly with people's tendency to perceive ambiguous information in line with their current expectations, beliefs, or feelings (Carmichael et al., 1932; Bartlett, 1932; Brewer \& Treyens, 1981; Nickerson, 1998).

\section{Theoretical implications}

As a whole, the set of findings blend well with the large body of literature showing that people draw on cognitive feelings that arise when information comes to mind easily, and do so even when those feelings are irrelevant to the task at hand (Alter \& Oppenheimer, 2009; Higgins, 1998; Schwarz \& Clore, 2007; Unkelbach \& Greifeneder, 2013). This bias arises because people are tuned into correlations between their cognitive feelings and states of the world that usually help them make decisions quickly and accurately (Damasio, 1994;

Goldstein \& Gigerenzer, 2002; Halberstadt, 2009; Halberstadt \& Catty, 2008; Unkelbach, 
2006, 2007). But as with any rule of thumb, every so often people's feelings lead them into error (see Kahneman \& Tversky, 1973; Kelley \& Lindsay, 1993; Reber \& Schwarz, 1999; Whittlesea, 1993). We see our findings as an instance of one of those errors: by providing semantic context, photos produced irrelevant feelings people assumed were relevant, and people used those feelings to evaluate the merit of claims.

Another interpretation of how semantic context boosts positive evaluations

Recall from the introduction that one way semantic context promotes positive evaluations is by making the targets people are evaluating come to mind more easily, producing feelings of conceptual fluency that people interpret as evidence targets are positive (Alter \& Oppenheimer, 2009; Schwarz, 2004; Unkelbach \& Greifeneder, 2013). But a common feature of the targets in each of the studies we described (a picture of a key, a claim about a turtle, or the word "boat") was that they represented ideas or objects people are familiar with - concepts people know fairly well, that they would have encountered many times (Newman et al., 2012; Whittlesea, 1993; Winkielman et al., 2003.

But being reminded for the twenty-thousandth time about keys, turtles, or boats is not the same as realizing for the first time that a rick is a haystack ${ }^{13}$. The photo of the haystack does more than help you bring to mind established concepts (haystacks, and your related knowledge): it also helps you learn a new concept (rick). Perhaps learning that a rick is a haystack was another reason photos led people to see Yellow Rick in a positive light. Such a possibility would qualify claims that semantic context promotes positive evaluations by

\footnotetext{
${ }^{13}$ In one version of the experiment that used unfamiliar wine names, we compared how long it took people to respond to the claims when they had just seen a photo, or had not just seen a photo. Seeing photos just before the wine names appeared did not speed people's response times, consistent with the idea that photos would not help people access unfamiliar concepts, such as "rick." We did not gather these data for the familiar wine names, but theories of spreading activation and the cognitive fluency literature predict that for known concepts, semantic context would speed response times (Collins \& Loftus, 1975; Whittlesea, 1993; Winkielman et al., 2003). Thus, our finding coupled with these predictions are consistent with the proposition that different processes occur when photos provide semantic context for known versus unknown concepts.
} 
facilitating people's access to known concepts. It may also do so by teaching people new concepts. And several lines of research bolster that interpretation.

We know that learning or solving problems can be pleasurable. In one study, when people successfully used contextual information to learn new words, areas of the brain associated with reward processing were more active (Ripolles et al., 2014). In another study, dogs behaved as though they were happier when they solved problems to reap rewards, as opposed to when they passively received those rewards (McGowan, Rehn, Norling, \& Keeling, 2014). And learning or problem solving can be especially pleasurable when it occurs rapidly —as when people experience "Eureka," or rush of insight (Lakshmanan \& Krishnan, 2011; Pronin, Jacobs, \& Wegner, 2008; Schilling, 2005; Topolinski \& Reber, 2010). Therefore, learning from a photo that a rick is a haystack could have increased positive feelings.

Other research suggests people could have mistaken those feelings from learning as evidence the wine was good. In one study, people said words out loud and decided whether they saw those words in an earlier phase of the experiment. People were more likely to call words "old" if they were real (bottle) versus made up (culse). More to the point, people were more likely to call made-up words "old" if, when pronounced, those words corresponded to real words (phrawg = frog; Whittlesea \& Williams, 1998). Put differently, realizing what words meant seemed like evidence for people's unrelated decisions about whether words were old. Likewise, realizing what "rick" meant could have seemed like evidence for people's decisions about the quality of wine.

Similar work shows that people can mistake their experience of solving a problem as evidence for unrelated judgments. People prefer products more if just before viewing those products they solve an unrelated anagram (Kronlund \& Bernstein, 2006). Solving unrelated anagrams also increases people's confidence in the answers to trivia claims (Bernstein, Whittlesea, \& Loftus, 2002). One way to explain these effects is that solving the anagrams was 
easier than people expected, and people misinterpreted their ability to solve the problems as being "about" their preference for a product or their confidence in an answer (see Whittlesea \& Williams, 1998, 2001a, 2001b). In a similar vein, learning what unfamiliar wine names meant might have served as problems people solved with the help of photos, an experience interpreted as evidence for the quality of wines.

Finally, the idea that photos operated by increasing learning overlaps with work showing that people can misread feelings of familiarity as evidence that they know something (such as knowing the answer to a problem, or knowing a concept well enough to remember it for a test; Rawson \& Dunlosky, 2002; Reder \& Ritter, 1992; Rhodes \& Castel, 2008; Schwartz \& Metcalfe, 1992; Yue, Castel, \& Bjork, 2012; Metcalfe \& Dunlosky, 2008). Given that the causes and consequences of familiarity can be bidirectional, a reasonable assumption is that people would also misread the feeling that they know something as evidence it is familiar (Garcia-Marques et al., 2013; Monin, 2003). These connections help explain how learning a word from a photo could seem relevant for decisions that have nothing to do with assessing learning: if photos produce feelings of knowing, people might mistake those feelings for familiarity which - due to its many positive connotations - seems like evidence relevant for the task (Carpenter \& Olson, 2012; Schwarz, 2004; Schwarz \& Clore, 2007).

The idea that learning promotes positive evaluations raises questions for future research. One question is whether learning new concepts would promote positive evaluations even when what people learn is clearly unrelated to the target of evaluation. Suppose people saw the wine Yellow Rick, but rather than learning that a "rick" is a haystack, they learned that an "aster" is a type of flower, or some other piece of unrelated trivia.

If we ignore the role of learning, then a reasonable prediction is that the unrelated semantic context would make it more difficult for people to access related knowledge, causing Yellow Rick to "feel" less positive, and therefore failing to promote positive evaluations (Collins 
\& Loftus, 1975; Winkielman et al., 2003). Indeed, in a recent study when people saw trivia claims paired with unrelated semantic context (such as a claim about turtles with a photo of a lamp) that semantic context did not lead people to think claims were true (Newman, Garry, Unkelbach, Bernstein, \& Lindsay, 2014; see also, Belke et al., 2010; Lee \& Labroo, 2004; Winkielman et al., 2003). But considering the role of learning suggests those patterns may not hold when the unrelated semantic context helps people learn new concepts (such as when the definition of "aster" appears with Yellow Rick). Under those conditions, the positive effects of learning could work against or overshadow the negative effects of unrelated semantic context.

Do the effects of learning depend on people making sense of new concepts themselves, as opposed to merely being told the new concepts? We suspect the answer is yes because having to grapple with what words mean would allow for an element of surprise at being able to "solve the problem" (see Bernstein et al., 2002; Kronlund \& Bernstein, 2006). And the more people are surprised by their cognitive feelings - that is, when they strongly contrast against ongoing cognitive operations - the more noticeable and influential those feelings are (Dechene et al., 2009; Hansen et al., 2008; Westerman, 2008; Whittlesea \& Williams, 1998, 2001a, 2001b). So although feeding people the meaning of "aster" might promote positive evaluations, we place our bets on when people extract that meaning themselves.

To what extent do photos operate by causing feelings of conceptual fuency?

Although we found evidence consistent with the idea that photos operate by causing feelings of conceptual fluency, there are several ways future research could further examine that idea. For a start, it would be useful to know whether photos cause positive feelings at all. One way to investigate that question is to measure people's automatic facial muscle responses. If photos produce feelings of conceptual fluency they should activate muscle responses 
associated with positive affect (the "smiling" muscles; Harmon-Jones \& Allen, 2001;

Topolinski et al., 2009; Winkielman \& Cacioppo, 2001; Winkielman et al., 2006).

Those measures could also provide insights about the role of learning. When photos relate to familiar concepts (such as "apple") they should cause positive affect. But when photos relate to unfamiliar concepts (such as "rick"), and allow people to learn something new, they might produce a different pattern of responses: perhaps the disfluency of unknown concepts produces negative affect, followed by more positive affect when people resolve what those concepts mean (for a similar idea, see Whittlesea \& Williams, 1998). Such a trajectory of affective responses would support the hypothesis that facilitating learning promotes positive evaluations through a route different to facilitating access to known concepts.

Another way to examine whether photos operate by producing seemingly relevant feelings of conceptual fluency is by using manipulations that lead people to see those feelings as irrelevant. One of those manipulations is giving people a phony explanation as to what caused their feelings. Recall the study where a researcher asked people about their life satisfaction on days the weather was nice or poor (Schwarz \& Clore, 1983). When the weather was nice, people reported being more satisfied with their lives. But that effect disappeared when the researcher called attention to the weather (by asking specifically about the weather, or saying the research examined how weather influenced moods). In other words, when people thought their good mood was due to the weather, they no longer thought those feelings were relevant for evaluating their life satisfaction (see also, Oppenheimer, 2004; Schwarz, Bless, Strack, Klumpp, Rittenauer, \& Simons, 1991; for a review, see Schwarz \& Clore, 2007). If photos work by producing feelings of conceptual fluency that people assume are relevant, then calling into question the relevance of those feelings should diminish the effects of photos.

A related way to diminish the effects of photos is to ask people to analyze reasons for their decisions. Analyzing reasons reduces the extent to which people use their feelings as 
information (including cognitive feelings associated with fluent processing) - an effect thought to occur because reasoning focuses people on seemingly more relevant or easier-to-articulate information, and shifts people toward processing information more analytically (Halberstadt \& Catty, 2008; Halberstadt \& Green, 2008; Halberstadt \& Hooton, 2008; Wilson et al., 1993; Wilson \& Schooler, 1991; for a review, see Halberstadt, 2009).

Finally, although people's default interpretation of fluency is that information is positive (familiar, favorable or true), there is evidence that people can learn the opposite interpretation (Unkelbach, 2006, 2007). Suppose we gave people a training phase where they saw no photos but instead learned that fluency (perhaps created via color contrast or semantic priming) is associated with negative stimuli. Then, during a subsequent phase people would evaluate targets, such as wine, that appear with related photos or alone. If photos operated by increasing conceptual fluency, then arming people with the interpretation that fluency is negative should cause photos to promote negative evaluations, not positive evaluations. Understanding the mechanisms behind "truthiness"

Our findings mesh well with prior work showing that non-probative photos can make trivia claims seem more true, promoting what Newman et al. (2012) called "truthiness." In that work, people saw a series of trivia claims, such as "Macadamia nuts are in the same evolutionary family as peaches," and decided whether the claims were true or false. When trivia claims appeared with related photos (of macadamia nuts), people more often said those claims were true. That finding has clear parallels with ours. Just like the photo of the rick, the photo of macadamia nuts was non-probative because it did not reveal whether the claim was true. But it would have provided context that helped people bring related thoughts and images to mind, producing feelings of conceptual fluency people used as evidence for the claim. 
Our findings help rule out an alternative explanation Newman et al. (2012) proposed: that people simply mined photos for details that confirmed their default bias to think claims are true (Gilbert et al., 1993; Newman et al., 2012; Nickerson, 1998). This mining strategy predicts that photos would operate independently of whether claims are about positive or negative attributes of targets; either way, people would find details in photos that confirm the claims. But in our experiments photos did not do that. Instead, they led people to think positive claims were true, a finding that fits better with a conceptual fluency explanation.

Still, our pattern of results is puzzling when up against one of Newman et al.'s studies in which photos of celebrities promoted the truth of claims that those celebrities were "alive" and that those celebrities were "dead." Assuming aliveness and deadness are positive and negative attributes of celebrities, those findings do not square with ours.

One explanation for this discrepancy is that the context of Newman et al.'s task encouraged people to construe claims about celebrities not in terms of their positive and negative attributes, but more generally as facts about the world. If so, people might have been biased to interpret feelings of conceptual fluency as evidence of accuracy or truth (see Kelley \& Lindsay, 1993; Reber \& Schwarz, 1999). By contrast, the evaluative nature of our task may have been more obvious, encouraging people to consider positive and negative attributes of wines, and biasing people to interpret fluency as evidence of preference or quality (see Reber et al., 1998; Winkielman et al., 2003). These speculations fit with people's tendency to impose on fluency the most plausible interpretation, given the context of the task (Greifeneder et al., 2011; Jacoby et al., 1989; Schwarz, 2004; Unkelbach \& Greifeneder, 2013).

A second explanation involves the extent to which people thought the details in Newman et al.'s photos versus our photos were appropriate for a mining strategy. People might use a mining strategy when photos contain details that could be be plausibly construed as evidence for hypotheses inherent in the claims, but rely on their feelings when photos 
contain seemingly useless details. For example, if a celebrity looked old or was wearing outdated clothing, those details might seem like evidence supporting the hypothesis that the celebrity was dead. But applying that strategy in our experiment may have seemed much less sensible. Perhaps it was too farfetched for people to believe that a detail from a photo of a haystack is evidence for judging not a haystack, but a wine. In that way, our materials may have made feelings seem more viable by limiting the extent to which people could mine, or thought it reasonable to do so $^{14}$. When people draw on the content of photos, versus feelings they produce, is a question worthy of future research.

\section{Practical implications}

The most obvious practical implication our findings have is that helping people make sense of product names (by adding related images, or using familiar words) should make those products seem better (see Labroo, Dhar, \& Schwarz, 2007; Lee \& Labroo, 2004). Foreign products, such as the French wine Le Chat Noir, might benefit from images on their labels (of a black cat) that reveal what those foreign words mean.

It would also be useful to know when in the real world photos would stop wielding their influence. Do photos continue to exert their effects when people choose from among many products, or sample the taste of different products (see Iyengar \& Lepper, 2000)? The opportunity to compare features could provide people with diagnostic information (price, brand name, prior experience) that seems more relevant than their feelings (Monin, 2003; Unkelbach, 2007). Indeed, the comparison process itself could obscure people's reliance on feelings by leading people to evaluate products more analytically (Halberstadt, 2009). Alternatively, overwhelming people with so many options to choose from might make for a

\footnotetext{
${ }^{14}$ We cannot rule out the possibility that people used a mining strategy coupled with feelings of conceptual fluency. For positive claims, mining and positive feelings would work together to make the claim seem true. But for the negative claim, mining would work against positive feelings, making the claim seem less false than it may have if feelings operated on their own. Future research could have people rate positive and negative targets on a scale (say, from $1=$ low quality to $6=$ high quality). Doing so would remove hypotheses inherent in the claims, and potentially reduce people's bias to confirm claims, while allowing for photos to promote positive evaluations.
} 
difficult task, depleting people's cognitive resources and leading them to resort to a simpler decision strategy — such as what "feels" right (or people may even defer choosing; Greifeneder et al., 2011; Novemsky, Dhar, Schwarz, \& Simonson, 2007).

The practical implications of our findings extend to other domains, such as education. Consider the illusion of comprehension, when people feel they know information when they actually do not (Jacoby, Bjork, \& Kelley, 1994). One way to promote this illusion is by making it feel easy for people to think about information they are studying (Metcalfe \& Dunlosky, 2008; Rawson \& Dunlosky, 2002; Rhodes \& Castel, 2008; Schwartz \& Metcalfe, 1992). Could photos that do not teach people new information, but that merely remind people of what they already know, also promote that illusion? Imagine a scientific passage about how plants reproduce; embedded in the passage is a generic photo of a plant. The photo would not illustrate processes involved in plant reproduction, but should help students bring related information to mind - a feeling students might interpret as evidence they "get" the material and can invest less effort studying it (Kornell \& Bjork, 2007; see Serra \& Dunlosky 2010).

In fact, because fluency can signal that more effortful cognitive operations are not necessary for a task, photos should also increase people's susceptibility to misleading information and increase logical errors (Alter, Oppenheimer, Epley, \& Eyre, 2007; Song \& Schwarz, 2008a). It is the malleable meaning of ease that suggests our findings should apply to a number of people's other every day decisions (Schwarz, 2004). Photos should make travel destinations seem closer, food recipes easier to execute, stocks more valuable, and a person's writing more intelligible (Alter \& Oppenheimer, 2006, 2008; Oppenheimer, 2006; Song \& Schwarz, 2008b). And because people tend to conclude personal experiences happened when it feels easy to bring related thoughts and images to mind, photos should even quickly lead people to believe claims about their personal pasts (Jacoby et al., 1989; Johnson, Hashtroudi, \& Lindsay, 1993; Lindsay, 2008; Whittlesea, 1993). We examined that hypothesis in Part 2. 


\section{Part 2}

\section{Chapter 1}

Suppose you and your friend are headed home from the zoo. She tells you she took many great photos, but regrets that she did not take one when you fed the shoebill. But you do not remember feeding a shoebill, and your attempts at remembering are stymied because you are not even sure what a shoebill is. And so, hoping to jog your memory, your friend Googles "shoebill" and shows you the photo in Figure 1.

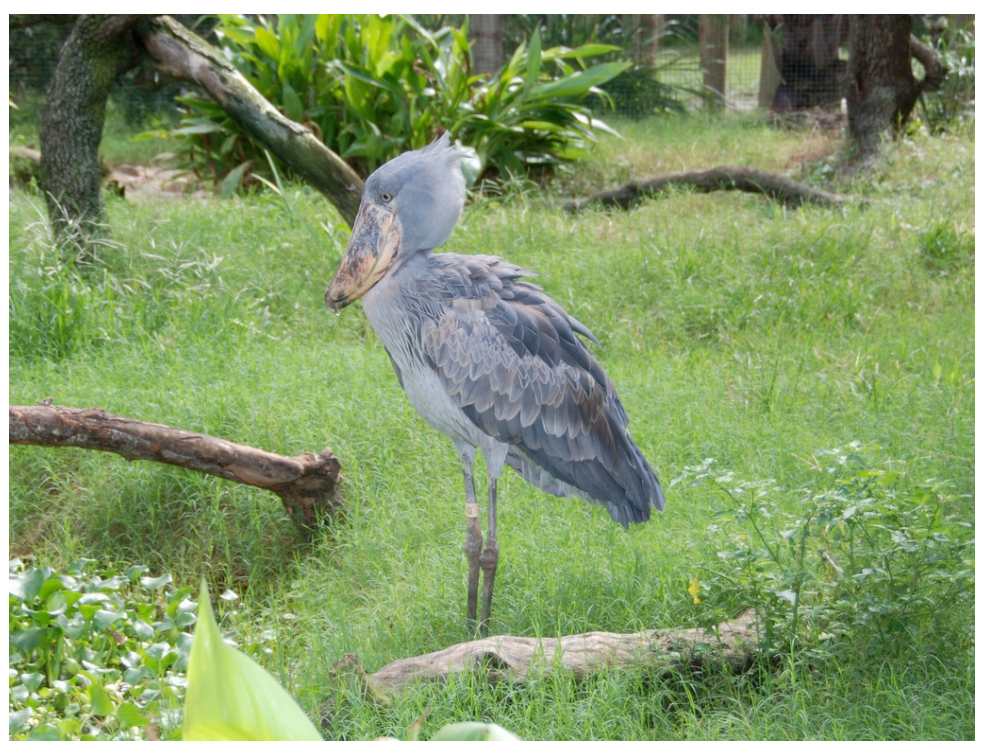

Figure 1. A photo of a shoebill. Photo credit: Jeff Whitlock, Creative Commons license.

The photo does not depict you feeding the animal, making it non-probative with respect to your friend's claim. Instead, it merely makes you realize that a shoebill is a large bird-like creature - an epiphany that is not all too surprising, given that photos aid comprehension and encourage inferences (Bransford \& Johnson, 1972; Carney \& Levin, 2002; Henkel, 2012; Mayer \& Gallini, 1990).

Of course, realizing that a shoebill is a bird is a far cry from remembering that you actually fed one. But perhaps having its appearance in mind would be enough to make you feel as though you are "thinking back" to feeding it: you "see" its dark feathers, long beak, 
and large eyes. These thoughts and images may not reflect what you truly experienced, but might they nonetheless quickly lure you into believing you remember? And would they also quickly lure you into believing you remember an experience that never really happened - if, for instance, your friend's claim about you feeding the shoebill was actually false? We examined those questions in this part of the thesis.

\section{Non-probative photos affect memories and beliefs}

We know that non-probative photos can over time lead people to report that they remember having experiences that never really happened. In one study, people were more likely to remember being involved in a suggested, but false, childhood prank (putting a slimy toy in their teacher's desk) if they saw a photo that related to but did not depict that prank (a photo of classmates from that grade; Lindsay, Hagen, Read, Wade, \& Garry, 2004; see also, Blandon-Gitlin \& Gerken, 2010).

Non-probative photos might have created these false memories in the way Lindsay et al. (2004) suggested: by helping people bring to mind related thoughts and images (say, about their long ago friends, teacher, and classroom) that people mistook as evidence of genuine experience. Even though the information gathered from the photo offered no proof the event occurred, it should have made it easier for people to speculate about how it could have. Perhaps people imagined what they wore that day, who helped them pull the prank, and the look of shock on their teacher's face. The source of those thoughts and images would have faded, but would nonetheless have come to mind with such detail and ease that people felt like they were remembering a genuine experience (see also, Garry \& Gerrie, 2005; Wade, Garry, Read, \& Lindsay, 2002).

Such a mechanism fits with the source monitoring framework, which proposes that when the thoughts and images people bring to mind have characteristics that match those expected of genuine experience, people will conclude that they are indeed thinking back to an 
experience that really happened, not one that was imagined (Johnson, 2006; Johnson, Hashtroudi, \& Lindsay, 1993; Johnson \& Raye, 1981; Lindsay, 2008; Lindsay, 2014; Mitchell \& Johnson, 2000). What characteristics do people expect of thoughts and images derived from genuine experiences, compared to imagined ones? That they have relatively more perceptual and contextual detail, lack evidence of effortful cognitive operations typical of having fabricated events, and feel relatively effortless to bring to mind (Jacoby \& Dallas, 1981; Johnson, Foley, Suengas, \& Raye, 1988). Indeed, a large body of research shows that when thoughts and images that come to mind have those characteristics, and to a degree consistent with how much time has gone by since the event, people tend to believe they are thinking back to an experience that actually happened (Finke, Johnson, \& Shyi, 1988; Henkel, Franklin, \& Johnson, 2000; Jacoby, Kelley, \& Dywan, 1989; Johnson, Foley, \& Leach, 1988). More often than not this strategy fares well: by exploiting the fact that detail and ease correlate with real world experience, people can accurately distinguish thoughts and images that result from an event that occurred in real life versus in one's own head (Jacoby \& Dallas, 1981; Johnson \& Raye, 1981; Johnson et al., 1993). But this strategy leads people astray when imagined thoughts and images are too similar to reality - as when a photo of old classmates makes an event come to mind with more detail and less effort than would be expected if it had been imagined (Lindsay et al., 2004). Those thoughts and images may have been so similar to ones people expected of reality that people concluded they were remembering a real experience, even though they were not (Johnson \& Raye, 1981; Johnson et al., 1993).

Taken together, this literature suggests a route through which the photo of the shoebill could lead you to believe you fed it. Realizing a shoebill is a bird helps you "see" the details of the event and makes it easier to bring related thoughts and images to mind. And although that mental picture may provide no proof the experience happened, you might nonetheless feel as though you are remembering. 
Still, that hypothesis suggests non-probative photos can cause these errors swiftly - in as much time as it takes for your friend to say you fed the shoebill, and the few seconds you spend viewing the photo and contemplating the event. But photos might need more time to wield these effects in order to capitalize on factors that increase your confusion as to the source of the thoughts and images you have in mind.

\section{Repetition, elaboration, and the passage of time}

There are several reasons to suspect the effects of non-probative photos would be tied to the passage of time, particularly because of the opportunities for repetition, elaboration, and mistakes about the source of thoughts and images time affords. Consider the Slime study (Lindsay et al., 2004). People did not just view a photo from their grade one class and remember immediately (in a matter of seconds) that they had put the slime toy in their teacher's desk. Instead, the process was much more drawn out than that. People came to remember the childhood prank over the course of a week, during which they were encouraged to view the photo repeatedly and to elaborate on details of the event (see also, Blandon-Gitlin \& Gerkens, 2010; Brown \& Marsh, 2008). These other factors (repetition, elaboration, and the passage of time) matter because they should combine to make it especially difficult for people to distinguish thoughts and images derived from real experience from those generated using photos (Johnson et al., 1993; Lindsay, 2008, 2014).

Take repetition: it reduces the effort needed for people to retrieve (and recognize) information, which makes remembering feel less effortful and therefore more like what people expect when thinking back to an event that really happened (Jacoby \& Dallas, 1981; Unkelbach, 2006). In fact, we know that repeatedly viewing photos can encourage false beliefs. In one study, people saw several photos of unfamiliar campus locations that they were unlikely to have visited before. Several days later, people saw those photos again mixed among other photos they had not seen, and decided how likely they were to have visited each 
location. People thought they were more likely to have visited locations they had previously seen in photos (Brown \& Marsh, 2008; see also, Henkel, 2011; Henkel \& Carbuto, 2008). Put differently, repeatedly viewing photos made unlikely experiences seem more likely.

Repetition wields similar effects alone, without photos. In another study, people performed some actions and imagined performing others; later, people again imagined performing actions zero, one, or five times. After two weeks, people decided which actions they had performed and which they had imagined. The more times people had imagined an action, the more likely they were to mistakenly claim that they had actually performed it (Thomas, Bulevich, \& Loftus, 2003; see also, Goff \& Roediger, 1998; Seamon, Philbin, \& Harrison, 2006; Thomas \& Loftus, 2002; Zaragoza \& Mitchell, 1996; see Henkel, 2004 for a demonstration that repeatedly retrieving information about an event also blurs the lines between what was seen versus imagined). Repetition has these effects because it reduces the effort needed to bring information to mind while increasing its vividness; those changes make imagined events more similar to reality, increasing confusion as to whether events were imagined or real (Jacoby \& Dallas, 1981; Seungas \& Johnson, 1988).

Moreover, encouraging people to elaborate on events exacerbates that confusion by adding detail to imagined thoughts and images, making their features even more similar to those derived from reality. For example, in the study just described, people received one of two types of instructions for imagining actions. One group of people was instructed to merely imagine performing the actions ("Imagine kissing the frog"), and another group was instructed to elaborate on what they were imagining ("Imagine kissing the frog...imagine the color of the frog...imagine the feel of the frog against your lips"). People who elaborated were more likely to conclude that imagined actions had actually been performed (Thomas et al., 2003; see also, Chrobak \& Zaragoza, 2008; Drivdahl \& Zaragoza, 2001; Garry, Manning, Loftus, \& Sherman, 1996; Hyman \& Pentland, 1996; Sharman, Manning, \& Garry, 2005). Combined, 
these findings suggest that repeatedly viewing non-probative photos while imagining and elaborating on details of the event would make people especially likely to end up remembering experiences that never happened.

And we know that the passage of time would only make things worse. Over time, memories fade, making it more difficult for people to identify the source of thoughts and images, causing increased confusion as to what caused them (Ebbinghaus, 1885/1913; Loftus, Miller, \& Burns, 1978; for a review see Zaragoza, Belli, \& Payment, 2007). It may be, for instance, that when people first viewed the photo of their classmates they were well aware that the thoughts and images they brought to mind were mere speculations about how the event unfolded. But the passage of time would have obscured that fact, leaving people with no reason to suspect those thoughts and images represented anything other than reality (for example, Chrobak \& Zaragroza, 2008; see also, Begg, Anas, \& Farinacci, 1992; Henkel \& Mattson, 2011).

Clearly, repetition, elaboration, and the passage of time would contribute to how nonprobative photos affect memories and beliefs. But are those factors necessary? That is, must you bring the photo of the shoebill home with you, take the time to view it repeatedly and elaborate on its details, and only then, after all that time has gone by, mistakenly conclude that you fed the animal? There are reasons to believe the answer is no. The photo should exert similar effects much more rapidly - in a matter of seconds.

\section{Immediate consequences of non-probative photos}

The source monitoring framework supports the idea that non-probative photos should work rapidly, without repetition or much time for elaboration. As long as photos can produce thoughts and images with characteristics similar enough to those expected when retrieving a real experience, they should immediately fool people into believing they are reflecting on 
reality (Johnson et al., 1993; Lindsay, 2008; see also, Hyman \& Kleinknect, 1999; Mazzoni, Loftus, \& Kirsch, 2001). Two related lines of evidence suggest photos would do exactly that.

The first line of evidence suggests that by providing semantic context, photos should make related information feel easier to bring to mind and cause people to think an experience happened. In one study, people saw several lists of words; after each list, people's task was to decide whether a target word was in the list. When target words (boat) appeared in highly related sentence fragments (The stormy seas tossed the), people more often thought those words had been in the list, compared to when target words appeared in loosely related sentence fragments (He saved up his money and bought $a$; Whittlesea, 1993). The highly related sentence fragments were non-probative because they did not reveal whether target words had actually been shown. But they should have made it feel surprisingly easy to bring those words to mind - a feeling people interpreted as evidence words felt familiar, and must therefore have been on the list (Westerman, 2008; Whittlesea \& Williams, 2001a, 2001b).

A second more recent line of evidence suggests that non-probative photos can exert similar immediate effects when people try to remember events from long ago. People read news headlines that described true events ("John Paul sainthood process begins") and false events ("Blair under fire for botched Baghdad rescue attempt: Won't step down") that had happened several years before and decided within a few seconds whether they remembered each event. People claimed to remember both true and false news events more often when headlines appeared with related but non-probative photos, such as a head shot of Tony Blair at a podium, compared to no photo (Strange, Garry, Bernstein, \& Lindsay, 2011). Much like the highly related sentence fragments, the related photos might have made thoughts and images about news events come to mind more easily, which people interpreted as evidence they were remembering those events. 
But one difference between the experiment using highly related sentence fragments and the news headlines experiment is that in the news headlines experiment people were probably under the assumption that each headline was true, given that a few false events were embedded among many true ones (Strange et al., 2011). This matters because if people already believed the false events were actually true, that could have bolstered the credibility of related thoughts and images that came into mind, making photos more powerful than they would otherwise have been (Nickerson, 1998). Nevertheless, other work shows that nonprobative photos should have similar effects even without suggestion. When people judged a series of trivia claims they knew were a mix of true and false, pairing those claims with nonprobative photos quickly made people more likely to think the claims were true (Newman, Garry, Bernstein, Kantner, \& Lindsay, 2012).

Taken together, these findings suggest that if photos help people bring related information to mind, they should immediately make people more inclined to think experiences happened. The photo of the shoebill should therefore quickly lure you into thinking you fed the animal.

\section{Personally experienced, recent events}

We know from the headlines study that non-probative photos can make people feel as though they are remembering specific personal experiences that happened long ago (Strange et al., 2011). But it is not obvious that photos would also exert these effects for experiences that happened not so long ago — such as when, right after leaving the zoo, you saw a photo of the shoebill and wondered whether you fed it.

Why should the time since an experience has gone by matter? Because compared to older experiences, more recent experiences typically contain more detailed records about what happened and require very little effort to bring to mind (Johnson et al., 1988; Johnson et al., 1993). This extreme detail and ease could thwart the effects of non-probative photos for 
two reasons. First, if you actually had just fed the shoebill, the remembered thoughts and images would be compelling by themselves, making the ones you gather from the photo pale in comparison. Second, even if you had not just fed the animal, and so nothing much came to mind, because the event supposedly just occurred you might expect thoughts and images to come to mind with more ease and detail than the photo can muster. For recent experiences, then, people's bar for accepting thoughts and images as evidence of reality may be too high for photos to clear.

Such an idea fits with work showing that when people can accurately recall details of their experiences, it can be harder to distort their memories for those details. We know, for example, that people are less susceptible to misleading suggestions and the effects of repeated exposure if they had paid full attention to an event compared to if their attention had been divided (Jacoby, Kelley, Brown, \& Jasechko, 1989; Johnson, 2006; Lindsay, 2008; Zaragroza \& Lane, 1998). And the same can be said of other non-diagnostic feelings that arise during retrieval. For example: although people can mistake positive feelings that arise from viewing attractive faces as evidence those faces have been encountered before, people tend to avoid that mistake when they encode faces well enough to remember details that discriminate ones they saw from ones they did not (Monin, 2003).

Of course, the idea that superior memories are protected from the influence of nondiagnostic feelings suggests that inferior memories are not. Thus, non-probative photos should affect people's judgments about recent experiences, as long as people's memories are hazy. Some evidence for this idea comes from the study using highly related sentence fragments. People in that study had to think back to a very recent experience (a list of words they had just seen seconds ago). The list of words was presented so rapidly that it would have been too difficult for people to remember whether they had seen the target words (an idea supported by 
people's poor accuracy rates; Whittlesea, 1993). But poor recollection is probably what opened the door to the influence of the sentence fragments.

There is also evidence non-probative photos wield more powerful influences over judgments for which people are uncertain - ones that they cannot draw on their memory to answer - as when people evaluate trivia claims for which they lack relevant background knowledge (such as "Macadamia nuts are in the same evolutionary family as peaches" compared to easier claims such as "Everest is the tallest mountain"; Newman et al., 2012). Parallel effects arise when it comes to other non-diagnostic feelings. Although printing trivia claims in easy-to-read high color contrast usually leads people to think those claims are true ("Orsono is in Chile"; Reber \& Schwarz, 1999), color contrast loses its influence when the answers to the claims are obvious ("Paris is in France"; Unkelbach, 2007). Combined, these findings hint that non-probative photos should wield their effects over personally experienced recent events as long as people cannot remember much about those events.

Now reconsider the zoo trip. Even though it just happened, consulting your memory failed to turn up details about feeding the shoebill. And you had no clue what a shoebill was, so you struggled to bring related thoughts and images to mind that would help you speculate about the event. The photo relieved that struggle, producing a feeling of ease that bore resemblance to feelings you usually get when thinking back to real experiences. And so you would probably have concluded the event happened, even if it did not.

\section{Overvieze of experiments}

Across six experiments, we examined the extent to which non-probative photos immediately lead people to think recent personal experiences happened. To do so, we showed people the names of several unfamiliar animals (such as shoebill). During a study phase, people saw the animal names and "interacted" with the animals on a computer (for example, in some studies people pretended to "give food to" or "take food from" each animal). Then, 
during a later test, we showed people the animal names again, except this time half the animal names appeared with a photo of the animal and half appeared alone. When each animal name appeared on the screen, people evaluated whether a claim about their earlier experience (such as "I gave food to this animal") was true or false.

In Experiment 1, when people judged the claim "I gave food to this animal," photos made people more likely to say the claim was true. In Experiments 2a-c, we found that these effects generalized to other claims ("I fed this animal," and "I gave healthy food to this animal"). But, as in Part 1, we also found that the valence of the claims mattered. Photos led people to say claims about their positive experiences were true, but not their negative experiences. Finally, in Experiments 3a-b, we found evidence that photos cause similar patterns when people guessed about other people's pasts, and that photos wielded their strongest effects when they could most help people bring related thoughts and images to mind. 


\section{Chapter 2}

\section{Experiment 1}

\section{Method}

Subjects

Based on our pilot work, we determined a sample size of 100 . We recruited a total of $89^{15}$ Victoria University of Wellington undergraduates, who participated in exchange for course credit. These subjects were on average 18.82 years old $(S D=1.24)$.

Design

We used a within subjects design, manipulating whether test items appeared with photos or alone.

Procedure

All instructions appeared on a computer, and each subject individually completed two phases: a study phase and a test phase.

Study phase. During the study phase, we told subjects they would see names of various zoo animals appear on the computer screen, and their task was to pretend to give food to some of the animals and take food from others. We created this list of 40 unfamiliar animals (see Appendix B) by searching the internet for unusual animals; we used unfamiliar animals because the effects of non-probative photos tend to be more powerful for judgments about unfamiliar stimuli (see Part 1; see also, Newman et al., 2012). These 40 animals were a mix of mammals, reptiles, fish, and birds.

We normed these items in two ways. First, we gathered data on how easily people could imagine the animals. We showed 83 Mechanical Turk subjects each animal name, one at a time, and asked them "How easily can you form a mental image of this animal?"

\footnotetext{
${ }^{15}$ We recruited as many subjects as we could, given constraints on funds, the length of the semester, and our allocation from the departmental subject pool. In Experiments 2a-c, we aimed to increase precision by collecting 200 observations per between subjects cell. Experiment 3a-b used a different design that we suspected (based on its similarity to the designs used in Part 1) would require fewer subjects per between subject cell.
} 
Subjects answered using a scale from $1=$ "Very difficult" to $7=$ "Very easy." The mean rating was $1.56(S D=1.34$, Median $=1)$, supporting our hunch that people struggle to picture these animals. Second, we examined whether people felt they could bring to mind thoughts and images about animals better with photos compared to without. Accordingly, a separate group of 34 Mechanical Turk subjects saw the animal names appear one at a time; half the animal names appeared with a photo of the animal, half appeared alone. We told subjects that when each animal name appeared on the screen their job was to rate how easy it felt to bring to mind information related to the animal. Subjects responded on a scale from $1=$ "Extremely difficult" to $6=$ "Extremely easy." In line with the idea that photos of animals increase the ease of bringing related information to mind, subjects gave higher ratings when animal names appeared with photos $(M=3.01, S D=1.37)$ compared to alone $(M=1.54, S D=$ 0.57); that is, photos produced a raw effect size of $1.47,95 \%$ CI $[1.05,1.88], t(33)=7.16, p$ $<.01^{16}$.

When subjects started the study phase, animal names appeared one at a time on the computer screen along with an instruction that subjects should either give food to or take food from the animal (such as "Give food to the Shoebill" and "Take food from the Hammerkop"). Animal names appeared randomly, counterbalanced to be paired equally often with the "give food" and "take food" instruction. Next to the computer were two objects: a brown paper bag (the "food bowl") and a small white dish (the "feed bag"), each of which contained dried beans. When an instruction to give food appeared on the screen, subjects were to pick up a bean from the feed bag and move their hand forward to put the bean in the food bowl; when instructions to take food appeared on the screen, subjects were to pick up a bean from the food bowl and move their hand backward to put the bean in the feed bag. Finally, instructions

\footnotetext{
${ }^{16}$ At the same time that we gathered these norms, another group of subjects made the same ratings for 40 familiar animals (such as zebra; see Appendix B). We report those data in Experiment 3b.
} 
reminded subjects to pay attention, because later they would answer more questions about the animals, though we did not specify the nature of those questions.

Test phase. After the study phase, subjects completed a 30-second filler task in which they counted the number of dots in an image. Then the second phase, the memory test, began. Subjects learned that each animal name would appear on the screen, one at a time, like they saw before - but this time, their job was to decide if the claim "I gave food to this animal" was true or false. Subjects also learned that some of the animal names would appear with a photo of that animal and other animal names would appear alone. Subjects practiced associating true responses with the a-key (which was labeled with a T sticker) and false responses with the l-key (labeled with an F sticker) with four animal names not used in the main experiment. Subjects then completed the test proper at their own pace.
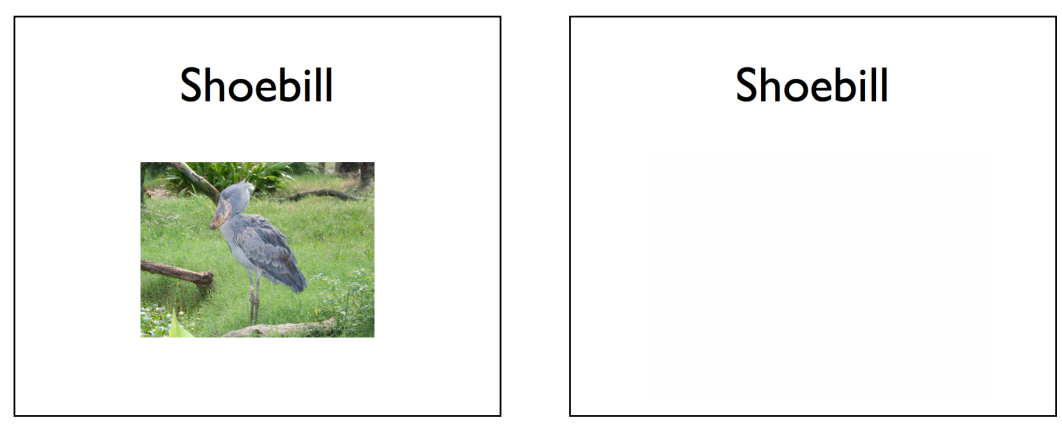

Figure 2. Example of an animal name with and without a photo.

Animal names appeared one at a time in a random order in large black font against a white background. Half the animal names appeared with a colored photograph of the animal, and half appeared alone (see Figure 2). The central object in the photo was the animal, but other contextual details (background scenes) were also visible. No photos depicted animals eating. Animal names appeared equally often with and without photos and equally often with the "gave food" and "took food" study phase instructions.

\section{Results \& Discussion}


We checked whether subjects had followed the study phase instructions to "give food to" and "take food from" animals by counting the number of beans left in the food bowl and feed bag at the end of the experiment. If subjects followed the instructions, there should be 20 beans in the feed bag and 20 in the food bowl. Although five subjects ended up with the wrong number of beans in their bowl, these subjects did not change the overall pattern of results so we included them in the analyses reported. There were no other exclusion criteria

We first examined whether the memory was test sufficiently difficult, such that subjects would have to resort to guessing about which experiences they did and did not have. Subjects struggled to remember which animals they gave food to and took food from, with accuracy rates near chance levels (see Appendix G for d' measures of accuracy across Experiments 1-2c). The accuracy rates were similar in Experiments 2a-c.

But our primary question is the extent to which non-probative photos can quickly lead people to say claims about their experiences are true. To answer this question, we calculated subjects' bias (Stanislaw \& Todorov, 1999) to respond true ${ }^{17}$. Bias measures the criterion subjects set for responding "true" and is derived from the hit rate (the proportion of times subjects respond true to claims that are true) and false alarm rate (the proportion of times subjects respond true to claims that are false). Bias is calculated by converting the hit and false alarm rates into z-scores, adding those scores, dividing by two, then multiplying by negative one $^{18}$. Negative values of bias represent a liberal criterion (a tendency to respond "true") and positive values represent a more conservative criterion (a tendency to respond "false").

\footnotetext{
${ }^{17}$ In the experiments reported in Part 2, we draw the same conclusions whether we analyze bias, or (as we did in Part 1) proportion of true responses. We present signal detection measures because, in addition to measuring the extent to which photos change people's threshold for claiming experiences happened (bias), they also measure independently people's ability to distinguish between experiences that really did versus did not happen (sensitivity or discrimination). We used these accuracy measures in the experiments that required people to remember events (Experiments 1-2c) in order to gauge the extent to which people were uncertain about which experiences really happened. In any case, interested readers can calculate the proportion of true responses by averaging the hit and false alarm rates shown in Appendix C.

18 The negative multiplier is arbitrary. It is merely the convention in the literature.
} 
We performed these bias calculations separately for animal names shown with photos and animal names shown alone, and display the results in Figure 3. As the figure shows, photos led subjects to respond true more often to the claim that they gave food to animals; that is, subjects' bias scores were more negative when animal names appeared with photos compared to alone. Indeed, calculating raw effect sizes by taking the difference in subjects' bias to respond true in photo versus no photo trials produced an effect size of $-0.18,95 \%$ CI $[-0.29,-0.07]$. In null hypothesis terms, there was an effect of photos, $t(88)=3.35, p<.01$. This pattern of results fits with the idea that non-probative photos make related thoughts and images come to mind more easily, which people immediately mistake as evidence of genuine experience (Johnson et al., 1993; Whittlesea, 1993). If true, then how might photos affect people's judgments when claims imply that experiences never happened - if, for instance, the claim people judged involved an inaction, such as "I did not feed the shoebill."

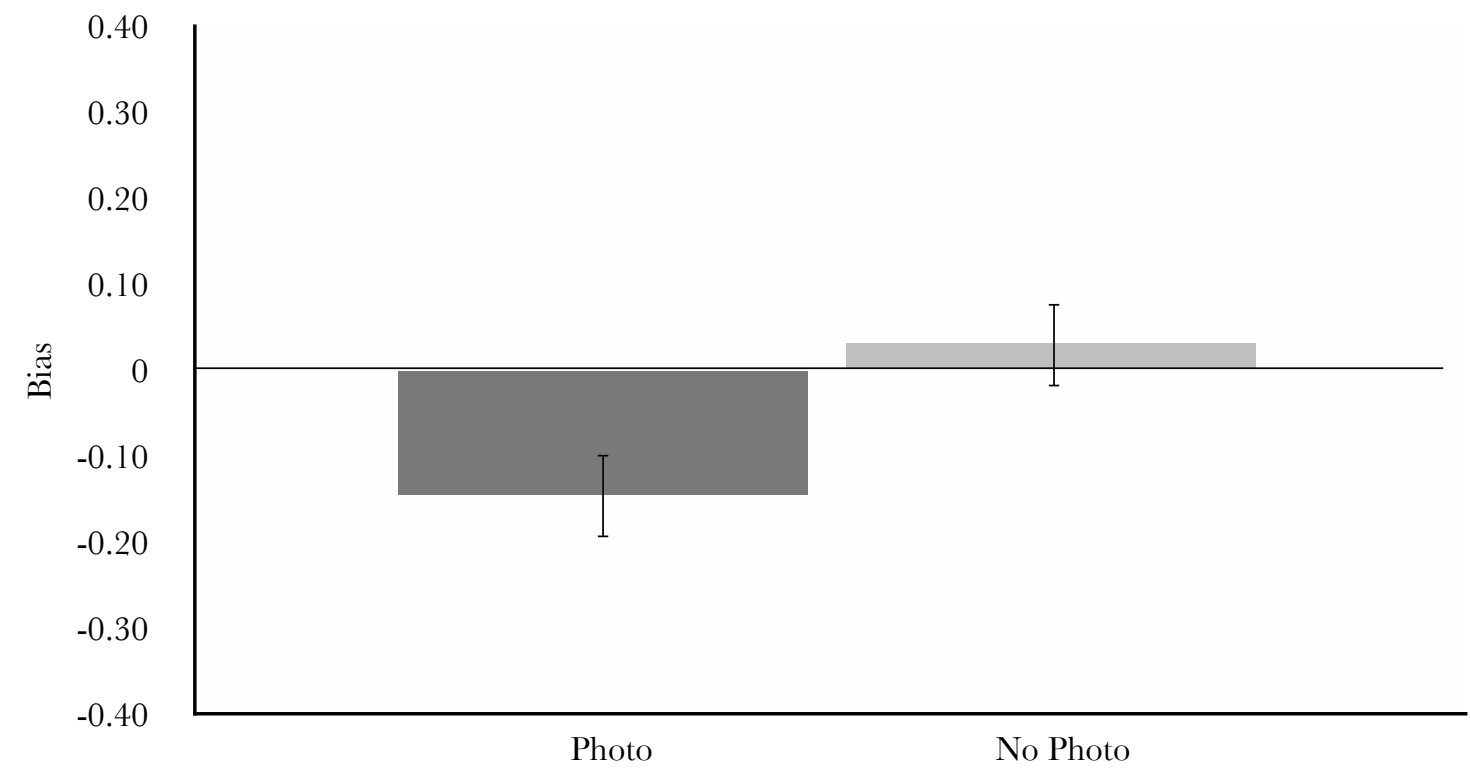

Figure 3. Bias scores for animal names that appeared with photos or alone. Error bars show 95\% withinsubject confidence intervals for the photo/no-photo effect (see Masson \& Loftus, 2003).

On the one hand, the association between ease and truth raises the possibility that easily bringing information to mind about animals would make any related claim seem to 
have more merit; if so, photos should also lead people to say claims involving inaction are true (Reber \& Schwarz, 1999; Unkelbach, 2007). On the other hand, ease is also associated with familiarity, raising another possibility: easily bringing information about animals makes them feel familiar - a feeling at odds with the claim about not having had an experience with the animal, and which might therefore steer people away from responding true (Jacoby \& Dallas, 1981; Unkelbach, 2006).

To address this question, in Experiment 2a we changed the study phase so that subjects' task sometimes involved action ("Feed the Shoebill") and other times involved inaction ("Don't feed the Hammerkop"). Then, during the test phase, some subjects judged the claim "I fed this animal," and others judged the claim "I did not feed this animal."

\section{Experiment 2a}

\section{Method}

Subjects

We recruited 406 subjects from Mechanical Turk. These subjects were on average 31.63 years old $(S D=11.59)$.

\section{Design \& Procedure}

We used a 2 (Photo: photo, no photo) x 2 (Claim Tested: fed, did not feed) mixed design, with Photo as the within subject factor and Claim Tested as the between subjects factor.

The procedure departed from Experiment 1 in four ways. First, subjects completed the experiment online through Qualtrics survey software (Qualtrics, Provo, UT). Second, during the study phase subjects were instructed to "feed" or "don't feed" each animal that appeared on the screen. When instructions said "feed" subjects were to click a green circle that appeared below the instruction, and when instructions said "don't feed" they were to refrain from clicking a red circle. We selected these colors to reduce errors, relying on well- 
known associations: green, the action, and red, the inaction. Subjects practiced responding to "feed" and "don't feed" instructions for four animals not included in the main experiment. Third, during the test phase, some subjects responded to the claim "I fed this animal" and other subjects responded to the claim "I did not feed this animal" by selecting one of two options that said "true" or "false." These response options appeared below each animal name, counterbalanced (between subjects) to appear on the right- or left-hand side of the screen.

Finally, after the test phase, subjects were asked to read a six paragraph article about a species of monkey that is going extinct, and to decide whether the photo that appeared with the article (a photo of a monkey) was appropriate to help boost understanding. As in the attention check described in Part 1, the fourth paragraph of the article contained a secret word. On the following page of the survey, subjects were asked to produce that secret word; successful subjects passed this attention check (Oppenheimer, Meyvis, \& Davidenko, 2009). Then subjects indicated whether they had maximized their web browser, used their "back" or "refresh" button, completed the experiment in a single session, engaged in other tasks, spoke to others, worked in an environment free of noise and distraction and without help, written any of the animal names down during the study phase or used a search engine to look up the animals. We encouraged truthful responses by promising subjects we would compensate them in full regardless of their answers.

\section{Results \& Discussion}


In all experiments, subjects who failed our measures of compliance ${ }^{19}$ did not change the overall pattern of results, so we included all subjects in the analyses reported in this and subsequent experiments. There were no other exclusion criteria.

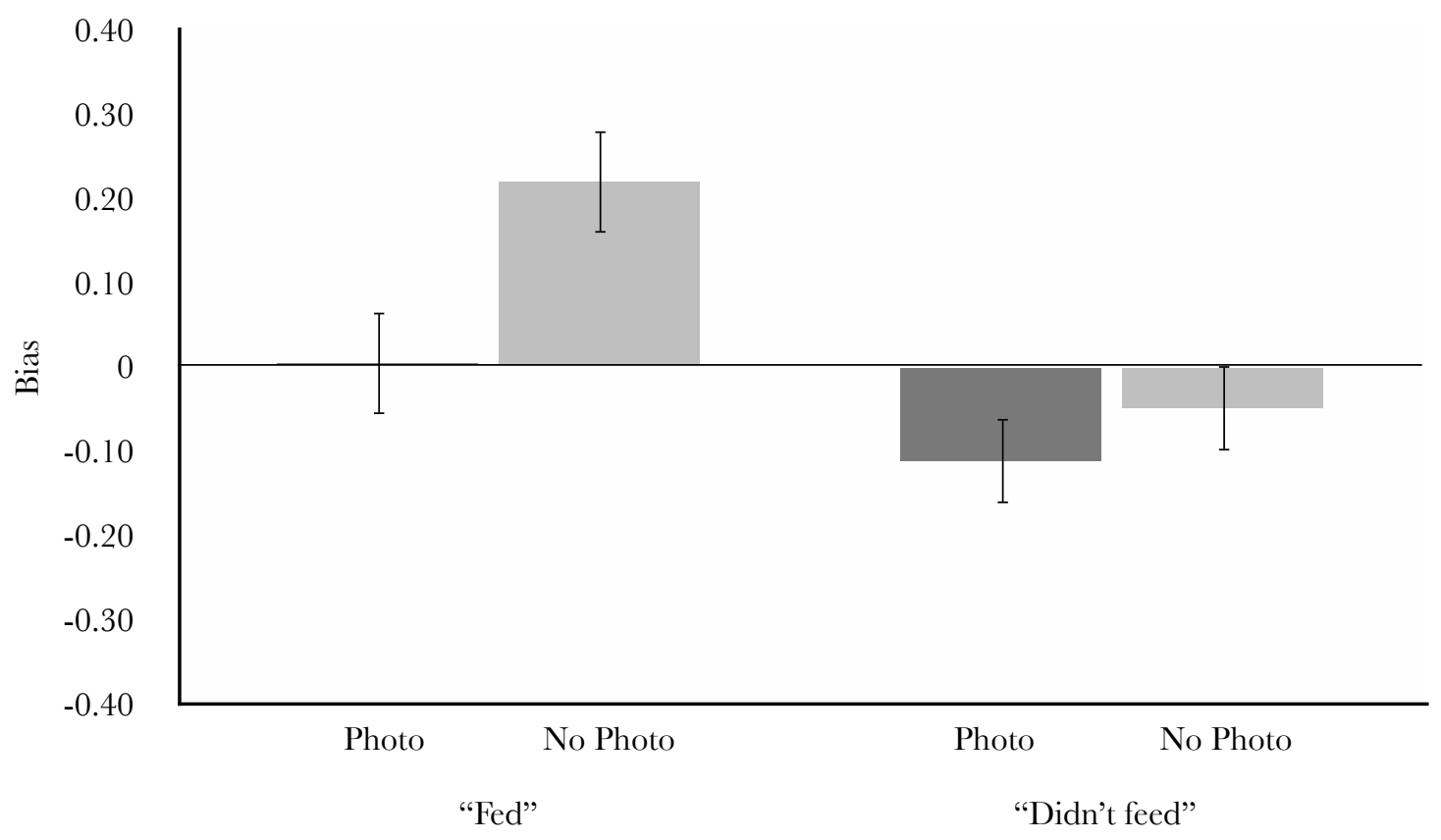

Figure 4. Bias scores for responses to the "fed" and "didn't feed" claims when animals names appeared with photos or alone. Error bars show 95\% within-subject confidence intervals for the photo/no-photo effect (see Masson \& Loftus, 2003).

To determine the extent to which photos lead people to respond true to claims involving actions versus inactions, we performed the bias calculations described in Experiment 1, grouped those data according to whether subjects evaluated the "fed" or the "did not feed" claim, and display the results in Figure 4. As the figure shows, photos led subjects to respond true more often to the "fed" claim, but not to the "did not feed" claim. Indeed, for the "fed" claim photos produced a raw effect size of $-0.22,95 \%$ CI [-0.30, -0.13] but for the "did not feed" claim they produced a raw effect size of $-0.06,95 \%$ CI [-0.13, 0.01]. In null hypothesis terms, there was a Photo $\mathrm{x}$ Claim Tested interaction, $F(1,404)=$

\footnotetext{
${ }_{19}$ As in Part 1, we recorded these failure rates for only the experiments that used the Mechanical Turk subject pool. In Experiment 2a, the percentage of subjects who failed the attention check was 38. In Experiments 2b, 2c, 3a, and 3b the percentages were 38, 38, 45 and 40 respectively. As explained in Part 1, these failure rates are higher than those reported research examining the Mechanical Turk subject pool (10-34\%; Goodman, Cryder, \& Cheema, 2012; Kapelner \& Chandler, 2010).
} 
$7.08, p<.01$. Note that subjects were overall more willing to claim the "did not feed" claim was true. We suspect that relates to the difficulty of the task. Perhaps it was so difficult to remember much about the experiences (particularly in the "did not feed" condition, as d' scores in Appendix C show) that subjects were more biased to endorse claims that implied no experience with the animals.

Table 1

Summary of results from each meta analysis for Experiments 1-2b

\begin{tabular}{|c|c|c|c|c|c|c|c|}
\hline \multirow[b]{2}{*}{ Claim } & \multirow[b]{2}{*}{$\mathrm{ES}$} & \multicolumn{2}{|c|}{$95 \% \mathrm{CI}$} & \multirow[b]{2}{*}{$z$} & \multirow[b]{2}{*}{$p$} & \multirow[b]{2}{*}{$\begin{array}{l}\text { Experiments included } \\
\text { in calculating ES }\end{array}$} & \multirow[b]{2}{*}{ Comments } \\
\hline & & LL & UL & & & & \\
\hline $\begin{array}{l}\text { Positive } \\
\text { ("Fed") }\end{array}$ & -0.15 & -0.22 & -0.09 & -4.78 & $<.01$ & $2 \mathrm{a}^{\mathrm{a}}, 2 \mathrm{a} \mathrm{R} 1^{\mathrm{b}}, 2 \mathrm{a} R 2^{\mathrm{b}}, 2 \mathrm{a}$ & 2a R1: same method as 2a \\
\hline & & & & & & & $\begin{array}{l}\text { 2a R2: same method as } 2 \mathrm{a} \text {, } \\
\text { but with an undergraduate }\end{array}$ \\
\hline $\begin{array}{l}\text { Positive } \\
\text { ("Gave food") }\end{array}$ & -0.11 & -0.15 & -0.06 & -4.62 & $<.01$ & $\begin{array}{l}1 \mathrm{a}^{\mathrm{a}}, 2 \mathrm{~b}^{\mathrm{a}}, 2 \mathrm{~b} \mathrm{R} 1^{\mathrm{b}}, 2 \mathrm{~b} \\
\mathrm{R} 2^{\mathrm{b}}, 2 \mathrm{~b} \mathrm{R} 3^{\mathrm{b}}\end{array}$ & $\begin{array}{l}\text { student sample, instead of a } \\
\text { Mechanical Turk sample }\end{array}$ \\
\hline $\begin{array}{l}\text { Negative } \\
\text { ("Did not feed") }\end{array}$ & 0.05 & -0.04 & 0.14 & 1.04 & .30 & $\begin{array}{l}2 \mathrm{a}^{\mathrm{a}}, 2 \mathrm{a} \mathrm{R} 1^{\mathrm{b}}, 2 \mathrm{a} R 2^{\mathrm{b}}, 2 \mathrm{a} \\
\mathrm{R} 3^{\mathrm{b}}\end{array}$ & $2 \mathrm{~b} \mathrm{R} \mathrm{l}$ : same method as $2 \mathrm{~b}$ \\
\hline & & & & & & & 2b R2: same method as $2 \mathrm{~b}$ \\
\hline $\begin{array}{l}\text { Negative } \\
\text { ("Took food") }\end{array}$ & 0.01 & -0.05 & 0.06 & 0.25 & .81 & $\begin{array}{l}2 \mathrm{~b}^{\mathrm{a}}, 2 \mathrm{~b} \mathrm{R} 1^{\mathrm{b}}, 2 \mathrm{~b} \mathrm{R} 2^{\mathrm{b}}, 2 \mathrm{~b} \\
\mathrm{R} 3^{\mathrm{b}}\end{array}$ & 2b R3: same method as $2 b$ \\
\hline
\end{tabular}

Note. Meta analyses split by claims across experiments 1-2b. ES = effect size, the difference between photo and no photo bias means. Negative effect size $=$ a bias to respond "true." Positive effect size $=$ a bias to respond "false." LL and UL = lower and upper limits of the $95 \%$ CI of the ES. R = replication of an experiment $(\mathrm{R} 1=$ first replication, $\mathrm{R} 2=$ second replication, and so on $)$.

${ }^{\mathrm{a}}$ Experiments and replications reported in the main text. ${ }^{\mathrm{b}}$ Replications not otherwise reported in the main text.

We replicated these patterns with two separate groups of Mechanical Turk subjects, and a group of undergraduate students. To arrive at a more precise estimate of the size of the photo bias, we subjected data from all of these experiments to random effects model mini meta-analyses and report those results, which are consistent with those reported here, in Table 1 (Cumming, 2012).

Photos did not make people more inclined to say that just any claim was true. Instead, they led people to say true only when claims implied that experiences happened. One explanation for this pattern is that by making information about animals more easily come to 
mind, photos made them feel familiar (see Whittlesea, 1993). And that feeling would have seemed more consistent with claims about experience than claims about inexperience. But an equally plausible explanation is that ease seemed consistent with the relatively more positive experiences about giving animals nutrition ("fed"), compared to the more negative claim about not ("did not feed").

Indeed, as we explained in Part 1, being able to bring information to mind easily is inherently pleasing, and people tend not to draw on that feeling as evidence for negative judgments (Reber, Schwarz, \& Winkielman, 2004; Reber, Winkielman, \& Schwarz, 1998; Seamon, McKenna, \& Binder, 1998; Topolinski, Likowski, Weyers, \& Strack, 2009; Winkielman \& Cacioppo, 2001; Winkielman, Halberstadt, Fazendeiro, \& Catty, 2006). This literature, coupled with the findings from Part 1, suggest photos could have made people feel more positively, biasing people to believe they had a positive past with the animal, not a negative past.

To examine that possibility, in Experiment $2 \mathrm{~b}$ we had subjects pretend to give food to and take food from animals; that way, during the test phase, subjects judged either a positive claim ("I gave food to this animal") or negative claim ("I took food from this animal"), both of which implied having an experience with animals. If easily bringing information to mind implies experience generally, photos should lead subjects to respond true more often to either claim. But if ease implies positive experiences, photos should lead subjects to respond true more often only to the "gave food" claim.

\section{Experiment $2 b$}

\section{Method}

Subjects

We recruited 416 subjects from Mechanical Turk. These subjects were on average 33.16 years old $(S D=12.17)$. 


\section{Design EP Procedure}

We used a 2 (Photo: photo, no photo) x 2 (Claim Tested: gave food, took food) mixed design, with Photo as a within subject factor and Claim Tested as a between subjects factor.

The procedure followed that of Experiment 2a with three exceptions. First, the study phase instructions explained that subjects were to "give food to" or "take food from" each animal. Second, rather than doing the action by clicking on a colored circle, subjects selected one of two options that said "give food" or "take food," counterbalanced (between subjects) to appear first or second. Third, during the test phase, some subjects judged the claim "I gave food to this animal" and others judged the claim "I took food from this animal."

\section{Results \& Discussion}

As Figure 5 shows, photos led subjects to respond true more often to the positive claim, but not to the negative claim. That is, for the "gave food" claim photos produced a raw effect size of $-0.16,95 \%$ CI $[-0.26,-0.05]$, but for the "took food" claim they produced a raw effect size of $-0.02,95 \%$ CI $[-0.12,0.07]$. In null hypothesis terms, there was a trend toward a Photo x Claim Tested interaction, $F(1,414)=3.55, p<.06$.

We replicated these patterns with three additional groups of Mechanical Turk subjects. To arrive at a more precise estimate of the size of the photo bias, we subjected data from all of these experiments, and data from Experiment 1, to random effects model mini meta-analyses (Cumming, 2012). We report those results, which are consistent with those reported here, in Table 1. 


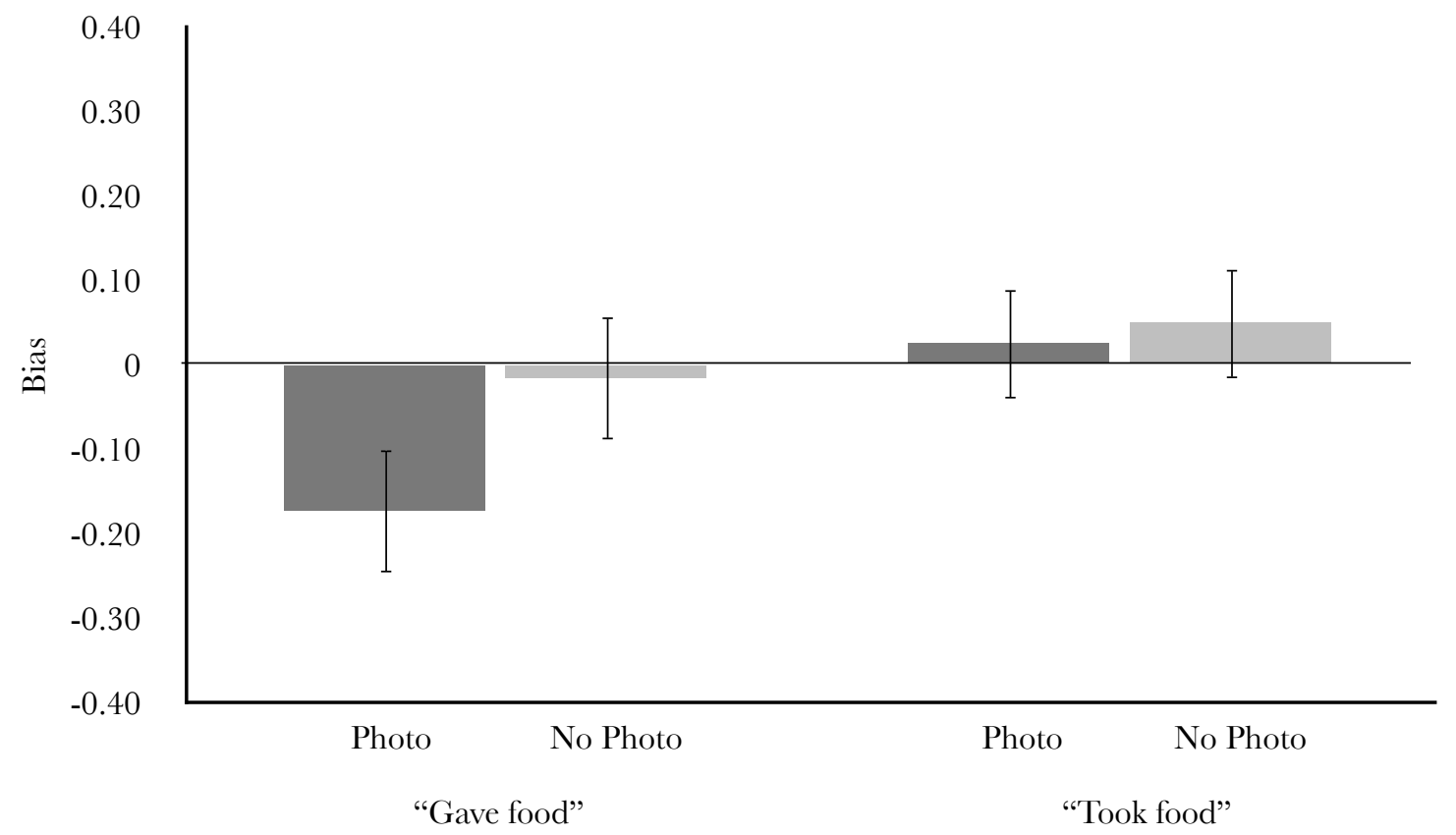

Figure 5. Bias scores for responses to the "gave food" and "took food" claims when animals names appeared with photos or alone. Error bars show 95\% within-subject confidence intervals for the photo/ no-photo effect (see Masson \& Loftus, 2003).

Photos led subjects to respond true more often to claims about positive experiences but not to claims about negative experiences. This result meshes well with the findings from Part 1 and, more broadly, people's tendency to interpret ease as evidence for positive but not negative judgments (Reber et al., 1998; Seamon et al., 1998). Although it is possible these patterns emerged because photos caused positive feelings that matched the positive outcomes of the actions suggested in the claims (giving animals nutrition, as opposed to taking it away), a confound clouds that interpretation. Perhaps it was not the outcome of the action that mattered, but the action (giving) itself.

In fact, we know that actions associated with giving can have positive connotations separate from the outcome of the action. Positive feelings, such as liking, are linked with the desire to approach a stimulus (Cacioppo, Gardner, \& Berntson, 1999; Elliot, 2006; Lang, Bradley, \& Cuthbert, 1990). Moreover, physiological responses associated with the desire to approach come about when people's bodies are merely positioned in a way similar to how one might approach a stimulus (such as when people lean forward; Price, Dieckman, \& Harmon- 
Jones, 2012). These findings raise the possibility that thinking about actions associated with approaching a stimulus (such as moving towards and animal to give it food) produced positive feelings that seemed consistent with positive feelings of ease.

To address this confound, in Experiment 2c subjects judged one of two claims that both used the word "gave," but referred to either a positive or negative outcome of the action. Specifically, during the study phase we instructed subjects to "give healthy food" and "give unhealthy food" to animals. Then during the test phase some subjects judged the claim "I gave healthy food to this animal" and others judged the claim "I gave unhealthy food to this animal." Assuming it is the positive outcome of the action that matters, and not the action of giving, photos should lead subjects to say true more often only to the "healthy food" claim.

\section{Experiment 2c}

\section{Method}

Subjects

We recruited 458 subjects (255 females, 155 males, and 48 subjects who did not report their gender) from Mechanical Turk. These subjects were on average 33.15 years old $(S D=$ 11.54).

Design \& Procedure

We used a 2 (Photo: photo, no photo) x 2 (Claim Tested: healthy food, unhealthy food) mixed design, with Photo as the within subject factor and Claim Tested as the between subjects factor.

The procedure followed that of Experiment 2b, except that instructions told subjects their task was to give "healthy food" or "unhealthy food" to the animals. We also explained what we meant by healthy and unhealthy food. Specifically, we said "You have an assortment of food that the animals can eat. Some of it is healthy (the people-equivalent of vegetables) and some of it is unhealthy (the people-equivalent of donuts or french fries)." This change 
meant that during the study phase, subjects clicked one of two options that said "healthy food" or "unhealthy food," and during the test phase some subjects judged the claim "I gave healthy food to this animal," and others judged the claim "I gave unhealthy food to this animal."

\section{Results \& Discussion}

Figure 6 shows that photos led subjects to respond true more often to the "healthy food" claim but not to the "unhealthy food," suggesting that the patterns from Experiment 2b were not tied to the actions associated with the word "gave" but to the outcome of those actions. In other words, for the "healthy food" claim, photos produced a raw effect size of $-0.18,95 \%$ CI [-0.26, -0.09], but for the "unhealthy food" claim they produced a raw effect size of $0.01,95 \%$ CI [-0.08, 0.11]. In null hypothesis terms, there was a Photo x Claim Tested interaction, $F(1,456)=8.69, p<.01$.

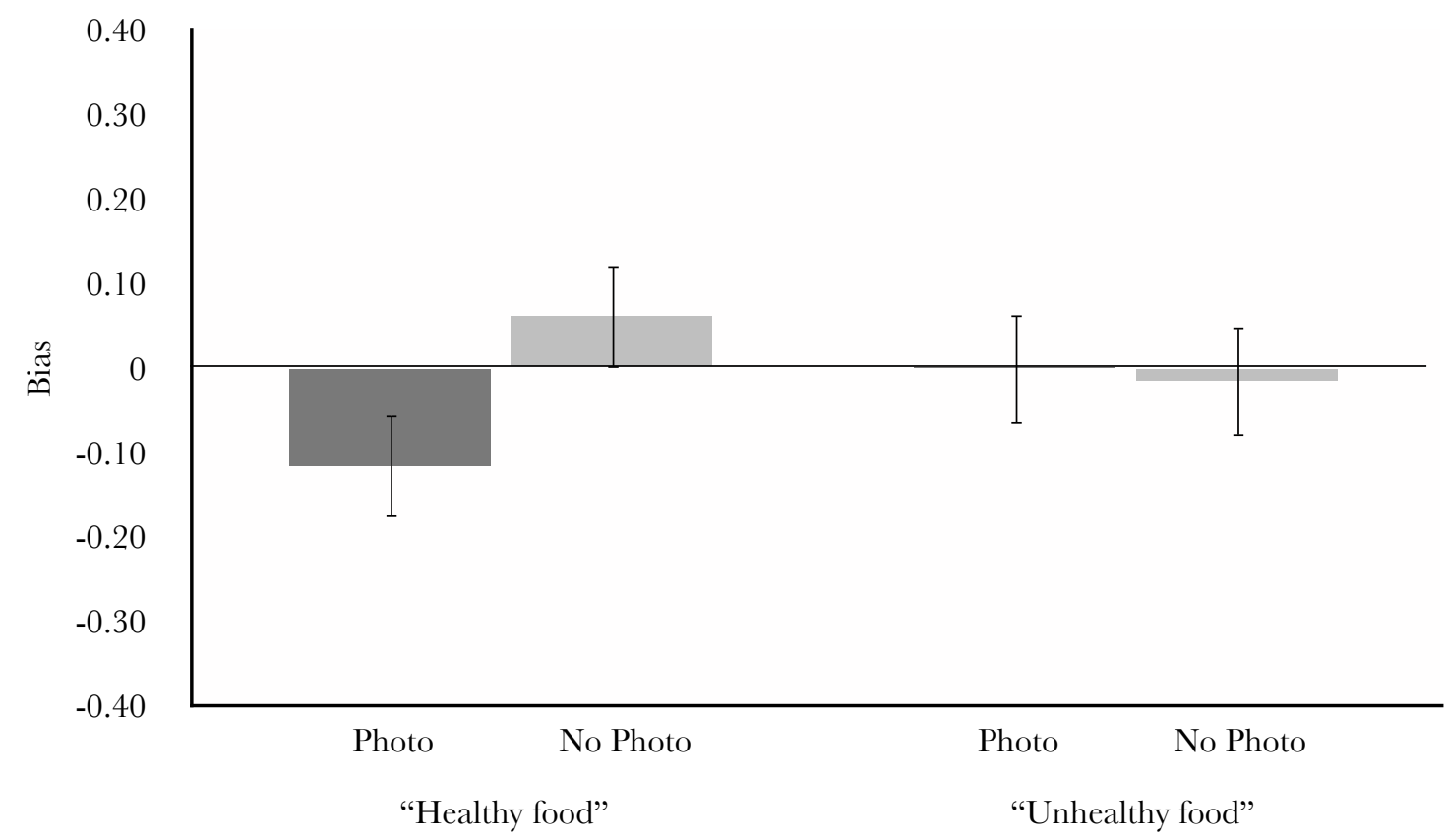

Figure 6. Bias scores for responses to the "healthy food" and "unhealthy food" claims when animals names appeared with photos or alone. Error bars show 95\% within-subject confidence intervals for the photo/no-photo effect (see Masson \& Loftus, 2003).

These findings suggest that it was the outcome of the action that mattered, not the valence of the word that described that action. But there is one remaining explanation for 
why photos selectively promoted claims about giving food or giving healthy food, but not claims about taking food or giving unhealthy food. Could it be that the claims we are calling "positive" are actually just describing relatively more plausible events? People may think taking food or giving unhealthy food is just generally implausible, suggesting that an alternative interpretation of our results is that photos selectively lead people to believe plausible events (see Blandon-Gitlin \& Gerkens, 2010).

One way to address that alternative interpretation is by using subjects' overall willingness to respond true across the conditions as a proxy for the plausibility of events. Returning to the results of Experiment 2b, Figure 5 suggests that subjects were overall more willing to respond true to the claim about giving food, consistent with the idea that giving food is more plausible than taking food. But that pattern did not emerge in the results of Experiment 2c. Returning to Figure 6 reveals that subjects were just as willing to respond true to the healthy food claim as they were to the unhealthy food claim, suggesting the two events were equally plausible. Therefore, a plausibility explanation does not account for all of our data.

Instead, considered as a whole Experiments 2a-c suggest non-probative photos immediately lead people to think positive experiences happened, but not negative experiences. These findings are conceptually similar to those described in Part 1, and fit more broadly with research suggesting that if photos cause feelings of ease, they should encourage more positive judgments, but not negative ones (Reber et al., 1998; Seamon et al., 1998).

So far we have demonstrated that photos can make it seem as though positive experiences happened in one's own past. Would photos also make those positive experiences seem more likely to have happened in other people's pasts? Such a finding would suggest that photos create a general aura of belief around positive experiences. But why would that be? 
For one thing, we know that people draw on ease broadly, as evidence not only of personal experience, but as evidence of truth, value, frequency, beauty, closeness, intelligence, loudness, and fame (and the list goes on; Alter \& Oppenheimer, 2006, 2008; Jacoby, Allan, Collins, \& Larwill, 1988; Jacoby et al., 1989; Oppenheimer, 2006; Reber \& Schwarz, 1999; Reber et al., 1998; Tversky \& Kahneman, 1973; for reviews, see Alter \& Oppenheimer, 2009; Jacoby et al., 1989; Schwarz, 2004; Winkielman et al., 2003). Ease can be "about" so many different things because the way people interpret it is constrained by what seems to be the most plausible cause, given the task at hand (Higgins, 1998; Schwarz, 2004). If a task encourages people to judge loudness, ease seems to be about loudness; if a task encourages people to judge fame, ease seems to be about fame; and if a task encourages people to judge the past (as in Experiments 1-2c), ease seems to be about the past (Jacoby et al., 1989).

These findings suggest that people would assume feelings of ease were relevant even if people's task focused them on evaluating other people's pasts, instead of their own. In line with that possibility, we know that a feeling of ease can make people more confident that a childhood experience happened to them and that the same feeling also makes people more confident that those childhood experiences would have happened to other people (Bernstein, Godfrey, \& Loftus, 2009; Bernstein, Whittlesea, \& Loftus, 2002). If photos increase the ease with which related thoughts and images come to mind then they too might continue to exert their effects when people make judgments about the experiences of others.

To investigate that idea, in Experiment 3a-b, we asked subjects to guess whether other people had experiences with the animals at the zoo. Specifically, subjects decided whether other people "gave food to" or "took food from" animals that appeared with photos or alone.

\section{Experiment 3a}

\section{Method}

\section{Subjects}


We recruited 282 subjects (135 females, 127 males, and 20 subjects who did not report their gender) from Mechanical Turk. These subjects were on average 30.49 years old ( $S D=$ 11.27).

Design $E$ Procedure

We used a 2 (Photo: photo, no photo) x 2 (Claim: gave food, took food) mixed design, with Photo as the within subject factor and Claim as the between subjects factor.

The procedure followed that of Experiment 2b, except that we removed the study phase, and changed the instructions accordingly. Rather than asking subjects to remember which animals they gave food to and took food from, we explained that we had instructed another group of Mechanical Turk workers to "give food to" or "take food from" each animal. Then we explained that subjects' task was to decide (between subjects) whether claim "The workers gave food to this animal" or "The workers took food from this animal" was true or false.

\section{Results \& Discussion}

To examine the extent to which photos affected people's judgments about the experiences of others, we calculated for each subject the proportion of "true" responses, grouped those responses according to whether animals had appeared with photos or alone, then further grouped them according to whether subjects had judged the "gave food" or "took food" claim. We used the "proportion true" measures because the experimental design does not afford calculations of the hit and false alarm rates required for signal detection analyses (Stanislaw \& Todorov, 1999). We display the results in Figure 7.

As the figure shows, when subjects guessed about what experiences other people had, photos produced patterns similar to when subjects decided what they themselves remembered experiencing (Experiments 1-2c). That is, photos led subjects to respond true more often to the positive claim but not the negative claim. For the "gave food" claim, photos produced a 
raw effect size of $0.30,95 \%$ CI $[0.25,0.36]$, but for the "took food" claim they produced a raw effect size of $-0.06,95 \%$ CI $[-0.13,0.00]^{20}$. In null hypothesis terms, there was a Photo $\mathrm{x}$ Claim interaction, $F(1,280)=70.86, p<.01$.

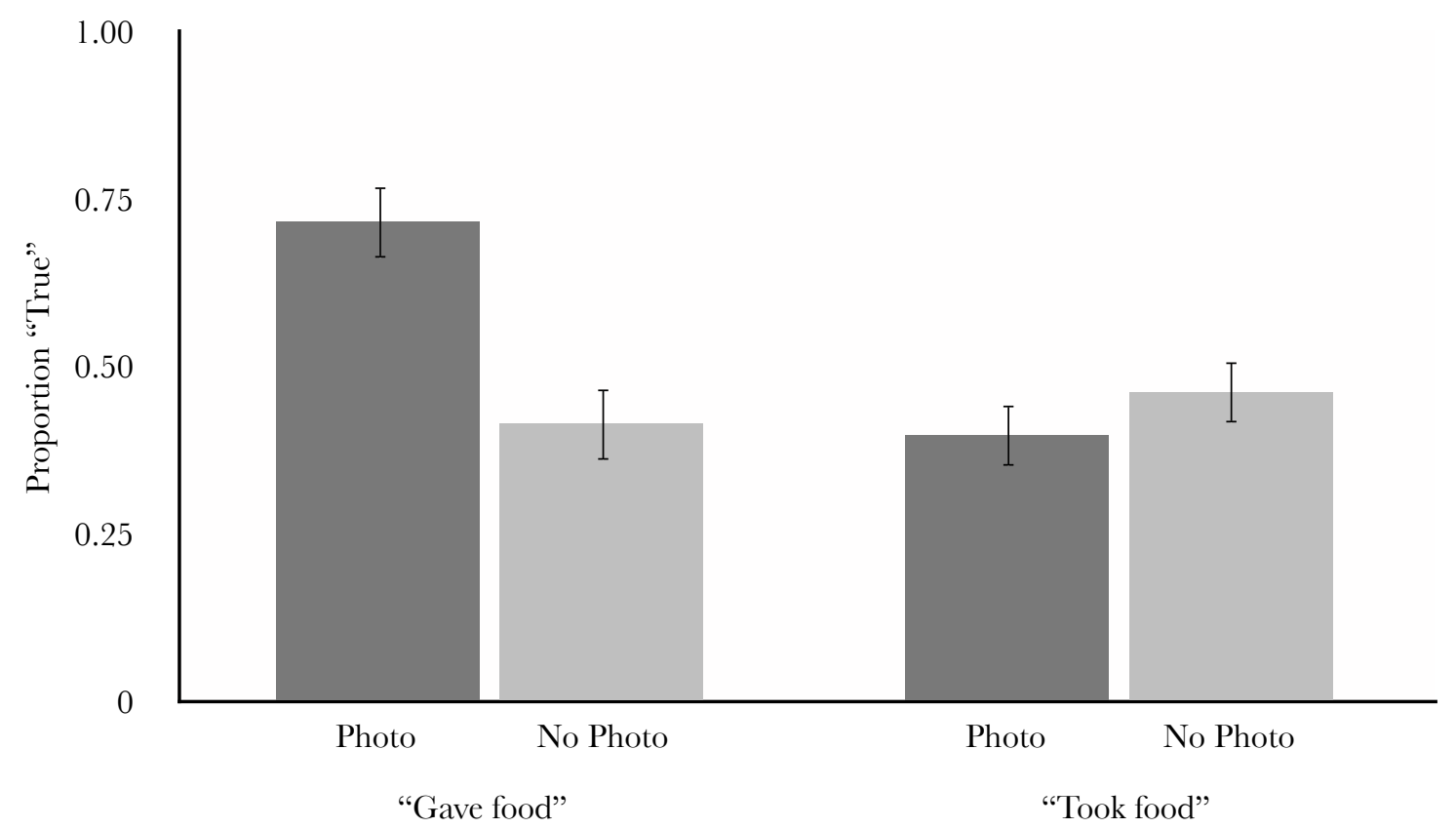

Figure 7. Proportion of "true" responses to the "gave food" and "took food" claims when animals names appeared with photos or alone. Error bars show 95\% within-subject confidence intervals for the photo/ no-photo effect (see Masson \& Loftus, 2003).

Combined with Experiments 1-2c, these findings suggest photos make positive experiences seem more believable regardless of whether those experiences refer to one's own past or to another person's past. The results are similar to those reported in Part 1, where photos also led subjects to think positive claims were true, but not negative claims, and fit with the idea that photos work by helping people more easily bring related information to mind.

But recall an alternative explanation we raised for the patterns in Part 1: aesthetically pleasing photos could cause feelings people mistake for familiarity, which would also encourage positive judgments (Garcia-Marques, Mackie, Claypool, \& Garcia-Marques, 2013;

\footnotetext{
${ }^{20}$ Note that these effect sizes are larger than those reported in Experiments 1-2c, as can be seen by comparing them to the average of the hits and false alarms shown in Appendix C. Our speculation for this difference is that in the "memory" experiments (Experiments 1-2c), people could at least attempt to draw on their memories to evaluate the claims; that is, people had a source of information other than photos (however poor their memories were; Monin, 2003; Unkelbach, 2007). By contrast, in the "no memory" experiments (Experiments 3a-b) people have only the photos as a source of information, allowing photos to wield more power.
} 
Monin, 2003). That explanation also applies to the findings in Part 2. In Part 1 we examined that alternative explanation by manipulating whether photos depicted nouns that were unfamiliar versus familiar. We used a similar approach in Experiment 3b, except that we manipulated whether animals were unfamiliar (shoebill) or familiar (zebra). Photos should exert more powerful effects when animals are unfamiliar - that is, when photos can most help people bring related thoughts and images to mind.

\section{Experiment $3 b$}

\section{Method}

Subjects

We recruited 314 subjects (152 females, 127 males, and 35 subjects who did not report their gender) from Mechanical Turk. These subjects were on average 31.44 years old ( $S D=$ 11.15).

Design EP Procedure

We used a 2 (Photo: photo, no photo) x 2 (Claim: gave food, took food) x 2 (Familiarity: familiar animals, unfamiliar animals) mixed design, with Photo and Familiarity as within subject factors and Claim as the between subjects factor.

Using the method described in Experiment 1, we developed a new set of 40 familiar animal names (see Appendix B). We also examined the extent to which photos made people feel they could bring to mind related thoughts and images about these familiar animals. Accordingly, a separate group of 38 Mechanical Turk subjects saw the familiar animal names, one at a time; half the animal names appeared with a photo of the animal, and half appeared alone. Subjects rated how easy it felt to bring to mind information related to the animal using a scale from $1=$ "Extremely difficult" to $6=$ "Extremely easy." In line with our idea that photos of familiar animals should provide little help in bringing related information to mind, subjects' ratings were similar whether animal names appeared with photos $(M=$ 
$5.24, S D=0.72)$ or alone $(M=5.08, S D=0.81)$; that is, photos produced a trivial raw effect size of $0.16^{21}, 95 \%$ CI $[-0.02, .34], t(37)=1.85, p=.07$.

Subjects saw a total of 80 animal names comprising a block of the 40 familiar animals plus a block of the 40 unfamiliar animals used in Experiments 1-3a. The order of the blocks was counterbalanced between subjects. The procedure was otherwise identical to that of Experiment 3a.

\section{Results \& Discussion}

Photos exerted stronger effects when subjects saw unfamiliar animals, compared to familiar animals. In fact, as Figure 8 shows, the pattern of results is strikingly similar to those reported in Part 1 (Experiments 2a-c) when we also manipulated familiarity of names.

There are three important findings to take away from the figure. First, we found patterns consistent with those reported in Experiments 1-3a: for unfamiliar animal names, photos led people to respond true more often to the "gave food" claim, but not to the "took food" claim. Second, in line with our hypothesis, photos exerted stronger effects for unfamiliar animals - when photos could most help people bring related information to mind (but as the figure shows, only for the positive claim). Third, a closer look at the patterns on the "gave food" side of the figure suggests that even in the absence of photos, people were more likely to response true to what was easier to bring to mind - the familiar animal names. The figure also shows raw effect sizes, confidence intervals, and (in null hypothesis terms) a Photo $\mathrm{x}$ Claim x Familiarity interaction, $F(1,312)=6.61, p=.01$.

\footnotetext{
${ }^{21}$ Consistent with the idea that it should be harder for people to bring to mind thoughts and images about unfamiliar animals compared to familiar animals, we found that the effect of photos for familiar animals reported here is smaller than that of the unfamiliar animals reported in Experiment 1, in which photos produced a raw effect size of $1.47,95 \%$ CI $[1.05,1.88], t(33)=7.16, p<.01$. In null hypothesis terms, there was a Photo x Familiarity interaction, $F(1,70)=36.60, p<.01$.
} 


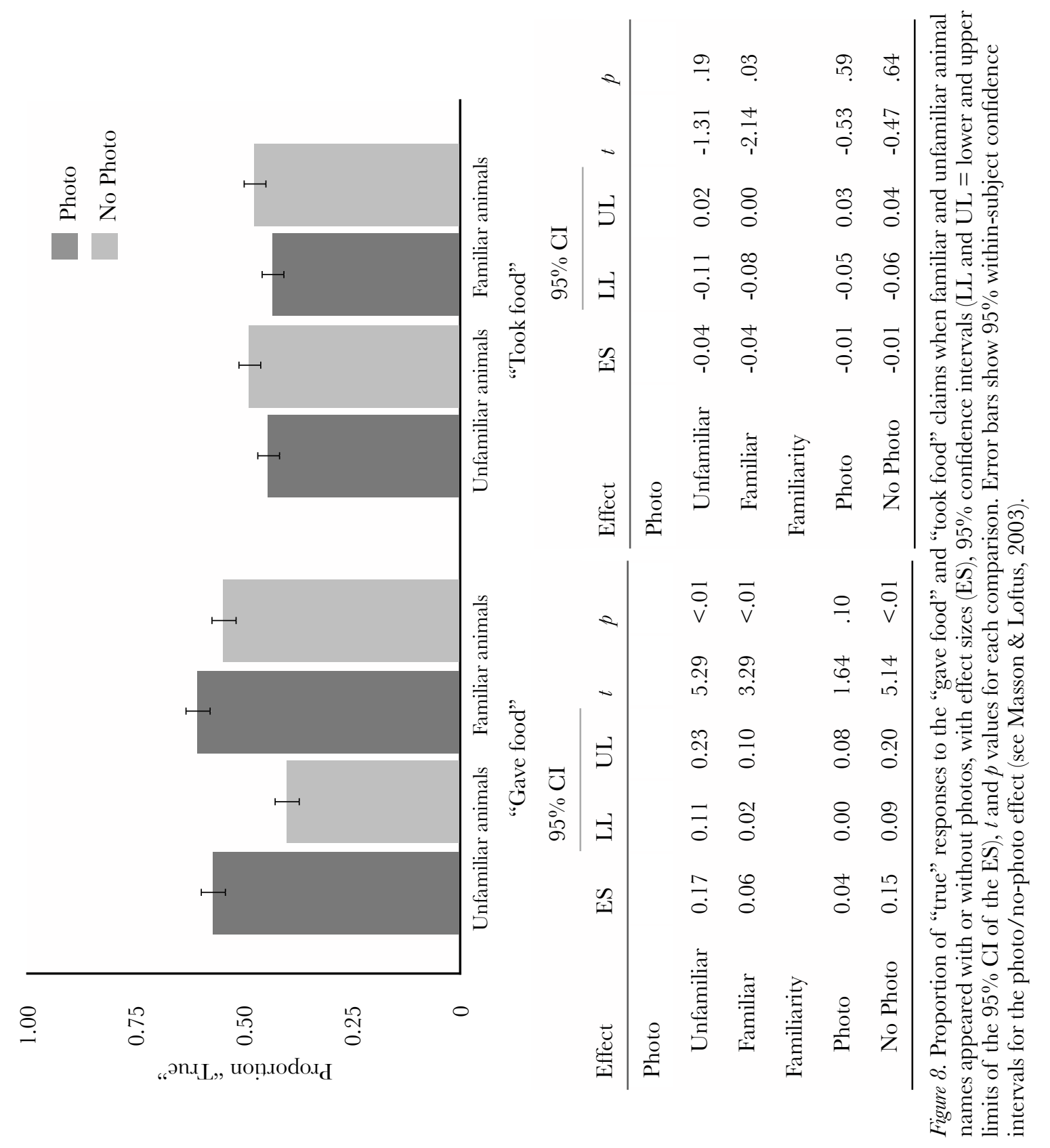


We replicated these patterns with another group of Mechanical Turk subjects. To arrive at a more precise estimate of the size of the photo effect for familiar and unfamiliar animal names, we subjected the data from both those experiments and data from Experiment 3a to random effects model mini meta-analyses and report those results, which are consistent with those reported here, in Table 2 (Cumming, 2012).

Table 2

Summary of results from each meta analysis for Experiments $3 a-b$

\begin{tabular}{|c|c|c|c|c|c|c|c|}
\hline \multirow[b]{2}{*}{ Claim } & \multirow[b]{2}{*}{ Manipulation } & \multirow[b]{2}{*}{$\mathrm{ES}$} & \multicolumn{2}{|c|}{$95 \%$ CI } & \multirow[b]{2}{*}{$z$} & \multirow[b]{2}{*}{$p$} & \multirow{2}{*}{$\begin{array}{l}\text { Experiments } \\
\text { included in } \\
\text { calculating ES }\end{array}$} \\
\hline & & & LL & UL & & & \\
\hline \multirow{2}{*}{$\begin{array}{l}\text { Positive } \\
\text { ("Gave food") }\end{array}$} & $\begin{array}{l}\text { Photo effect } \\
\text { (Unfamiliar names) }\end{array}$ & 0.26 & 0.18 & 0.34 & 6.53 & $<.01$ & $3 a^{a}, 3 b^{a}, 3 b R^{b}$ \\
\hline & $\begin{array}{l}\text { Photo effect } \\
\text { (Familiar names) }\end{array}$ & 0.04 & 0.02 & 0.07 & 3.29 & $<.01$ & $3 b^{a}, 3 b R^{b}$ \\
\hline \multirow{2}{*}{$\begin{array}{l}\text { Negative } \\
\text { ("Took food") }\end{array}$} & $\begin{array}{l}\text { Photo effect } \\
\text { (Unfamiliar names) }\end{array}$ & -0.05 & -0.08 & -0.01 & -2.63 & .01 & $3 \mathrm{a}^{\mathrm{a}}, 3 \mathrm{~b}^{\mathrm{a}}, 3 \mathrm{~b} \mathrm{R}^{\mathrm{b}}$ \\
\hline & $\begin{array}{l}\text { Photo effect } \\
\text { (Familiar names) }\end{array}$ & -0.03 & -0.06 & 0.01 & -1.55 & .12 & $3 b^{a}, 3 b R^{b}$ \\
\hline
\end{tabular}

\footnotetext{
Note. Meta analyses split by manipulations used in Experiments 3a-b. ES = effect size, the difference between photo and no photo means. Positive effect size $=$ a higher proportion of "true" responses when animal names appeared with photos compared to alone. LL and UL = lower and upper limits of the $95 \%$ CI of the ES. R = replication of an experiment $(\mathrm{R} 1=$ first replication, $\mathrm{R} 2=$ second replication, and so on). Replication 3b R used the same method as Experiment 3b.

${ }^{a}$ Experiments and replications reported in the main text. ${ }^{b}$ Replications not otherwise reported in the main text.
}

Experiment $3 \mathrm{~b}$ supports the idea that the ease with which people could bring information about animals to mind matters. Just as in Part 1, photos that helped people make sense of unfamiliar names, and therefore most helped people bring related thoughts and images to mind, wielded the most powerful effects over people's judgments. 


\section{Chapter 3}

In six experiments we examined the extent to which non-probative photos rapidly lead people to believe recent personal experiences happened. Across these experiments, photos of animals that offered no probative information about people's personal pasts nonetheless led people to think related positive (but not negative) claims were true. Photos also produced these patterns when people judged claims about others' experiences, and exerted their strongest effects when they depicted unfamiliar animals - that is, when they could most help people bring related thoughts and images to mind.

In Experiment 1, photos led people to think a claim about an event that happened just minutes before ("I gave food to this animal") was true. This finding fits with the idea that by helping people bring related thoughts and images to mind, photos quickly produce mental products that resemble those typical of genuine experience (Johnson et al., 1993; see Strange et al., 2011). This effect also fits with work showing that increasing semantic context makes information seem more familiar, accurate, and true (Hansen \& Wanke, 2010; Kelley \& Lindsay, 1993; Newman et al., 2012; Westerman, 2008; Whittlesea, 1993; for reviews, see Alter \& Oppenheimer, 2009; Unkelbach \& Greifeneder, 2013).

In Experiments 2a-c we investigated the conditions under which photos would exert these effects, and concluded that photos lead people to think positive events happened, but not negative events (a pattern consistent with those reported in Part 1). In Experiment 2a photos led people to respond true to the claim "I fed this animal" but not to the claim "I did not feed this animal," a finding suggesting that photos do not simply make any claim about one's past seem to have more merit. But there were two ways that pattern could have emerged. One possibility was that by making thoughts and images about animals come to mind easily photos made the animals feel familiar. Such a feeling would have been at odds with the idea that the event never happened, therefore steering people away from saying the 
“did not feed” claim was true (Jacoby \& Dallas, 1981; Unkelbach, 2006; Whittlesea, 1993). But a second possibility was that experience of ease produced positive feelings that aligned with positive claims ("fed"), not with negative claims ("did not feed"). We found evidence for this second possibility in Experiment 2b when people evaluated one of two claims that implied having an experience with animals - one that was either positive ("I gave food to this animal") or negative ("I took food from this animal")— - photos led people to say only the positive claim was true. This pattern matches the findings from Part 1 and fits with work suggesting that cognitive ease "feels good" and is therefore more likely to be construed as evidence for positive than for negative judgments (Reber et al., 1998; Seamon et al., 1998; Topolinski et al., 2009; Winkielman \& Cacioppo, 2001; Winkielman et al., 2006).

Experiment 2c built further support for this idea by addressing a confound. Positive feelings of ease could have aligned not with the outcome of the positive actions described by the claims (providing food), but with the positive connotations of those actions (giving; Cacioppo et al., 1999; Elliot, 2006; Lang et al., 1990; Price et al., 2012). Yet when positive and negative claims were both associated with a positive action ("I gave healthy food to this animal" versus "I gave unhealthy food to this animal") photos led people to respond true only when claims implied positive outcomes (providing healthy food). And because people were overall just as willing to say they gave healthy food as they were to say they gave unhealthy food, the findings also provide evidence against the interpretation that photos selectively promoted the truth of claims that described more plausible events (see Blandon-Gitlin \& Gerkens, 2010).

Experiments 1-2c suggest that non-probative photos rapidly lead people to think recent positive experiences happened. We found similar patterns in Experiments 3a-b when people evaluated others' pasts - a result in line with work showing that increased ease not only makes events seem more likely to have happened to oneself, it also makes those events 
seem more likely to have happened to others (Bernstein et al., 2009; Bernstein et al., 2002). Considered as a whole, Experiments 1-3b suggested that non-probative photos create an aura of belief around positive past events.

As in Part 1, an alternative explanation was that pairing animal names with colorful, interesting photos made animals seem more attractive. If so, people could have mistaken feelings of attraction for familiarity which - due to its many positive connotations - seemed like evidence for positive claims (Garcia-Marques et al., 2013; Monin, 2003; Schwarz, 2004). In Experiment 3b we found patterns at odds with that explanation. Photos exerted stronger effects when they depicted unfamiliar animals compared to familiar animals, a finding suggesting a mechanism not about the attractiveness of photos, but about the ease with which they bring related thoughts and images to mind. Indeed, even in the absence of these potentially attractive photos, people responded more positively when animals were familiar, and therefore easier to bring to mind (see Whittlesea, 1993; Winkielman et al., 2003; Zajonc, 1968).

Of course, a critic might argue that because the evidence for this mechanism came from an experiment in which people evaluated claims about others' pasts (Experiment 3b), we cannot be certain it applies to when people evaluated claims about their own pasts (Experiments 1-2c). That is true. But there is no reason to suspect the mechanism would change across other's pasts versus people's own pasts. After all, a large body of literature shows that increasing cognitive ease affects how people make decisions about their personal pasts (Bernstein et al., 2002; Whittlesea, 1993; for reviews, see Alter \& Oppenheimer, 2009; Jacoby et al., 1989; Unkelbach \& Greifeneder, 2013). And feelings of ease have similar effects over how people evaluate the pasts of others (Bernstein et al., 2009). Thus, the patterns across all of the experiments we reported fit best with the idea that photos operated by making it easier for people to bring related thoughts and images to mind. 
In fact, the set of findings from Parts 1 and 2 both support that mechanism, and overall tell similar stories. In each experiment photos depicted unfamiliar, difficult to represent words - the nouns in wine names (rick), or the names of animals (shoebill). And even though those photos were non-probative with respect to the claims people were evaluating, they led people to think positive claims were true. Both sets of findings suggested photos exerted these effects by making it easier for people to bring to mind (or comprehend) these unfamiliar words. Those mental experiences would have been just as non-probative as the photos that produced them. But people's bias to assume that feelings arising during a task are relevantcoupled with the positive spin they impose on ease - would have bolstered the positive claims (Higgins, 1998; Reber et al., 1998; Winkielman et al., 2003).

\section{Theoretical Implications}

Because the findings from Parts 1 and 2 are so similar, their theoretical implications also overlap. For instance, the set of findings from Part 2 fit with the idea described in Part 1 that photos might increase positive evaluations not just by helping people access known concepts, but also by helping people learn new concepts. The difference is a matter of context. People learned what an animal was (a shoebill is a large bird), rather than what a word in a wine name meant (a rick is a haystack); and people might have misread feelings from that learning as being about their own (or another person's) past, rather than about the quality of a product. Indeed, assuming that feelings associated with learning are just as open to interpretation as feelings associated with accessing known concepts, then they too should be interpreted as being "about" whatever is the focus of people's task — whether that is a product, or a personally experienced event (Higgins, 1998; Kronlund \& Bernstein, 2006; Schwarz, 2004; Whittlesea \& Williams, 1998).

Both sets of findings are also captured under the source monitoring framework (Johnson et al., 1993). The result that photos led people to believe events happened (Part 2) 
supports the source monitoring framework's proposition that streamlining the mental operations people are experiencing in the present systematically changes how they interpret the past - leading people to think experiences happened or are real (Alter \& Oppenheimer, 2009; Jacoby \& Dallas, 1981; Johnson \& Raye, 1981; Johnson \& Mitchell, 2006; Kelley \& Lindsay, 1993; Lindsay, 2008, 2014; Whittlesesa, 1993). A similar interpretation fits the data in Part 1; the difference is that rather than construing ease as evidence about one's past, people construed ease as evidence about the quality of a product (see Lindsay, 2008). But categorizing these findings as source monitoring errors is really just another way of saying that people use feelings of cognitive ease - sometimes mistakenly - as evidence for their judgments, particularly when other more relevant information is sparse (Schwarz \& Clore, 2007; Unkelbach, 2007).

Indeed, we draw on the fluidity of our ongoing cognitive operations whenever we are forced to guess about the world, assuming that if things are running surprisingly smoothly "inside," that represents something good about what is "out there" — be that its familiarity, attractiveness, value, or some other quality (Schwarz, 2002; Unkelbach \& Greifeneder, 2013; Whittlesea \& Williams, 1998; Whittlesea \& Williams, 2001a, 2001b). And because these are not random guesses, but predictions based on correlations in the real world, our judgments are on target more often than not (Goldstein \& Gigerenzer, 2002; Halberstadt, 2009; Halberstadt \& Catty, 2008; Johnson et al., 1993; Unkelbach, 2006, 2007). The effects demonstrated in Parts 1 and 2 reveal evidence of those relatively rare instances in which our predictions are off target (for reviews, see Alter \& Oppenheimer, 2009; Schwarz, 2004; Unkelbach \& Greifeneder, 2013). But that is just our cognitive system doing its job: using the limited information it has to make educated guesses about the world that are efficient, often accurate, but sometimes erroneous (Damasio, 1994; Bartlett, 1932; Brewer \& Treyens, 1981; Carmichael, 1932). 
To what extent do non-probative photos cause the subjective experience of remembering?

An important question in the false memory literature is "What was it about the mental characteristics people had in mind that led people to decide the event happened?" (Jacoby et al., 1989; Johnson et al., 1993; Lindsay, 2008, 2014). That is because there is more than one basis for deciding that an event happened (see Jacoby, 1991; Mandler, 1980; Rajaram, 1993). A common distinction is between when people "remember" an event and when they just "know" it occurred. People's subjective experience could be that they are reliving the details of an event (what would be classified as "remembering"). Or people's subjective experience could be one of pure certainty that the event occurred without being able to retrieve details to confirm that knowledge (what would be classified as "knowing"; Gardiner, 1988; Rajaram, 1993, 1996; Tulving, 1985).

Because the mental characteristics associated people's subjective experiences of "remembering" are typically more detailed than those associated with "knowing," examining which of those experiences non-probative photos produce would provide insight into their immediate power to cause false memories (see Strange et al., 2011). The more photos encourage "remember" relative to "know" responses, the more people's mental characteristics match those expected of reality, and the further people are down the track to false memories (Hyman, Gilstrap, Decker, \& Wilkinson, 1998; Hyman \& Kleinknecht, 1999; Johnson et al., 1993; Lindsay et al., 2004; Mazzoni et al., 2001; Paddock, Terranova, Kwok, \& Halpern, 2000; Scoboria et al., 2004).

So which of these subjective experiences might non-probative photos have caused? As much as we would like to claim that photos immediately created false "remembering," there are reasons to suspect they would not have.

We know that increasing fluency increases feelings of familiarity (Jacoby \& Dallas, 1981; Whittlesea, 1993). Moreover, feelings of familiarity are linked to the subjective 
experience of "knowing" more so than "remembering" (Gardiner, Ramponi, \& Richardson-

Klavehn, 1998; Rajaram, 1993; Rajaram \& Geraci, 2000). In one study, people explained what made them decide to assign "know" and "remember" responses to words they recognized from a list; for "know" responses people typically explained that the words just seemed familiar, but for "remember" responses people offered details about the context in which they saw the word, such as what it looked like or the thoughts they had at the time they saw it (Gardiner et al., 1998). Given the links between fluency, familiarity, and "knowing," we might expect that if photos increase conceptual fluency they would promote the experience of "knowing," not "remembering."

Indeed, other work shows that increased fluency (perceptual, or conceptual) selectively promotes the subjective experience of "knowing” (Rajaram, 1993; Rajaram \& Geraci, 2000; Wang \& Yonelinas, 2012). In another study, people decided whether they had seen target words (book) in an earlier phase of the experiment. When target words appeared after related words (author), people more often thought they had seen them, compared to when target words appeared after unrelated words (tree). But, more to the point, the related words increased people's reports of "knowing," but not "remembering" (Rajaram \& Geraci, 2000).

These findings suggest that if photos work by helping people bring related thoughts and images to mind, boosting conceptual fluency, they might selectively promote "know" responses ${ }^{22}$. So although photos might make people more likely to believe (positive) events

\footnotetext{
${ }^{22}$ The idea that non-probative photos would cause "knowing" more so than "remembering" conflicts with the findings from Strange et al. (2011). In their study, when people read news headlines paired with non-probative photos, people reported "remembering" more than "knowing." We cannot say for sure why that would be, given the literature described here. But we can speculate. In Strange et al.'s study, people's expectations for recalling news events should have been low, given that the news headlines described events that had supposedly happened years before (Johnson et al., 1988; Johnson et al., 1993). Perhaps people's low expectations (coupled with the suggestion that all the events actually did occur) made them willing to claim they "remembered" after gleaning few details from photos. It is difficult to say what people's expectations would have been for recalling details in our experiments. The recency of the events could have caused the expectation that people would be able to recall details - expectations photos could not meet, and would therefore fail to encourage "remember" responses. But considering our difficult encoding conditions, we think it is more plausible that people's expectations for recalling details were extremely low (probably lower than in Strange et al.'s study). Perhaps under conditions where people expect not to recall any detail, photos and other manipulations that boost conceptual processing would be more likely to encourage "knowing" responses.
} 
happened, they may not produce the subjective experience of remembering those events - at least, not immediately.

Could non-probative photos encourage the processes that turn "knowing" into "remembering"?

Of course, "known" events can become "remembered" ones (Hyman \& Kleinknecht, 1999). Getting people to spend time thinking about or imagining events they claimed to only "know" happened makes people subsequently rate those "known" events as more like "remembered" ones (Hyman et al., 1998; Paddock et al., 2000).

In fact, the mere conviction that an event happened should encourage those processes that turn "knowns" to "remembers." Just consider what typically happens when a face pops out at you from the crowd, evoking a feeling of familiarity (Whittlesea \& Williams, 1998). That feeling may not bring with it details about who the person is, how you met them, and when that meeting occurred, but it should make you confident you have seen the face and lead you to try retrieving details about the person (Jacoby et al., 1989; Mandler, 1980). After some time dwelling on the face, you might recollect (or concoct) details about meeting this person at a party, the friends that introduced you, and the snippets of conversation you had. Right or wrong, those details could end up seeming like evidence that you "remember" how you know that person (Lindsay, 2008, 2014).

Non-probative photos could promote an analogous process. By causing people to feel they just know the event occurred, photos might make people believe they could retrieve more about the event if they tried. And people's attempts to do so could turn what was once merely a feeling, a belief, into a detailed memory - one people might ultimately mistake as evidence of genuine experience (Hyman \& Kleinknect, 1999; Johnson et al., 1993; Lindsay et al., 2004; Wade et al., 2002). Thus, even if non-probative photos do not immediately create detailed false memories, by making events seem "known" to have happened they might encourage the processes that do. 
One step toward testing that idea would be to set up an experiment similar to the ones reported in Part 2. But rather than deciding whether each event occurred, people would decide whether they think they could retrieve more details about each event (see Lindsay, Wade, Hunter, \& Read, 2004). If photos lead people to think they could retrieve more, that would support the hypothesis that photos do not just immediately cause false beliefs - by doing so they also spur the processes that drive false memories. Are the effects of non-probative photos tied to positive events?

In our experiments, non-probative photos exerted their effects for positive events, but not for negative events - a pattern we suspect relates to the pleasure people derive from easily bringing information to mind (Winkielman \& Cacioppo, 2001). The idea that photos make positive events seem more likely by evoking feelings consistent with those events implies that photos could also make negative events seem more likely if they evoke negative feelings.

Imagine that the photos we used in Part 2 depicted animals that were scary, deformed, or just plain ugly. Just as with the more "neutral" versions of the photos, these "negative" photos should help people bring related thoughts and images to mind. But the content of those thoughts would have relatively more negative associations, and therefore cause negative feelings (Bower, 1981; see Lee \& Labroo, 2004). Those feelings would provide no evidence a negative event really happened, but might nonetheless seem like evidence that it did. Of course, this possibility hinges on people not realizing their feelings are caused by the negative image, because they would otherwise deem those feelings irrelevant for the task at hand (Schwarz \& Clore, 1983, 2007).

The extent to which non-probative photos immediately make negative events seem more believable is an area worthy of future research, particularly because the literature on false memories for entire autobiographical events grew out of the concern that people were developing painful memories (of abuse) in therapy (Lindsay \& Read, 1994; Loftus, 1993; 
Shobe \& Kihlstrom, 1997). Although our findings work against the idea that non-probative photos make negative events believable, that should not be taken to mean they cannot contribute to negative false memories; rather, the findings hint that photos may be immediately less likely to do so.

\section{Practical Implications}

These findings have practical implications for the law. The idea that non-probative photos immediately make people inclined to believe events happened suggests investigators exercise caution when using photos to “jog” suspects' and eyewitness' memories (see Henkel, 2011; Henkel \& Carbuto, 2008). Suppose you could not recall much about an event you were involved in or had witnessed (perhaps due to intoxication). Seeing a related but non-probative photo could make you more inclined to believe it happened, even if it did not. And that belief could encourage you to try retrieving more information, ultimately leaving you with a "memory" that does not truly reflect the details of the event (Johnson et al., 1993). If you were a suspect and decided to divulge your memory to the police, it may be used as evidence against you; and if you were an eyewitness you might confidently recount that memory to jurors.

Related concerns apply to the decisions of jurors, who will not have experienced the crime but must decide whether (or in what way) others were involved. Non-probative photos might make jurors inclined to believe claims about a suspect's involvement in a crime (Newman \& Feigenson, 2013). And such a belief may have downstream effects on jurors' interpretations of subsequent evidence; jurors could unwittingly confirm the belief photos forged by selectively attending to consistent evidence, while ignoring inconsistent evidence (Nickerson, 1998; Pennington \& Hastie, 1992). This possibility raises an interesting question: would photos be most influential if presented early on in the sequence of evidence, and least influential later? We suspect the answer is yes. The feelings photos produce should be most 
persuasive before people have a firm hypothesis about how a crime unfolded (Monin, 2003; Unkelbach, 2007).

Another decision jurors might face is whether a defendant is liable for an outcome. That decision requires determining how foreseeable, and therefore preventable, the outcome was. A large body of literature suggests that jurors have trouble ignoring known outcomes to estimate how foreseeable that outcome should have been; that is, they tend to think the outcome was more foreseeable than it actually was - an effect known as hindsight bias (Blank, Musch, \& Pohl, 2007; Hastie, Schkade, \& Payne, 1999). That literature also shows that feelings of fluency can increase hindsight bias, suggesting that photos might wield similar effects (Bernstein \& Harley, 2007). If so, photos could lead people to perceive the consequences of another person's actions as more foreseeable, and charge that person as more liable or negligent (see Harley, 2007).

A critic might have begun to wonder why we think photos could promote beliefs about crimes. After all, our findings suggest photos selectively lead people to think positive events happened, and crimes typically involve negative events. Although we too believe most crimes center around negative events, it is not so rare that seemingly trivial details of crimes (the tool used to break into the house) end up being the evidence that "gets the guy" or "closes a case." So even if the crime itself is negative, these other trivial aspects of crimes could be positive (or neutral ${ }^{23}$. If photos make these aspects of a crime seem more likely, related claims could also seem to have more merit. Through that route, photos could sway decisions about even negative events.

Moreover, jurors' status of "fact finder" could twist how they interpret the positive feelings arising while they evaluate details of a crime. Their task is to solve a problem, to piece

\footnotetext{
${ }^{23}$ In one version of these experiments (and a replication) we asked people to do neutral actions with animals (for example, "Paint the animal's cage yellow") then tested them on those actions. Photos led people to think those relatively more neutral experiences happened, a raw bias effect of $-0.10,95 \%$ CI [- $0.17,-.02]$ for the original experiment, and $-0.07,95 \%$ CI $[-0.14,0.01]$ for the replication.
} 
together evidence and arrive at the best guess about what really happened. In that context, it seems unlikely that people would focus on determining whether the crime itself was morally right or wrong. More likely is that people would focus on determining the accuracy of the evidence presented. That frame of mind might lead people to interpret ease as evidence that specific facts are accurate or true, despite that the crime itself is negative (Kelley \& Lindsay, 1993; Reber \& Schwarz, 1999; Toplinski \& Reber, 2010). Of course, given the serious nature of jurors' task, it is also plausible that they would approach the evidence more analytically, which would steer them away from drawing on feelings to evaluate facts of the case (Halberstadt \& Catty, 2008; Halberstadt, 2009).

These legal implications are worrying not just because of the serious nature of the events people are evaluating, but because we doubt that it is widely known that non-probative photos can have these immediate effects (and long term effects, for that matter). Although we know of no work examining people's beliefs about non-probative photos, our hunch is that most people (including police investigators, judges, and lawyers) would consider it ludicrous that a photo - one that did not depict a crime or suggest it occurred, but that merely helped people consider an aspect of it-could produce the effects reported in this thesis. 


\section{References}

Alter, A. L., \& Oppenheimer, D. M. (2006). Predicting short-term stock fluctuations by using processing fluency. Proceedings of the National Academy of Sciences, USA, 103, 9369-9372. doi: $10.1073 /$ pnas.0601071103

Alter, A. L., \& Oppenheimer, D. M. (2008). Effects of fluency on psychological distance and mental construal (or why New York is a large city, but New York is a civilized jungle). Psychological Science, 19, 161-167. doi: 10.1111/j.1467-9280.2008.02062.x

Alter, A. L., \& Oppenheimer, D. M. (2009). Uniting the tribes of fluency to form a metacognitive nation. Personality and Social Psychology Reviewe, 13, 219-235. doi: $10.1177 / 1088868309341564$

Alter, A. L., Oppenheimer, D. M., Epley, N., \& Eyre, R. N. (2007). Overcoming intuition: Metacognitive difficulty activates analytic reasoning. Fournal of Experimental Psychology: General, 136, 569-576. doi: 10.1037/0096-3445.136.4.569

Becker, L., van Rompay, T. J. L., Schifferstein, H. N. J., \& Galetzka, M. (2011). Tough package, strong taste: The influence of packaging design on taste impressions and product evaluations. Food Quality and Preference, 22, 17-23. doi: 10.1016/j.foodqual. 2010.06 .007

Begg, I. M., Anas, A., \& Farinacci, S. (1992). Dissociation of processes in belief: Source recollection, statement familiarity, and the illusion of truth. Fournal of Experimental Psychology: General, 121, 446-458. doi: 10.1037/0096-3445.121.4.446

Belke, B., Leder, H., Strobach, T., \& Carbon, C. C. (2010). Cognitive fluency: High-level processing dynamics in art appreciation. Psychology of Aesthetics, Creativity, and the Arts, 4, 214-222. doi: 10.1037/a0019648 
Bernstein, D. M., Godfrey, R. D., \& Loftus, E. F. (2009). False memories: The role of plausibility and autobiographical belief. In K. Markman, W. Klein, \& J. Suhr (Eds.) Handbook of imagination and mental simulation (pp. 89-102). Psychology Press.

Bernstein, D. M., \& Harley, E. M. (2007). Fluency misattribution and visual hindsight bias. Memory, 15, 548-560. doi: 10.1080/09658210701390701

Bernstein, D. M., Whittlesea, B. W. A., \& Loftus, E. F. (2002). Increasing confidence in remote autobiographical memory and general knowledge: Extensions of the revelation effect. Memory E Cognition, 30, 432-438. doi: 10.3758/BF03194943

Blandon-Gitlin, I., \& Gerkens, D. (2010). The effects of photographs and event plausibility in creating false beliefs. Acta Psychologica, 135, 330-334. doi: 10.1016/j.actpsy.2010.08.008

Blank, H., Musch, J., \& Pohl, R. F. (2007). Hindsight bias: On being wise after the event. Social Cognition, 25, 1-9. doi: 10.1521/soco.2007.25.1.1

Bornstein, R. F. (1989). Exposure and affect: Overview and meta-analysis of research, 1968-1987. Psychological Bulletin, 106, 265-289. doi: 10.1037/0033-2909.106.2.265

Bower, G. H. (1981). Mood and memory. American Psychologist, 36, 129-148. doi: 10.1037/0003-066X.36.2.129

Bowers, K. S., Regehr, G., Balthazarad, C., \& Parker, K. (1990). Intuition in the context of discovery. Cognitive Psychology, 22, 72-110. doi: 10.1016/0010-0285(90)90004-N

Bransford, J. D., \& Johnson, M. K. (1972). Contextual prerequisites for understanding: Some investigations of comprehension and recall. Journal of Verbal Learning and Verbal Behavior, 11, 717-726. doi: 10.1016/S0022-5371(72)80006-9

Brewer, W. F., \& Treyens, J. C. (1981). Role of schemata in memory for places. Cognitive Psychology, 13, 207-230. doi: 10.1016/0010-0285(81)90008-6

Brown, A. S., \& Marsh, E. J. (2008). Evoking false beliefs about autobiographical experience. Psychonomic Bulletin E̊ Review, 15, 186-190. doi: 10.3758/PBR. 15.1.186 
Cacioppo, J. T., Gardner, W. L., \& Berntson, G. G. (1999). The affect system has parallel and integrative processing components: Form follows function. Fournal of Personality and Social Psychology, 76, 839-855. doi: 10.1037/0022-3514.76.5.839

Carmichael, L., Hogan, H. P., \& Walter, A. A. (1932). An experimental study of the effect of language on the reproduction of visually perceived form. Journal of Experimental Psychology: General, 15, 73-86. doi: 10.1037/h0072671

Carney, R. N., \& Levin, J. R. (2002). Pictorial illustrations still improve students' learning from text. Educational Psychology Review, 14, 5-26. doi: 10.1023/A:1013176309260

Carpenter, S. K., \& Olson, K. M. (2012). Are pictures good for learning new vocabulary in a foreign language? Only if you think they are not. Fournal of Experimental Psychology: Learning, Memory, and Cognition, 38, 92-101. doi: 10.1037/a0024828

Chrobak, Q. M., \& Zaragoza, M. S. (2008). Inventing stories: Forcing witnesses to fabricate entire fictitious events leads to freely reported false memories. Psychonomic Bulletin $\mathbb{E}$ Review, 15, 1190-1195. doi: 10.3758/PBR.15.6.1190

Clemente, S., Dolansky, E., Mantonakis, A., \& White, K. (2013). The effects of perceived product-extrinsic cue incongruity on consumption experiences: The case of celebrity sponsorship. Marketing Letters, August 2013. doi: 10.1007/s1 1002-013-9257-y

Collins, A. M., \& Loftus, E. F. (1975). A spreading-activation theory of semantic processing. Psychological Review, 82, 407-428. doi: 0.1037/0033-295X.82.6.407

Cumming, G. (2012). Understanding the new statistics: Effect sizes, confidence intervals, and metaanalysis. New York: Routledge.

Cumming, G. (2014). The new statistics: Why and how. Psychological Science, 25, 7-29. doi: $10.1177 / 0956797613504966$

Damasio, A. R. (1994). Descartes' error: Emotion, reason, and the human brain. Avon, New York. 
Dechene, A., Stahl, C., Hansen, J., \& Wanke, M. (2009). Mix me a list: Context moderates the truth effect and the mere-exposure effect. Fournal of Experimental Social Psychology, 45, 1117-1122. doi: 10.1016/j.jesp.2009.06.019

Dechene, A., Stahl, C., Hansen, J., \& Wanke, M. (2010). The truth about the truth: A metaanalytic review of the truth effect. Personality and Social Psychology Review, 14, 238-257. doi:10.1177/1088868309352251

Downs, J. S., Holbrook, M. B., Sheng, S., \& Cranor, L. F. (2010). Are your participants gaming the system? Screening Mechanical Turk workers. Proceedings of the 28th International Conference on Human Factors in Computing Systems, CHI 2010, 2399-402. New York: ACM Press.

Drivdahl, S. B., \& Zaragoza, M. S. (2001). The role of perceptual elaboration and individual differences in the creation of false memories for suggested events. Applied Cognitive Psychology, 15, 265-281. doi: 10.1002/acp.701

Dutton, D. G., \& Aron, A. P. (1974). Some evidence for heightened sexual attraction under conditions of high anxiety. Fournal of Personality and Social Psychology, 30, 510-517. doi: $10.1037 / \mathrm{h} 0037031$

Ebbinghaus (1885/1913). Memory: A contribution to experimental psychology. [H. A. Ruger \& C. E. Bussenius, Trans.]. New York: Columbia University, Teachers College.

Elliot, A. J. (2006). The hierarchical model of approach-avoidance motivation. Motivation and Emotion, 30, 111-116. doi: 10.1007/s11031-006-9028-7

Finke, R. A., Johnson, M. K., \& Shyi, G. G. (1988). Memory confusions for real and imagined completions of symmetrical visual patterns. Memory \& Cognition, 16, 133-137. doi: $110.3758 / \mathrm{BF} 03213481$

Garcia-Marques, T., Mackie, D. M., Claypool, H. M., \& Garcia-Marques, L. (2013). Once more with feeling! Familiarity and positivity as integral consequences of previous 
experience. In C. Unkelbach \& R. Greifeneder (Eds.), The experience of thinking: How the fluency of mental processes influences cognition and behavior (pp. 50-69). New York, NY:

Psychology Press.

Gardiner, J. M. (1988). Functional aspects of recollective experience. Memory E̊ Cognition, 16, 309-313. doi: 10.3758/BF03197041

Gardiner, J. M., Ramponi, C., \& Richardson-Klaven, A. (1998). Experiences of remembering, knowing, and guessing. Consciousness and Cognition, 7, 1-26. doi: 10.1006/ cog. 1997.0321

Garry, M., \& Gerrie, M. P. (2005). When photographs create false memories. Current Directions in Psychological Science, 14, 321-324. doi: 10.1111/j.0963-7214.2005.00390.x

Garry, M., Manning, G. G., Loftus, E. F., \& Sherman, S. J. (1996). Imagination inflation: Imagining a childhood event inflates confidence that it occurred. Psychonomic Bulletin $\mathbb{E}$ Reviere, 3, 208-214. doi: 10.3758/BF03212420

Gigerenzer, G. (2008). Why heuristics work. Perspectives on Psychological Science, 3, 20-29. doi: $10.1111 / \mathrm{j} .1745-6916.2008 .00058 . \mathrm{x}$

Gilbert, D. T. (1991). How mental systems believe. American Psychologist, 46, 107-119. doi: 10.1037/0003-066X.46.2.107

Gilbert, D. T., Tafarodi, R. W., \& Malone, P. S. (1993). You can’t not believe everything you read. Fournal of Personality and Social Psychology, 65, 221-233. doi: $10.1037 / 0022-3514.65 .2 .221$

Goff, L. M., \& Roediger, H. L., III (1998). Imagination inflation for action events: Repeated imaginings lead to illusory recollections. Memory \& Cognition, 26, 20-33. doi: 10.3758/ BF03211367

Goldstein, D., \& Gigerenzer, G. (2002). Models of ecological rationality: The recognition heuristic. Psychological Review, 1, 75-90. doi: 10.1037//0033-295X.109.1.75 
Goodman, J. K., Gryder, C. E., \& Cheema, A. (2012). Data collection in a flat world: The strengths and weaknesses of Mechanical Turk samples. Fournal of Behavioral Decision Making, wileyonlinelibrary.com. doi: 10.1002/bdm.1753

Graesser, A. C., \& Hemphill, D. (1991). Question answering in the context of scientific mechanisms. Fournal of Memory and Language, 30, 186-209. doi: 10.1016/0749-596X (91)90003-3

Greifeneder, R., Bless, H., \& Pham, M. T. (2011). When do people rely on affective feelings in judgment? A review. Personality and Social Psychology Review, 15, 107-141. doi: $10.1177 / 1088868310367640$

Halberstadt, J. (2009). Intuition: Dumb but lucky. Fortuitous affective cues and their disruption by analytic thought. Social and Personality Psychology Compass, 4, 64-76. doi: $10.1111 / \mathrm{j} .1751-9004.2009 .00242 . \mathrm{x}$

Halberstadt, J., \& Catty, S. (2008). Analytic thought disrupts familiarity-based decision making. Social Cognition, 26, 755-765. doi: 10.1521/soco.2008.26.6.755

Halberstadt, J., \& Green, J. (2008). Carryover effects of analytic thought on preference quality. Fournal of Experimental Psychology, 44, 1199-1203. doi: 10.1016/j.jesp. 2008.03.008

Halberstadt, J., \& Hooton, K. (2008). The affect disruption hypothesis: The effect of analytic thought on the fluency and appeal of art. Cognition and Emotion, 22, 964-976. doi: $10.1080 / 02699930701597668$

Hansen, J., Dechene, A., \& Wanke, M. (2008). Discrepant fluency increases subjective truth. Fournal of Experimental Social Psychology, 44, 687-691. doi: 10.1016/j.jesp.2007.04.005

Hansen, J., \& Wanke, M. (2010). Truth from language and truth from fit: The impact of linguistic concreteness and level of construal on subjective truth. Personality and Social Psychology Bulletin, 36, 1576-1588. doi: 10.1177/0146167210386238 
Harley, E. M. (2007). Hindsight bias in legal decision making. Social Cognition, 25, 48-63. doi: $10.1521 /$ soco.2007.25.1.48

Harmon-Jones, E., \& Allen, J. J. B. (2001). The role of affect in the mere exposure effect: Evidence from psychophysical and individual differences approaches. Personality and Social Psychology Bulletin, 27, 889-898. doi: 10.1177/0146167201277011

Hasher, L., Goldstein, D., \& Toppino, T. (1977). Frequency and the conference of referential validity. Fournal of Verbal Learning and Verbal Behavior, 16, 107-112. doi: 10.1016/ S0022-5371(77)80012-1

Hastie, R., Schkade, D. A., \& Payne, J. W. (1999). Juror judgments in civil cases: Hindsight effects on judgments of liability for punitive damages. Law and Human Behavior, 23, 597-614. doi: 10.1023/A:1022352330466

Henkel, L. A. (2004). Erroneous memories arising from repeated attempts to remember. Fournal of Memory and Language, 50, 26-46. doi: 10.1016/j.jml.2003.08.001

Henkel, L. A. (2011). Photograph-induced memory errors: When photographs make people claim they have done things they have not. Applied Cognitive Psychology, 25, 78-86. doi: 10.1002/acp. 1644

Henkel, L. A. (2012). Seeing photos makes us read between the lines: The influence of photos on memory for inferences. The Quarterly fournal of Experimental Psychology, 65, 773-795. doi: 10.1080/17470218.2011.628400

Henkel, L. A., \& Carbuto, M. (2008). Remembering what we did: How source misattributions arise from verbalization, mental imagery, and pictures. In Matthew R. Kelley (Ed.), Applied memory (pp. 213-234). Hauppauge, NY: Nova Science Publishers.

Henkel, L. A., Franklin, N., \& Johnson, M. K. (2000). Cross-modal source monitoring confusions between perceived and imagined events. Fournal of Experimental Psychology: Learning, Memory, and Cognition, 26, 321-335. doi: 10.1037/0278-7393.26.2.321 
Henkel, L. A., \& Mattson, M. E. (2011). Reading is believing: The truth effect and source credibility. Consciousness and Cognition: An International fournal, 20, 1705-1721. doi: 10.1016/j.concog.2011.08.018

Herzog, S. M., \& Hertwig, R. (2013). The ecological validity of fluency. In C. Unkelbach \& R. Greifeneder (Eds.), The experience of thinking: How the fluency of mental processes influences cognition and behavior (pp. 190-217). New York, NY: Psychology Press.

Higgins, E. T. (1998). The aboutness principle: A pervasive influence on human inference. Social Cognition, 16, 173-198. doi: 10.1521/soco.1998.16.1.173

Hudson, J. A., \& Fivush, R. (1991). As time goes by: Sixth graders remember a kindergarten experience. Applied Cognitive Psychology, 5, 347-360. doi: 10.1002/acp.2350050405

Hyman, I. E., Jr., Gilstrap, L. L., Decker, K., \& Wilkinson, C. (1998). Manipulating remember and know judgments of autobiographical memories: An investigation of false memory creation. Applied Cognitive Psychology, 12, 371-386. doi: 10.1002/(SICI) 1099-0720(199808)12:4

Hyman, I. E., Jr., \& Kleinkneckt, E. E. (1999). False childhood memories: Research, theory, and applications. In L. M. Williams \& V. L. Banyard (Eds.), Trauma and memory (pp. 175-188). Thousand Oaks, CA: Sage.

Hyman, I. E., Jr., \& Pentland, J. (1996). The role of mental imagery in the creation of false childhood memories. Fournal of Memory and Language, 35, 101-117. doi: 10.1006/jmla. 1996.0006

Iyengar, S. S., \& Lepper, M. R. (2000). When choice is demotivating: Can one desire too much of a good thing? Fournal of Personality and Social Psychology, 79, 995-1006. doi: 10.1037/0022-3514.79.6.995 
Jacoby, L. L. (1991). A process dissociation framework: Separating automatic from intentional uses of memory. Fournal of Memory and Language, 30, 513-541. doi: 10.1016/0749-596X (91)90025-F

Jacoby, L. L., Allan, L. G., Collins, J. C., \& Larwill, L. K. (1988). Memory influences subjective experience: Noise judgments. Fournal of Experimental Psychology: Learning, Memory, and Cognition, 14, 240-247. doi: 10.1037/0278-7393.14.2.240

Jacoby, L. L., Bjork, R. A., \& Kelley, C. M. (1994). Illusions of comprehension and competence. In D. Druckman \& R. A. Bjork (Eds.), Learning, remembering, believing: Enhancing individual and team performance (pp. 57-80). Washington, DC: National Academy Press.

Jacoby, L. L., \& Dallas, M. (1981). On the relationship between autobiographical memory and perceptual learning. Fournal of Experimental Psychology: General, 110, 306-340. doi: 10.1037/0096-3445.110.3.306

Jacoby, L. L., Kelley, C., Brown, J., \& Jasechko, J. (1989). Becoming famous overnight: Limits on the ability to avoid unconscious influences of the past. Fournal of Personality and Social Psychology, 56, 326-338. doi: 10.1037/0022-3514.56.3.326

Jacoby, L. L., Kelley, C. M., \& Dywan, J. (1989). Memory attributions. In H. L. Roediger \& F. I. M. Craik (Eds.), Varieties of memory and consciousness: Essays in honour of Endel Tulving (pp. 391-422). Hillsdale, NJ: Erlbaum.

Johnson, M.K. (2006). Memory and reality. American Psychologist, 61, 760-77 1. doi: 10.1037/0003-066X.61.8.760

Johnson, M.K., Foley, M. A., \& Leach, K. (1988). The consequences for memory of imagining in another person's voice. Memory $\mathcal{E}^{2}$ Cognition, 16, 337-342. doi: 10.3758/ BF03197044 
Johnson, M. K., Foley, M. A., Suengas, A. G., \& Raye, G. L. (1988). Phenomenal characteristics of memories for perceived and imagined autobiographical events. Fournal of Experimental Psychology: General, 117, 371-376. doi:

$10.1037 / 0096-3445.117 .4 .371$

Johnson, M. K., Hashtroudi, S., \& Lindsay, D. S. (1993). Source monitoring. Psychological Bulletin, 114, 3-28. doi: 10.1037/0033-2909.114.1.3

Johnson, M. K., \& Raye, C. L. (1981). Reality monitoring. Psychological Reviere, 88, 67-85, doi: 10.1037/0033295X.88.1.67

Kapelner, A., \& Chandler, D. (2010, October). Preventing satisficing in online surveys: A "kapcha" to ensure higher quality data. Paper presented at CrowdConf, San Francisco, CA. Retrieved from: http://www.crowdconf2010.com/images/ finalpapers/kapelner.pdf

Kelley, C. M., \& Lindsay, D. S. (1993). Remembering mistaken for knowing: Ease of retrieval as a basis for confidence in answers to general knowledge questions. Fournal of Memory and Language, 32, 1-24. doi: 10.1006/jmla. 1993.1001

Kornell, N., \& Bjork, R. A. (2007). The promise and perils of self-regulated study. Psychonomic Bulletin \& Review, 14, 219-224. Retrieved from: http://search.proquest.com/docview/ 621844853 ?accountid=14782

Koutstaal, W., Schacter, D. L., Johnson, M. K., Angel, K. E., \& Gross, M. S. (1998). Postevent review in older and younger adults: Improving memory accessibility of complex everyday events. Psychology \& Aging, 13, 277-296. doi: 10.1037/0882-7974.13.2.277

Krishna, A. (2012). An integrative review of sensory marketing: Engaging the senses to affect perception, judgment and behavior. Fournal of Consumer Psychology, 22, 332-351. doi: 10.1016/j.jcps.2011.08.003 
Kronlund, A., \& Bernstein, D. M. (2006). Unscrambling words increases brand name recognition and preference. Applied Cognitive Psychology, 20, 681-687. doi: 10.1002/acp. 1220

Kunst-Wilson, W. R., \& Zajonc, R. B. (1980). Affective discrimination of stimuli that cannot be recognized. Science, 207, 557-558. doi: 10.1126/science.7352271

Labroo, A. A., Dhar, R., \& Schwarz, N. (2007). Of frog wines and frowning watches: Semantic priming, perceptual fluency, and brand evaluation. Fournal of Consumer Research, 34, 819-831. doi: 10.1086/523290

Lakshmanan, A., \& Krishnan, H. S. (2011). The Aha! experience: Insight and discontinuous learning in product usage. Fournal of Marketing, 75, 105-123. doi: 10.1509/jm.10.0348

Lang, P. J., Bradley, M. M., \& Cuthbert, B. N. (1990). Emotion, attention, and the startle reflex. Psychological Reviere, 97, 377-395. doi: 10.1037/0033-295X.97.3.377

Lee, A. Y., \& Labroo, A. A. (2004). The effect of conceptual and perceptual fluency on brand evaluation. Fournal of Marketing Research, 41, 151-165. doi: 10.1509/jmkr.

\subsubsection{5}

Liang, P., Roy, S., Chen, M., \& Zhang, G. (2013). Visual influence of shapes and semantic familiarity on human sweet sensitivity. Behavioural Brain Research, 253, 42-47. doi: 10.1016/j.bbr.2013.07.001

Lindsay, D. S. (2008). Source monitoring. In H. L. Roediger III \& J. Byrne (Eds.), Learning and memory: A comprehensive reference. Vol. 2: Cognitive psychology of memory (pp. 325-348). Amsterdam: Elsevier.

Lindsay, D. S. (2014). Memory source monitoring applied. In T. J. Perfect \& D. S. Lindsay (Eds.), The Sage handbook of applied memory (pp. 59-75). Los Angeles/London/New Delhi/Singapore/Washington DC: SAGE. 
Lindsay, D. S., Hagen, L., Read, J. D., Wade, K. A., \& Garry, M. (2004). True photographs and false memories. Psychological Science, 15, 149-154. doi: 10.1111/j. 0956-7976.2004.01503002.x

Lindsay, D. S., \& Read, J. D. (1994). Psychotherapy and memories of childhood sexual abuse: A cognitive perspective. Applied Cognitive Psychology, 8, 281-338. doi: 10.1002/acp. 2350080403

Lindsay, D. S., Wade, K. A., Hunter, M. A., \& Read, J. D. (2004). Adults' memories of childhood: Affect, knowing, and remembering. Memory, 12, 27-43. doi: $10.1080 / 09658210244000243$

Loftus, E. F. (1993). The reality of repressed memories. American Psychologist, 48, 518-537. doi: 10.1037/0003-066X.48.5.518

Loftus, E. F., Miller, D. G., \& Burns, H. J. (1978). Semantic integration of verbal information into visual memory. Fournal of Experimental Psychology: Human Learning and Memory, 4, 19-31. doi: 10.1037/0278-7393.4.1.19

Mandler, G. (1980). Recognizing: The judgment of previous occurrence. Psychological Review, 37, 252-271. doi: 10.1037/0033-295X.87.3.252

Mantonakis, A., Rodero, P., Lesschaeve, I., \& Hastie, R. (2009). Order in choice: Effects of serial position on preferences. Psychological Science, 20, 1309-1312. doi: 10.1111/j. $1467-9280.2009 .02453 . x$

Masson, M. E. J., \& Loftus, G. R. (2003). Using confidence intervals for graphically based data interpretation. Canadian Fournal of Experimental Psychology, 57, 203-220. doi: $10.1037 / \mathrm{h} 0087426$

Mayer, R. E., \& Gallini, J. K. (1990). When is an illustration worth ten thousand words? Fournal of Educational Psychology, 82, 715-726. doi: 10.1037/0022-0663.82.4.715 
Mazzoni, G. A. L., Loftus, E. F., \& Kirsch, I. (2001). Changing beliefs about implausible autobiographical events: A little plausibility goes a long way. Fournal of Experimental Psychology: Applied, 7, 51-59. doi: 10.1037/1076-898X.7.1.51

McGowan, R. T. S., Rehn, T., Norling, Y., \& Keeling, L. J. (2014). Positive affect and learning: Exploring the "Eureka effect" in dogs. Animal Cognition, 17, 577-587. doi: 10.1007/ s10071-013-0688-x

Metcalfe, J., \& Dunlosky, J. (2008). Metamemory. In H.L. Roediger, III (Ed.), Learning and memory: A comprehensive reference (pp. 349-362). Oxford: Elsevier.

Mitchell, K. J., \& Johnson, M. K. (2000). Source monitoring: Attributing mental experiences. In E. Tulving \& F. I. M. Craik (Eds.), The Oxford Handbook of Memory (pp. 179-195). New York: Oxford University Press.

Monin, B. (2003). The warm glow heuristic: When liking leads to familiarity. Fournal of Personality and Social Psychology, 85, 1035-1048. doi: 10.1037/0022-3514.85.6.103

Newman, E. J., \& Feigenson, N. (2013). The truthiness of visual evidence. The Fury Expert: The Art and Science of Litigation Advocacy, 25, 1-6.

Newman, E. J., Garry, M., Bernstein, D. M., Kantner, J., \& Lindsay, D. S. (2012). Nonprobative photographs (or words) inflate truthiness. Psychonomic Bulletin $\mathcal{E}$ Review, 19, 969-974. doi: 10.3758/s13423-012-0292-0

Newman, E. J., Garry, M., Unkelbach, C., Bernstein, D. M., \& Lindsay, D. S. (Manuscript under review). Truthiness and falsiness of trivia claims depends on judgmental contexts.

Nickerson, R. S. (1998). Confirmation bias: A ubiquitous phenomenon in many guises. Review of General Psychology, 2, 175-220. doi: 10.1037/1089-2680.2.2.175

Novemsky, N., Dhar, R., Schwarz, N., \& Simonson, I. (2007). Preference fluency in choice. Fournal of Marketing Research, 44, 347-356. doi: 10.1509/jmkr.44.3.347 
Oppenheimer, D. M. (2004). Spontaneous discounting of availability in frequency judgment tasks. Psychological Science, 15, 100-105. doi: 10.1111/j.0963-7214.2004.01502005.x

Oppenheimer, D. M. (2006). Consequences of erudite vernacular utilized irrespective of necessity: Problems with using long words needlessly. Applied Cognitive Psychology, 20, 139-156. doi: 10.1002/acp.1178

Oppenheimer, D. M., Meyvis, T., \& Davidenko, N. (2009). Instructional manipulation checks: Detecting satisficing to increase statistical power. Fournal of Experimental Social Psychology, 45, 867-872. doi: 10.1016/j.jesp.2009.03.009

Paddock, J. R., Terranova, S., Kwok, R., \& Halpern, D. V. (2000). When knowing becomes remembering: Individual differences in susceptibility to suggestion. The fournal of Genetic Psychology: Research and Theory on Human Development, 161, 453-468. doi: $10.1080 / 00221320009596724$

Paivio, A. (1969). Mental imagery in associative leaning and memory. Psychological Reviere, 76, 241-263. doi: 10.1037/h0027272

Pennington, N., \& Hastie, R. (1992). Explaining the evidence: Tests of the Story Model for juror decision making. Fournal of Personality and Social Psychology, 62, 189-206. doi: $10.1037 / 0022-3514.62 .2 .189$

Plassmann, H., O’Doherty, J., Shiv, B., \& Rangel, A. (2008). Marketing actions can modulate neural representations of experienced pleasantness. Proceedings of the National Academy of Sciences, USA, 105, 1050-1054. doi: 10.1073/pnas.0706929105

Price, T. F., Dieckman, L. W., \& Harmon-Jones, E. (2012). Embodying approach motivation: Body posture influences startle eyeblink and event-related potential responses to appetitive stimuli. Biological Psychology, 90, 211-217. doi: 10.1016/j.biopsycho. 2012.04 .001 
Pronin, E., Jacobs, E., \& Wegner, D. M. (2008). Psychological effects of thought acceleration. Emotion, 8, 597-612. doi: 10.1037/a0013268

Rajaram, S. (1993). Remembering and knowing: Two means of access to the personal past. Memory \& Cognition, 21, 89-102. doi: 10.3758/BF03211168

Rajaram, S. (1996). Perceptual effects on remembering: Recollective processes in picture recognition memory. Fournal of Experimental Psychology: Learning, Memory, and Cognition, 22, 365-377. doi: 10.1037/0278-7393.22.2.365

Rajaram, S., \& Geraci, L. (2000). Conceptual fluency selectively influences knowing. Fournal of Experimental Psychology: Learning, Memory, and Cognition, 26, 1070-1074. doi: 10.1037/0278-7393.26.4.1070

Rawson, K. A., \& Dunlosky, J. (2002). Are performance predictions for text based on ease of processing? Journal of Experimental Psychology: Learning, Memory, and Cognition, 28, 69-80. doi: $10.1037 / / 0278-7393.28 .1 .69$

Reber, R., \& Schwarz, N. (1999). Effects of perceptual fluency on judgments of truth. Consciousness and Cognition, 8, 338-342. doi: 10.1006/ccog.1999.0386

Reber, R., Schwarz, N., \& Winkielman, P. (2004). Processing fluency and aesthetic pleasure: Is beauty in the perceiver's processing experience? Personality and Social Psychology Review, 8, 364-382. doi: 10.1207/s15327957pspr0804_3

Reber, R., Winkielman, P., \& Schwarz, N. (1998). Effects of perceptual fluency on affective judgments. Psychological Science, 9, 45-48. doi: 10.1111/1467-9280.00008

Reder, L. M., \& Ritter, F. E. (1992). What determines initial feeling of knowing? Familiarity with question terms, not with the answer. Fournal of Experimental Psychology: Learning, Memory, and Cognition, 18, 435-451. doi: 10.1037/0278-7393.18.3.435 
Rhodes, M. G., \& Castel, A. D. (2008). Memory predictions are influenced by perceptual information: Evidence for metacognitive illusions. Fournal of Experimental Psychology: General, 137, 615-625. doi: 10.1037/a0013684

Ripolles, P., Marco-Pallares, J., Hielscher, U., Mestres-Misse, A., Tempelmann, C., Heinze, H., Rodriguez-Fornells, A., \& Noesselt, T. (2014). The role of reward in word learning and its implications for language acquisition. Current Biology, 24, 1-6. doi: 10.1016/ j.cub.2014.09.044

Russell, P. A. (2003). Effort after meaning and the hedonic value of paintings. British fournal of Psychology, 94, 99-110. doi: 10.1348/000712603762842138

Schachter, S., \& Singer, J. E. (1962). Cognitive, social, and physiological determinants of emotional state. Psychological Review, 69, 379-399. doi: 10.1037/h0046234

Schilling, M. A. (2005). A "small-world" network model of cognitive insight. Creativity Research Fournal, 17, 131-154. doi: 10.1207/s15326934crj1702\&3_2

Schwartz, B. L., \& Metcalfe, J. (1992). Cue familiarity but not target retrievability enhances feeling-of-knowing judgments. Fournal of Experimental Psychology: Learning, Memory, and Cognition, 18, 1074-1083. doi: 10.1037/0278-7393.18.5.1074

Schwarz, N. (2002). Situated cognition and the wisdom of feelings: Cognitive tuning. In L. F. Barrett \& P. Salovey (Eds.), The Wisdom of Feeling: Psychological Processes in Emotion Intelligence. Emotions and Social Behavior. (pp. 144-166). New York: Guilford.

Schwarz, N. (2004). Metacognitive experiences in consumer judgment and decision making. Fournal of Consumer Psychology, 14, 332-348. doi: 10.1207/s15327663jcp1404_2

Schwarz, N., Bless, H., Strack, F., Klumpp, G., Rittenauer, H., \& Simmons, A. (1991). Ease of retrieval as information: Another look at the availability heuristic. Fournal of Personality and Social Psychology, 61, 195-202. doi: 10.1037/0022-3514.61.2.195 
Schwarz, N., \& Glore, G. L. (1983). Mood, misattribution, and judgments of well-being: Informative and directive functions of affective states. Fournal of Personality and Social Psychology, 45, 513-523. doi: 10.1037/0022-3514.45.3.513

Schwarz, N., \& Clore, G. L. (2007). Feelings and phenomenal experiences. In E. T. Higgins \& A. W. Kruglanski (Eds.), Social psychology: Handbook of basic principles (2nd ed.; pp. 385-407). New York: Guilford.

Scoboria, A., Mazzoni, G., Kirsch, I., \& Relyea, M. (2004). Plausibility and belief in autobiographical memory. Applied Cognitive Psychology, 18, 791-807. doi: 10.1002/acp. 1062

Seamon, J. G., McKenna, P. A., \& Binder, N. (1998). The mere exposure effect is differentially sensitive to different judgment tasks. Consciousness and Cognition, 7, 85-102. doi: 10.1006/ccog. 1998.0334

Seamon, J. G., Philbin, M. M., \& Harrison, L. G. (2006). Do you remember proposing marriage to the Pepsi machine? False recollections from a campus walk. Psychonomic Bulletin \& Review, 13, 752-756. doi: 10.3758/BF03193992

Serra, M. J., \& Dunlosky, J. (2010). Metacomprehension judgements reflect the belief that diagrams improve learning from text. Memory, 18, 698-711. doi: $10.1080 / 09658211.2010 .506441$

Sharman, S. J., Manning, C. G., \& Garry, M. (2005). Explain this: Explaining childhood events inflates confidence for those events. Applied Cognitive Psychology, 19, 67-74. doi: 10.1002/acp. 1041

Shobe, K. K., \& Kihlstrom, J. F. (1997). Is traumatic memory special? Current Directions in Psychological Science, 6, 70-74. doi: 10.1111/1467-8721.ep11512658 
Song, H., \& Schwarz, N. (2008a). Fluency and the detection of misleading questions: Low processing fluency attenuates the Moses Illusion. Social Cognition, 26, 791-799. doi: $10.1521 /$ soco.2008.26.6.791

Song, H., \& Schwarz, N. (2008b). If it's hard to read, it's hard to do: Processing fluency affects effort prediction and motivation. Psychological Science, 19, 986-988. doi: 10.1111/j. 1467-9280.2008.02189.x

Song, H., \& Schwarz, N. (2009). If it’s difficult to pronounce, it must be risky: Fluency, familiarity, and risk perception. Psychological Science, 20, 135-138. doi: 10.1111/j. 1467-9280.2009.02267.x

Stanislaw, H., \& Todorov, N. (1999). Calculation of signal detection theory measures. Behavior Research Methods, Instruments, E Computers, 31, 137-149. doi: 10.3758/BF03207704

Strack, F., Martin, L. L., \& Stepper, S. (1988). Inhibiting and facilitating conditions of the human smile: A nonobtrusive test of the facial feedback hypothesis. Fournal of Personality and Social Psychology, 54, 768-777. doi: 10.1037/0022-3514.54.5.768

Strange, D., Garry, M., Bernstein, D. M., \& Lindsay, D. S. (2011). Photographs cause false memories for the news. Acta Psychologica, 136, 90-94. doi: 10.1016/ j.actpsy. 2010.10.006

Suengas, A. G., \& Johnson, M. K. (1988). Qualitative effects of rehearsal on memories for perceived and imagined complex events. Fournal of Experimental Psychology: General, 117, 377-389. doi: 10.1037/0096-3445.117.4.377

Thomas, A. K., Bulevich, J. B., \& Loftus, E. F. (2003). Exploring the role of repetition and sensory elaboration in the imagination inflation effect. Memory \& Cognition, 31, 630-640. doi: 10.3758/BF03196103

Thomas, A. K., \& Loftus, E. F. (2002). Creating bizarre false memories through imagination. Memory \& Cognition, 30, 423-431. doi: 10.3758/BF03194942 
Topolinski, S., Likowski, T. U., Weyers, P., \& Strack, F. (2009). The face of fluency: Semantic coherence automatically elicits a specific pattern of facial muscle reactions. Cognition and Emotion, 23, 260-27 1. doi: 10.1080/02699930801994112

Topolinski, S., \& Reber, R. (2010). Gaining insight into the "Aha" experience. Current Directions in Psychological Science, 19, 402-405. doi: 10.1177/0963721410388803

Topolinski, S., \& Strack, F. (2009a). Scanning the "Fringe" of consciousness: What is felt and what is not felt in intuitions about semantic coherence. Consciousness and Cognition, 18, 608-618. doi: 10.1016/j.concog.2008.06.002

Topolinski, S., \& Strack, F. (2009b). The architecture of intuition: Fluency and affect determine intuitive judgments of semantic and visual coherence and judgments of grammaticality in artificial grammar learning. Fournal of Experimental Psychology: General, 138, 39-63. doi: $10.1037 / \mathrm{a} 0014678$

Topolinski, S., \& Strack, F. (2009c). The analysis of intuition: Processing fluency and affect in judgments of semantic coherence. Cognition and Emotion, 23, 1465-1503. doi: $10.1080 / 02699930802420745$

Tulving, E. (1985). How many memory systems are there? American Psychologist, 40, 385-398. doi: 10.1037/0003-066X.40.4.385

Tversky, A., \& Kahneman, D. (1973). Availability: A heuristic for judging frequency and probability. Cognitive Psychology, 5, 207-232. doi: 10.1016/0010-0285(73)90033-9

Unkelbach, C. (2006). The learned interpretation of cognitive fluency. Psychological Science, 17, 339-345. doi: 10.1111/j.1467-9280.2006.01708.x

Unkelbach, C. (2007). Reversing the truth effect: Learning the interpretation of processing fluency in judgments of truth. Fournal of Experimental Psychology: Learning, Memory, and Cognition, 33, 219-230. doi: 10.1037/0278-7393.33.1.219 
Unkelbach, C., \& Greifeneder, R. (2013). The experience of thinking: How the fluency of mental processes influences cognition and behaviour. New York, NY: Psychology Press.

Wade, K. A., Garry, M., Read, D. J., \& Lindsay, S. (2002). A picture is worth a thousand lies: Using false photographs to create false childhood memories. Psychonomic Bulletin $\mathcal{E}^{\circ}$ Review, 9, 597-603. doi: 10.3758/BF03196318

Wang, W., \& Yonelinas, A. P. (2012). Familiarity is related to conceptual implicit memory: An examination of individual differences. Psychonomic Bulletin \& Reviere, 19, 1154-1164. doi: $10.3758 / \mathrm{s} 13423-012-0298-7$

Westerman, D. L. (2008). Relative fluency and illusions of recognition memory. Psychonomic Bulletin E Reviere, 15, 1196-1200. doi: 10.3758/PBR.15.6.1196

Whittlesea, B. W. A. (1993). Illusions of familiarity. Fournal of Experimental Psychology: Learning, Memory, and Cognition, 19, 1235-1253. doi: 10.1037/0278-7393.19.6.1235

Whittlesea, B. W. A., Jacoby, L. L., \& Girard, K. (1990). Illusions of immediate memory: Evidence of an attributional basis for feelings of familiarity and perceptual quality. Journal of Memory and Language, 29, 716-732. doi: 10.1016/0749-596X(90)90045-2

Whittlesea, B. W. A., \& Williams, L. D. (1998). Why do strangers feel familiar, but friends don't? A discrepancy-attribution account of feelings of familiarity. Acta Psychologica, 98, 141-165. doi: 10.1016/S0001-6918(97)00040-1

Whittlesea, B. W. A., \& Williams, L. D. (2001a). The discrepancy-attribution hypothesis: I. The heuristic basis of feelings of familiarity. Fournal of Experimental Psychology: Learning, Memory, and Cognition, 27, 3-13. doi: 10.1037//O278-7393.27.1.3

Whittlesea, B. W. A., \& Williams, L. D. (2001b). The discrepancy-attribution hypothesis: II. Expectation, uncertainty, surprise, and feelings of familiarity. Fournal of Experimental Psychology: Learning, Memory, and Cognition, 27, 14-33. doi: 10.1037//0278-7393.27.1.14 Wickens (2002). Elementary Signal Detection Theory. Oxford University Press: New York. 
Wilson, M. (1988). The MRC psycholinguistic database: Machine readable dictionary, version 2. Behavioural Research Methods, Instruments, E Computers, 20, 6-10. doi: 10.3758/ BF03202594

Wilson, T. D., Lisle, D. J., Schooler, J. W., Hodges, S. D., Klaaren, K. J., \& LaFleur, S. J. (1993). Introspecting about reasons can reduce post-choice satisfaction. Personality and Social Psychology Bulletin, 19, 331-339. doi: 10.1177/0146167293193010

Wilson, T. D., \& Schooler, J. W. (1991). Thinking too much: Introspection can reduce the quality of preferences and decisions. Fournal of Personality and Social Psychology, 60, 181-192. doi: 10.1037/0022-3514.60.2.181

Winkielman, P., \& Cacioppo, J. T. (2001). Mind at ease puts a smile on the face: Psychophysiological evidence that processing facilitation elicits positive affect. Fournal of Personality and Social Psychology, 81, 989-1000. doi: 10.1037/0022-3514.81.6.989

Winkielman, P., Halberstadt, J., Fazendeiro, T., \& Catty, S. (2006). Prototypes are attractive because they are easy on the mind. Psychological Science, 17, 799-806. doi: 10.1111/j. $1467-9280.2006 .01785 . x$

Winkielman, P., Schwarz, N., Fazendeiro, T., \& Reber, R. (2003). The hedonic marking of processing fluency: Implications for evaluative judgment. In J. Musch \& K.C. Klauer (Eds.), The psychology of evaluation: Affective processes in cognition and emotion (pp. 189-217). Mahwah, NJ: Erlbaum.

Yue, C. L., Castel, A. D., \& Bjork, R. A. (2012). When disfluency is - and is not - a desirable difficulty: The influence of typeface clarity on metacognitive judgments and memory. Memory and Cognition, 41, 229-241. doi: 10.3758/s13421-012-0255-8

Zajonc, R. B. (1968). Attitudinal effects of mere exposure. Fournal of Personality and Social Psychology, 9, 1-27. doi: 10.1037/h0025848 
Zaragoza, M. S., Belli, R. F., \& Payment, K. E. (2007). Misinformation effects and the suggestibility of eyewitness memory. In M. Garry \& H. Hayne, (Eds)., Do justice and let the sky fall: Elizabeth F. Loftus and her contributions to science, law, and academic freedom (pp. 35-63). Mahwah, NJ: Erlbaum.

Zaragoza, M. S., \& Lane, S. M. (1998). Processing resources and eyewitness suggestibility. Legal and Criminological Psychology, 3, 305-320. doi: 10.1111/j. 2044-8333.1998.tb00368.x

Zaragoza, M. S., \& Mitchell, K. J. (1996). Repeated exposure to suggestion and the creation of false memories. Psychological Science, 7, 294-300. doi: 10.1111/j. 1467-9280.1996.tb00377.x 


\section{Appendix A}

Table A.

Wine names used in the experiments.

\begin{tabular}{ll}
\hline Unfamiliar names & Familiar names \\
\hline Rare Cylix & Early Rose \\
Yellow Rick & Scarlet Apples \\
Blue Larkspur & Private Beach \\
Fancy Phaeton & Old Letters \\
Rich Dais & Idle Road \\
Dark Sloe & Deep Well \\
Big Prow & Open Window \\
Nobel Leghorn & Vacant Coast \\
Fresh Plaice & Nine Mirrors \\
Last Aster & Blind Artist \\
Shiny Pommel & Busy City \\
Broad Bole & Slow River \\
Crooked Nave & Cheery Cottage \\
Ornate Cornice & Fat Bottles \\
Two Yuccas & First Tulip \\
Heavy Pestle & Straight Tunnel \\
Little Wherry & Rural Hills \\
Dry Sward & One Candle \\
Southern Morass & Fair Gardens \\
Great Frieze & Eternal Fog \\
Coarse Tapis & Empty Kettle \\
Magic Coffer & Calm Lake \\
Quiet Rote & Native Flower \\
Tranquil Fane & Humble Mountain \\
Eerie Lune & Green Banks \\
Fussy Cuttle & Angry Horse \\
Golden Hank & Gray Rat \\
Clear Tarn & Dusty Clock \\
Abundant Marl & Stubborn Ship \\
Mystic Betel & Ancient Key \\
\hline
\end{tabular}

Note. We used the unfamiliar wine names in all experiments, and added familiar wine names in Experiments 2a-c. 


\section{Appendix B}

Table B.

Animal names used in the experiments.

\begin{tabular}{|c|c|}
\hline Unfamiliar animals & Familiar animals \\
\hline Banteng & Giraffe \\
\hline Kagu & Parrot \\
\hline Chuckwalla & Lizard \\
\hline Dhole & Wolf \\
\hline Capybara & Rabbit \\
\hline Onager & Lion \\
\hline Chital & Tiger \\
\hline Avocet & Sparrow \\
\hline Colocolo & Baboon \\
\hline Uguisu & Crow \\
\hline Hammerkop & Pelican \\
\hline Takin & Zebra \\
\hline Partincole & Dove \\
\hline Aardwolf & Cheetah \\
\hline Adjutant & Flamingo \\
\hline Argali & Moose \\
\hline Dik-dik & Deer \\
\hline Biscacha & Beaver \\
\hline Coypu & Seal \\
\hline Zonure & Turtle \\
\hline Carancho & Eagle \\
\hline Addax & Elephant \\
\hline Anole & Frog \\
\hline Shoebill & Owl \\
\hline Accentor & Bat \\
\hline Fossa & Bear \\
\hline Aasvogel & Ostrich \\
\hline Grysbok & Kangaroo \\
\hline Gundi & Raccoon \\
\hline Hutia & Fox \\
\hline Antechinus & Otter \\
\hline Guillemot & Goose \\
\hline Bittern & Turkey \\
\hline Gannet & Duck \\
\hline Anhinga & Peacock \\
\hline Pika & Squirrel \\
\hline Barisingha & Sheep \\
\hline Colobus & Gorilla \\
\hline Dunnart & Skunk \\
\hline Ibex & Camel \\
\hline
\end{tabular}

Note. We used unfamiliar animals in all experiments, and added familiar animals in Experiment 3b. 


\section{Appendix C}

Table C.

Means and standard deviations (in parentheses) for hits, false alarms, $c$, and d' measures of Experiments 1-2c.

\begin{tabular}{|c|c|c|c|c|c|c|c|c|c|}
\hline \multirow[b]{2}{*}{ Experiment } & \multirow[b]{2}{*}{ Claim } & \multicolumn{2}{|l|}{ Hits } & \multicolumn{2}{|c|}{ False alarms } & \multicolumn{2}{|l|}{ Bias (c) } & \multicolumn{2}{|c|}{ Sensitivity (d') } \\
\hline & & Photo & $\begin{array}{l}\text { No } \\
\text { Photo }\end{array}$ & Photo & $\begin{array}{l}\text { No } \\
\text { Photo }\end{array}$ & Photo & $\begin{array}{l}\text { No } \\
\text { Photo }\end{array}$ & Photo & $\begin{array}{l}\text { No } \\
\text { Photo }\end{array}$ \\
\hline 1 & "Gave food" & $.57(.16)$ & $.51(.17)$ & $.54(.18)$ & $.47(.17)$ & $-.15(.42)$ & $.03(.35)$ & $.09(.57)$ & $.12(.69)$ \\
\hline \multirow{2}{*}{$2 \mathrm{a}$} & "Fed" & $.58(.22)$ & $.53(.21)$ & $.42(.22)$ & $.34(.22)$ & $.00(.58)$ & $.22(.50)$ & $.54(1.03)$ & $.65(1.13)$ \\
\hline & "Did not feed" & $.59(.20)$ & $.55(.22)$ & $.49(.19)$ & $.48(.18)$ & $-.11(.44)$ & $-.05(.46)$ & $.32(.94)$ & $.23(.91)$ \\
\hline \multirow{2}{*}{$2 b$} & "Gave food" & $.57(.21)$ & $.52(.22)$ & $.52(.22)$ & $.49(.20)$ & $-.17(.59)$ & $-.02(.56)$ & $.17(.83)$ & $.12(.96)$ \\
\hline & "Took food" & $.52(.21)$ & $.52(.21)$ & $.47(.21)$ & $.46(.21)$ & $.03(.53)$ & $.05(.53)$ & $.17(.95)$ & $.21(.98)$ \\
\hline \multirow{3}{*}{$2 c$} & "Healthy" & $.58(.21)$ & $.53(.23)$ & $.50(.22)$ & $.44(.23)$ & $-.12(.60)$ & $.06(.66)$ & $.26(.90)$ & $.32(.99)$ \\
\hline & & & & & & & & & \\
\hline & "Unhealthy" & $.53(.22)$ & $.52(.21)$ & $.48(.23)$ & $.50(.22)$ & $.00(.64)$ & $-.02(.60)$ & $.16(.94)$ & $.07(.96)$ \\
\hline
\end{tabular}

Note. Hits $=$ the proportion of times people responded true to claims that were true. False alarms $=$ the proportion of times people responded true to claims that were false. Bias (c) = the z-converted hits plus the z-converted false alarms, averaged, then multiplied by negative one, with negative values of bias representing a liberal criterion (a tendency to respond "true") and positive values representing a conservative criterion (a tendency to respond "false"; measured in standard deviation units to represent the distance between people's criterion and the half-way point between the signal and noise distributions, or what would be considered a neutral criterion). Sensitivity $\left(d^{\prime}\right)=$ the z-converted hits minus the z-converted false alarms (higher values indicate better accuracy; measured in standard deviation units to represent the amount of overlap between the signal and noise distributions). Hit and false alarm rates that would be undefined when z-converted were adjusted such that hit and false alarm rates of 1 and 0 were changed to .99 and .01, respectively (Wickens, 2002). 